\title{
1 Linking shape and rotation of grains during triaxial compression of
}

2 sand

3 Riccardo Rorato, Dr.

4 Universitat Politécnica de Catalunya (UPC), Barcelona (Spain) - Department of Civil and

5 Environmental Engineering.

6 riccardo.rorato@upc.edu

7 ORCID ID: 0000-0002-4189-3058

8 UPC - Barcelonatech

9 Moduli D2 Campus Nord UPC - Office 212

10 C Jordi Girona 1-3

11 Barcelona 08034

Marcos Arroyo Alvarez de Toledo, Prof.

15 Environmental Engineering

16 marcos.arroyo@upc.edu

17 ORCID ID: 0000-0001-9384-9107

\section{Edward Carlo Giorgio Andò, Prof.}

20 Univ. Grenoble Alpes, CNRS, Grenoble INP, 3SR, F-38000 Grenoble (France)

21 edward.ando@3sr-grenoble.fr

22 ORCID ID: 0000-0001-5509-5287

\section{Antonio Gens, Prof.}

Universitat Politécnica de Catalunya (UPC), Barcelona (Spain) - Department of Civil and antonio.gens@upc.edu ORCID ID: 0000-0001-7588-7054

\section{Gioacchino Viggiani, Prof.}

Univ. Grenoble Alpes, CNRS, Grenoble INP, 3SR, F-38000 Grenoble (France)

cino.viggiani@3sr-grenoble.fr

ORCID ID: 0000-0002-2609-6077 
36 Funding:

37 - Spanish Ministry of Economy (grants BIA2014-59467-R and BIA2017-84752-R).

38 - Laboratoire 3SR is part of the LabEx Tec21 (Investissements d'Avenir - grant agree-

39 ment nANR-11-LABX-0030).

40

41 Conflicts of interest/Competing interests: Not applicable.

42

43 Availability of data and material (data transparency): Available on request.

44

45 Code availability (software application or custom code): Open-source Python programming

46 language used.

\section{Compliance with ethical standards}

48 Not applicable. No conflicts of interests. All sources of funding have been cited. 


\section{Abstract}

51 Particle shape has a strong effect on the mechanical response of coarse soils. This has

52 been usually observed examining specimen-scale or engineering-scale responses, which

53 are the sum of many microscale interactions. In this work we observe the effects of par-

54 ticle shape directly at the microscale level. X-ray tomography $(\mu-\mathrm{CT})$ of two sand speci-

55 mens is exploited to measure three-dimensional particle shape descriptors but also to

56 track individual particle motions during triaxial compression. The systematic use of a

57 discrete Digital Volume Correlation (DVC) algorithm allows the systematic tracking of in-

58 dividual grains (around 50000 for each sand specimen) during the test and measure,

59 with good precision, their cumulated displacements and rotations. The specimens exam-

60 ined failed in a clearly localised shear mode. Advantage is taken of this to obtain data

61 relevant for very different kinematical regimes: one quasi-static and the other close to

62 critical state. A direct comparison between the shape and kinematic databases shows to

63 what degree particle shape descriptors are related to observed kinematics. It appears

64 that true sphericity is a good predictor of upper bound rotational restraint.

65

66 Keywords: Laboratory equipment; Microscopy; Particle-scale behaviour; Sands; Shear

67 strength; Statistical analysis.

\section{$68 \quad 1$ Introduction}

69 Granular soils are made of discrete particles that interact with each other, therefore

70 changes at the small-scale (i.e., grain-scale) affect the material response at the large-scale

71 (i.e., engineering-scale) [1-3]. For granular soils, for instance, it is well-documented that 
72 particle shape strongly affects soil properties such as extreme void ratios [4, 5], critical

state friction [6] or dilatancy and peak friction [7], as well as engineering scale responses, like liquefaction resistance [8] or cone tip resistance [9].

It follows that particle shape must affect grain-scale interactions to produce those effects.

This hypothesis has been repeatedly supported, from various perspectives, by the results of numerical simulation. In numerous discrete element models direct control of element shape has been shown to result in major changes in ensemble mechanical responses [1015].

It is noteworthy, however, that similar macroscopic effects are observed when particle shape effects are represented indirectly, through appropriately modified element contact interaction laws, for instance introducing some resistance against rolling at the contact [16-19]. Both direct and indirect shape modelling strategies inevitably involve some degree of simplification, to be adjusted in applications under typically conflicting constraints of computational speed, accuracy and ease of calibration [20].

In this context, direct experimental observation of the microscale effects of particle shape appears relevant, as it may provide evidence beyond that implicit in the ensemble behaviour of the specimen. This has been a relatively unexplored avenue, because it requires relevant and accurately measured shape descriptors, as well as particle-scale resolution of internal mechanisms. There are few experimental techniques useful for that purpose [21] and the main one is relatively recent: microfocus or x-rays $\mu$-tomography [22-25]. 
96 Despite significant difficulties, progress in 3D tomographic imaging and post-processing

97 technologies [26-30], has made accurate grain shape determination feasible for most

98 sands. Identification of particle-scale mechanisms is more difficult, as it requires imaging

99 not just isolated particles, but particles in collective interaction, within specimens. Parti-

100 cles need to be separated from one another, within the imaged ensemble. Ideally, the

101 existing contacts amongst particles need to be identified, as interactions between parti-

102 cles occur through contact forces in coarse soils. Single snapshots of microstructures

103 (typically acquired "post-mortem", after dismounting the test $[22,25,31]$ ) cannot reveal

104 kinematics. For that purpose a sequence of images needs to be acquired during a test,

105 and triaxial tests have been the target for most of this kind of work [32-36]. Clearly, one

106 added difficulty here is the need to track particles confidently across different images.

107 Progress in these tasks has been also very significant, but there are still some important 108 obstacles, particularly in the area of contact detection and measurement. Indeed, the 109 level of image resolution required to image particle contacts - and contact properties 110 such as orientation - appears far more demanding than that required to image, identify 111 and measure particles [37-39]. This has implicitly limited the scope (number of tracked 112 particles and/or number of imaged test steps) of kinematic contact fabric imaging studies $113[33,40-42]$.

115 Current technology may be exploited to obtain more statistically sound results if the focus is restricted to particle kinematics. This is the avenue explored in this work, in which

117 we examine in detail the relations between individual grain shape and individual kine118 matical history of sand grains as observed during triaxial compression of two dense sand 119 specimens that jointly provide a database of 110000 grains. For the purposes of this 
study, the specimens selected for examination had the advantage of failing in sharply

121 localised shear modes. As clearly identified in previous research [22, 24, 25] the structure and kinematics of particles within a shear band are very different from those outside, as particles in a shear band approach critical state conditions. As long as a criterion for

124 belonging or not into the shear band could be clearly established, this experimental feature ensured that the influence of particle shape could be examined in two very different and separate kinematic settings (i.e., within the band and outside it), thus making the study relevant for a larger set of conditions. In what follows, we first give some background on particle tracking and shape description terminology. We then describe the test and image analysis procedures employed and the results obtained before presenting some conclusions.

\section{Background}

\subsection{Digital image correlation for quantifying particle kinematics}

Digital Image Correlation (DIC) is the ideal tool for comparing and analysing images of deforming materials, such the ones obtained from x-ray scans. DIC is a widely used technique in experimental mechanics to deduce motion and shape features of an object by comparing its appearance in different images [43]. A first classification of DIC may be

137 based on the dimensional support of the images employed in the comparison [44]: surface-DIC is based on bi-dimensional images, whereas volumetric DIC (or, simply, digital volume correlation, DVC), is based on three-dimensional images. Surface-DIC is widely 
140 employed in field and laboratory experimental geotechnics [45]. DVC has seen fewer 141 applications because of the increased difficulties associated with 3D image acquisition.

142 In DIC a subset $F$ of intensity values from a reference image is systematically compared

143 with subsets $G i$ of the transformed image until some optimality condition is achieved

144 [46]. This optimality condition is frequently based on a cross correlation measure, for 145 instance searching for a maximum normalised cross correlation:

$$
N C C=\frac{F * G_{i}}{\|F\|\left\|G_{i}\right\|}
$$

147 Different algorithms are obtained depending on how the subset $F$ is chosen, what kind 148 of motion is assumed to relate $F$ and $G_{i}$ and how the search window (SW, the zone in 149 which $G_{i}$ is searched for) is defined.

150 Two broad variants of DVC have been employed in geotechnical applications: continuum

151 (C-DVC) and discrete (D-DVC). In C-DVC, the subset $F$ (usually referred to as correlation 152 window, $C W$ ) is a cubical cell centred around some pre-established evaluation grid 153 points. Although more complex transformations are sometimes used [47], the motion 154 relating $F$ and $G$ is usually assumed as a simple rigid translation, and cross correlation 155 is employed to find a displacement vector, which is assigned to the grid node. From the 156 displacement field thus obtained, strain measures are derived using different procedures 157 [48]. The underlying assumption is that subset $F$ is a representative volume element RVE 158 in a continuum; therefore, the scale of the $C W$ should contain enough grains to make that 159 assumption realistic.

160 C-DVC is not well adapted to identify particle kinematics. When the resolution of the 161 images is such that individual grains may be identified, other alternatives are possible. 
162 Hall et al. [24] proposed a novel discrete grain-based approach (D-DVC) to track individ163 ual particles. The method has as a starting point a segmented labelled image, in which 164 groups of voxels are identified as grains. In D-DVC the subset $F$ is selected considering 165 which voxels have been previously assigned to a certain grain and is named a grain 166 mask. The assumed motion between $F$ and $G$ is a rigid body motion, including transla167 tion and rotation. With D-DVC the kinematics of each identified particle is thus directly 168 obtained. Hall et al. [24] went on to illustrate the potential of D-DVC obtaining maps of 169 incremental displacements and rotations in a triaxial specimen of Hostun sand, showing 170 also that the kinematic history of single grains was very different if they were involved 171 in a shear band or not.

172 Andò et al. [32] proposed an alternative method to follow grain kinematics across 173 images, called ID-track. In this method grain match between successive images is based 174 on listed properties of grains, such as volume, surface area, etc. obtained through single175 image analysis. The method requires two segmented images as input. The grain match176 ing operation is faster than in D-DVC, as volume cross-correlation is not needed. With 177 some modifications, ID-track has been later used by Alshibli et al. [35] and Cheng \& 178 Wang [36], amongst others. However, ID-track has some difficulties to assign precise 179 rotation values, particularly when dealing with very spherical particles [32], and was 180 therefore extended to include a D-DVC based technique for rotation measurement in 181 Andò et al. [49]. For this reason, the work presented here was based on the more robust, if slower, D-DVC technique. 


\subsection{Particle shape description}

184 There are different approaches to describe the shape of soil grains and, as a result, many

185 different shape descriptors are currently in use. Table 1 summarises the 3D shape de-

186 scriptors that are employed in this work whereas Table 2 lists the fundamental measures

187 from which the shape descriptors are derived. Several shape descriptors try to measure

188 particle similitude with a sphere (i.e., sphericity), i.e., the historical proposal of Wadell

189 [50], called true sphericity, but also the convexity and operational sphericity descriptors. We

190 also use some shape descriptors that are more relevant to particle form [51] such as flat-

191 ness index, elongation index and - despite its name - intercept sphericity. Rorato et al. [26]

192 present a detailed study of the relationships amongst these and other 3D and 2D shape 193 descriptors.

\begin{tabular}{cccc}
\hline Name & Symbol & Definition & Reference \\
\hline True Sphericity & $\Psi$ & $\frac{\mathrm{s}_{n}}{S}$ & {$[50]$} \\
\hline Flatness index & FI & $c / b$ & {$[52]$} \\
\hline Elongation index & EI & $b / a$ & {$[52]$} \\
\hline $\begin{array}{c}\text { Intercept sphericity } \\
\text { Operational } \\
\text { Sphericity }\end{array}$ & $\Psi_{\mathrm{int}}$ & $\sqrt[3]{\frac{b c}{a^{2}}}=\sqrt[3]{F I(E I)^{2}}$ & {$[53]$} \\
\hline Convexity & $\Psi_{\mathrm{op}}$ & $\sqrt[3]{\frac{V}{V_{c m}}}=\frac{D_{n}}{D_{c m}} \approx \frac{D_{n}}{a}$ & {$[53]$} \\
\hline & Co & $V / V_{c H}$ & {$[30]$} \\
\hline
\end{tabular}

194

Table 1: Selected 3D shape descriptors [26]

195

\begin{tabular}{ccc}
\hline Shape property & Symbol & $\begin{array}{c}\text { Equivalent } \\
\text { diameter }\end{array}$ \\
\hline Volume & $V$ & $D_{n}$ \\
\hline Surface area & $S$ & \\
\hline
\end{tabular}




\begin{tabular}{ccc}
\hline $\begin{array}{c}\text { Shape property } \\
\text { Surface area of the equivalent } \\
\text { sphere (same volume) }\end{array}$ & $s_{n}$ & $\begin{array}{c}\text { Equivalent } \\
\text { diameter }\end{array}$ \\
\hline $\begin{array}{c}\text { Maximum, intermediate, minimum } \\
\text { lengths }\end{array}$ & $a, b, c$ & \\
\hline $\begin{array}{c}\text { Convex hull volume } \\
\text { sphere }\end{array}$ & $V_{C H}$ & $D_{C H}$ \\
\hline $\begin{array}{c}\text { Volume of the maximum inscribed } \\
\text { Volume of the minimum circum- } \\
\text { scribing sphere }\end{array}$ & $V_{i M}$ & $D_{i M}$ \\
\hline
\end{tabular}

196

197

198

Table 2: Fundamental measures from which 3D shape descriptors are derived [26]

\section{Methodology}

\subsection{Data acquisition}

This study analyses data obtained at Laboratoire 3SR (Grenoble, France) from two sand triaxial specimens, approximately $10 \mathrm{~mm}$ diameter and $20 \mathrm{~mm}$ height [54]. Both specimens were prepared by dry pluviation and then subject to triaxial compression under $100 \mathrm{kPa}$ of confining pressure. The triaxial tests were performed "in-camera" within the x-ray scanner at Laboratoire 3SR. Results from two sand specimens that cover a wide range of particle sphericity values were selected.

The first specimen (HNEA01) was formed with Hostun HN31 sand at relative density of $83.2 \%$ (dry density value, $\gamma_{d}$, equal to $1.60 \mathrm{~g} / \mathrm{cm}^{3}$ ). Hostun is a quartz quarry sand whose grains appear very irregular, see Figure 1a. The grain size distribution, Figure 1c, is very narrow $\left(C_{U}=1.41\right)$, with a D50 equal to $338 \mu \mathrm{m}$. The second specimen analysed (COEA04) was formed with Caicos ooids $\left(\gamma_{d}=1.76 \mathrm{~g} / \mathrm{cm}^{2}\right.$, minimum and maximum 
210 density not recorded). This sand is a natural sand made of calcium carbonate (CaCO3)

211 minerals. Ooids are formed by slow chemical accretion and have a very round shape

212 (Figure 1b). The grain size distribution (Figure 1c) is close to that of HNEA01, being also

213 poorly graded $\left(C_{U}=1.39\right)$ with a D50 of $420 \mu m$.

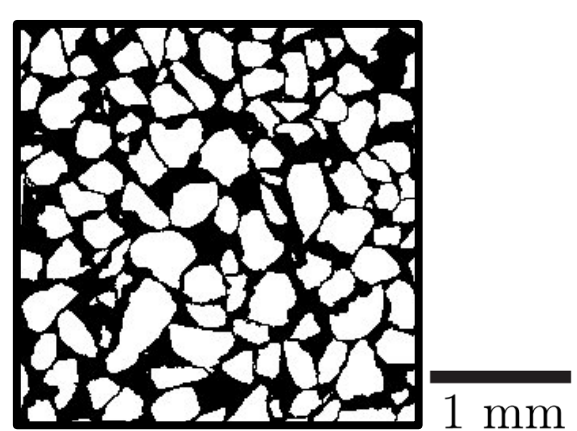

(a)

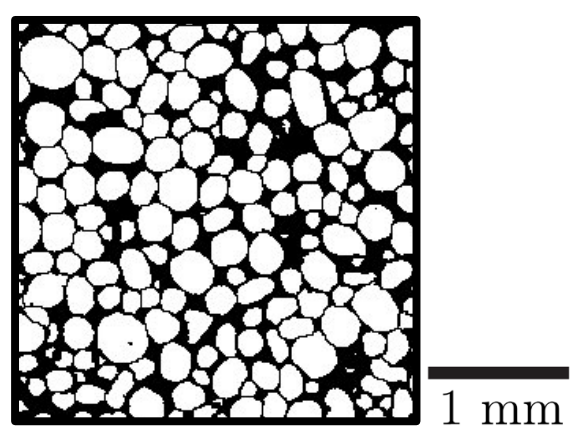

(b)

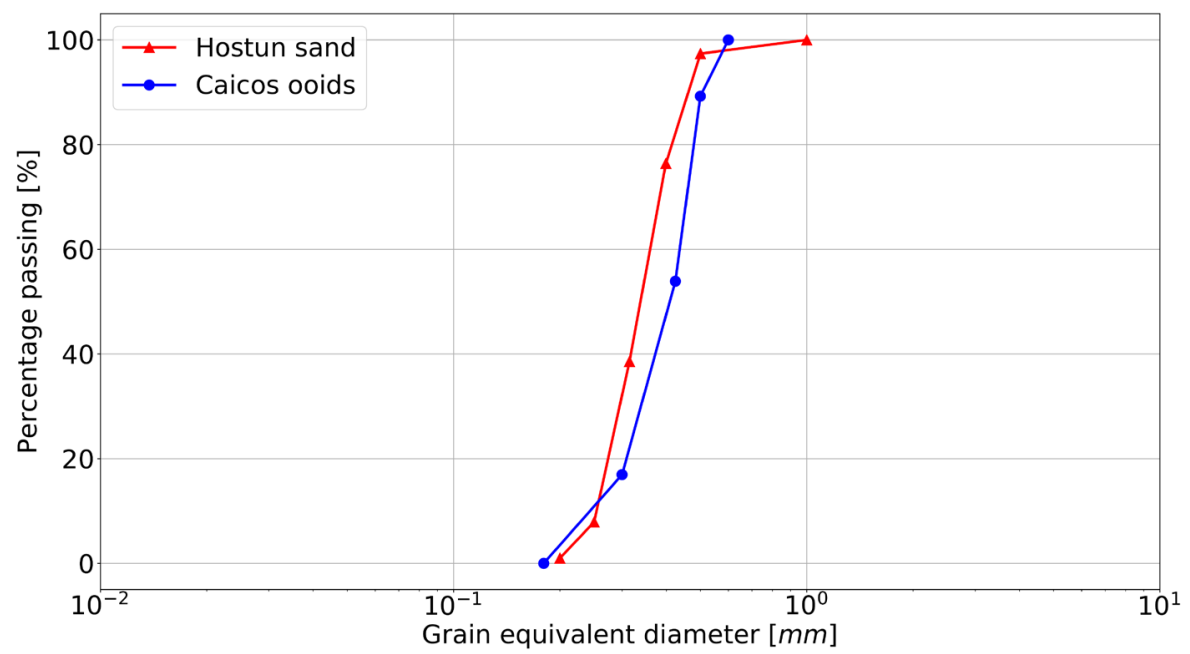

(c)

214 Figure 1a-b-c: (a) Horizontal section of the scanned Hostun (a) and Caicos (b) specimens. (c) Grain Size

Distribution of both sands from sieving [54]

216 The specimens were scanned by $\mathrm{x}$-rays at several loading stages during the test (16 for test HNEA01 and 11 for COEA04). The stress-volumetric-strain curves, with indication of scanning stages are shown in Figure 2. The macroscopic responses of both specimens are typical of dense sands, with a stress peak followed by shearing at overall constant volume. Both specimens failed in a localized shear mode: Andò [32] verified that within 
221 the shear zone constant volume was also attained (at different porosity than the overall

222 value, see also [55]).

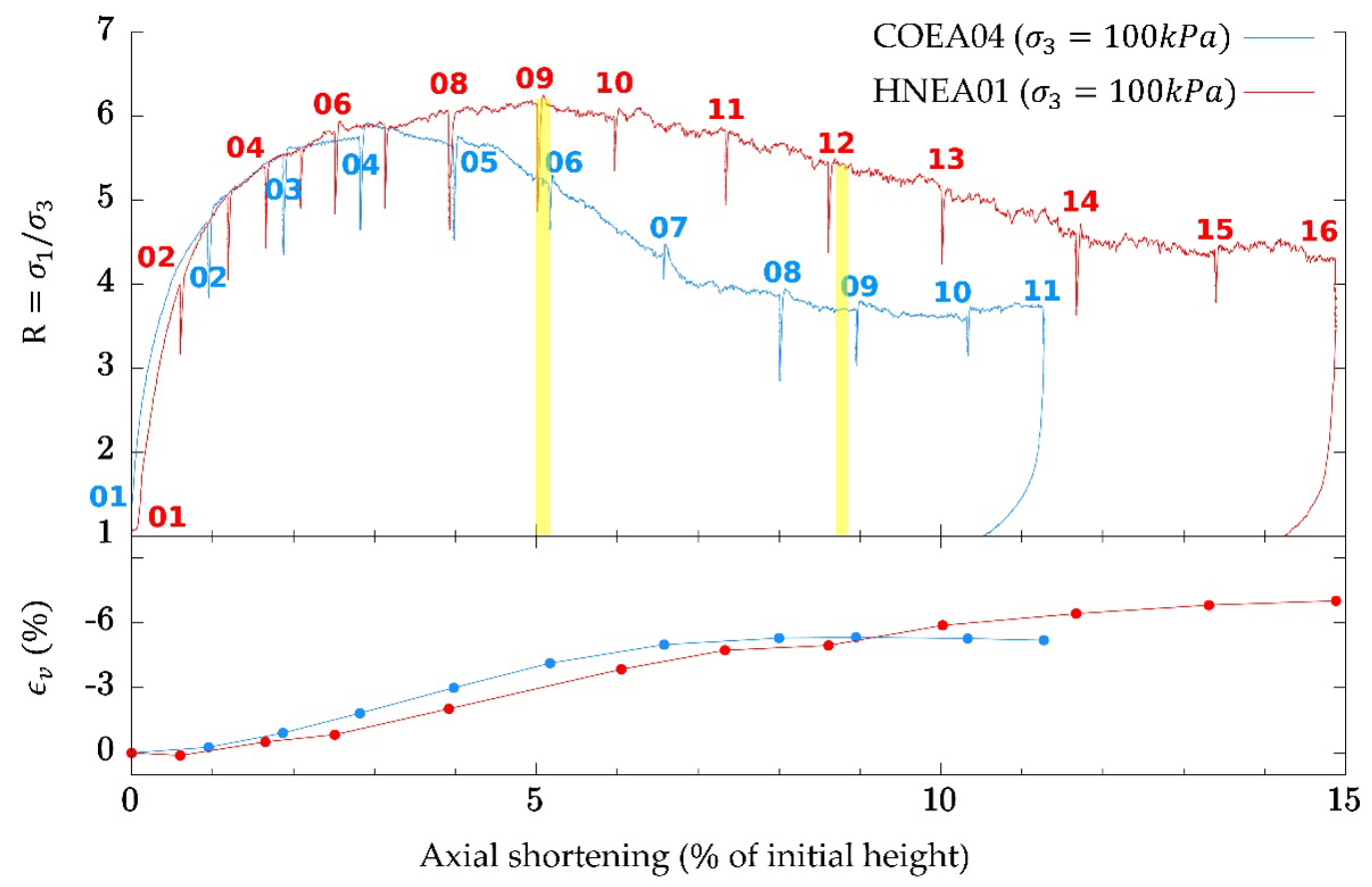

224 Figure 2: Triaxial responses of the specimens HNEA01 and COEA04 with loading stages markers. The 225 yellow stripes indicate loading stages that are later investigated in more detail.

226 The pixel size selected to image the sand specimens was $15.56 \mu \mathrm{m} / p x$, to maintain a field 227 of view of approximately $30.5 \mathrm{~mm} \times 23.0 \mathrm{~mm}$. For the specimens analysed, this results 228 in about 22/26 pixels across a grain. Further details of these tests, including the scanning 229 equipment and tomographic image acquisition procedures have been presented else230 where $[54,56]$.

\subsection{Single-image post-processing}

232 The reconstruction of each x-ray scan results simply in a 3D distribution of grey-scale 233 values which represents the frequency-lumped x-ray attenuation coefficient measured 234 in that location. Therefore, before studying individual grains, it is necessary to binarise, 
235

236

237

238

239

240

241

242

243

244

245

246

247

248

249

250

251

252

253

254

255

separate and label the tomographic images. The procedures applied here for these tasks are described by Andò [32]. At this point, it is possible to extract single grains from the 3D labelled images. The 3D tomographic images representing Hostun (specimen HNEA01) and Caicos (specimen COEA04) sands contain respectively 48612 and 65056 particles.

Geometrical properties (e.g. volume, surface area, inertia tensor...) of the image subset assigned to each grain are obtained through subsequent post-processing. These properties may be used, in turn, to obtain different shape descriptors in 3D or 2D. The procedures applied for this purpose are described in detail by Rorato et al. [26]; who also presented an exhaustive database of 3D shape descriptors for all the grains in this specimens, evaluating significant statistics. It is worth mentioning that surface area measurements for grains were obtained using a Marching Cubes algorithm [57], to ensure precision in the evaluation of Wadell true sphericity values. Rorato [26] also verified that there were no significant shape changes during the triaxial tests.

\subsection{Tracking grain kinematics with D-DVC}

The D-DVC software that has been used in this work to obtain the grains kinematics (3D displacements and rotations) is the TomoWarp2 code [58]. In this code, grain displacements are expressed in pixels (the pixel-size is fixed) and 3D rotations as rotation vectors using a Rodrigues parametrisation [59]. In a rotation vector, the components represent the direction of the axis of rotation and the norm the magnitude of the angle of rotation 
256 around that axis. This representation system for rigid body rotations has practical ad257 vantages over more complex alternatives, such as those based on Euler angles or quater258 nions [59].

259 To visualize the 3D unit rotation vector orientation, stereographic projection is some260 times used below. The angular coordinates used in this projection are illustrated in Fig261 ure 3 . The angle $\theta$ (inclination) goes from $0^{\circ}$ (vertical) to $90^{\circ}$ (horizontal), while the angle $\varphi$ (azimuth) goes from $0^{\circ}$ to $360^{\circ}$, being the north $\left(\varphi=0^{\circ}\right)$ the direction of the Cartesian $x-$ axis of the specimen. Stereograms were created using the plotting tool "orientationPlotter" from the external open-source Python package SPAM [60].

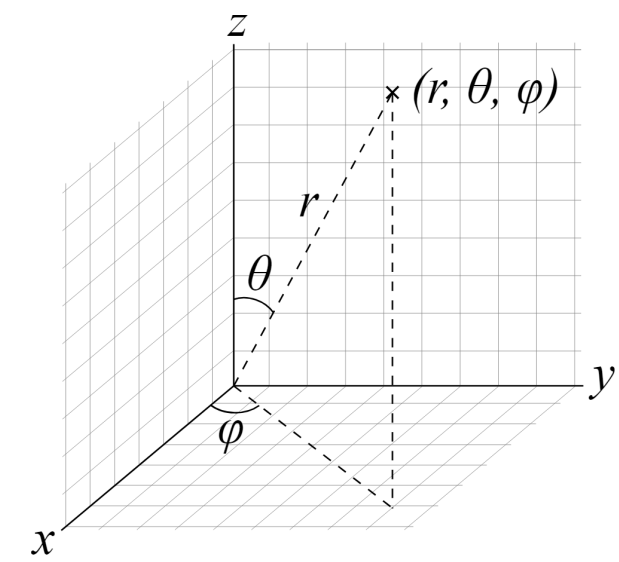

Figure 3: Spherical coordinates system adopted for the stereoplots

267 Previous applications of D-DVC had focused mostly on incremental grain kinematics

$268[24,32]$. In such approach only the incremental kinematics between two subsequent 269 loading steps (e.g. 1-2, 2-3, 3-4, etc...) were obtained. The starting point are the two 3D greyscale images bracketing the increment (i.e., initial and deformed configurations); of these two the image corresponding to the initial configuration has to be already labelled, so that grain bounding-boxes that are used as correlation windows can be extracted. This incremental or "tangent" correlation approach cannot be applied sequentially to obtain cumulative kinematics of the grains. The reason is that grain labels assigned to 
275 the same grains by processing different scans of the same specimen will be different. To 276 ensure consistency, a single set of grain labels, obtained from the first scan, is required.

277 The method used here to get the history of grain displacements and rotations is based 278 on "secant" correlation (usually referred to as "leapfrog" in C-DVC applications). In this 279 approach, the initial labelled image is always selected for paired searches on those re280 sulting from all the subsequent scans (i.e., 1-2, 1-3, 1-4, etc...). A direct secant approach 281 has clear limitations, being both very expensive (as the grain search window would have 282 to increase during the process) and prone to errors.

283 The algorithm applied here aims to overcome those difficulties using a mixed approach, 284 in which a secant correlation scheme $(1-2,1-3, \ldots, 1-10)$ is still employed, but the search 285 is aided by the results of the previous steps, namely the cumulative grains displacement 286 up to the last correlation step. The initial search window is translated by a vector point287 ing the position of the grain in the previous correlation and can remain of a small size,

288 saving calculation time. The inputs required in this procedure are four: two greyscale 289 images, one labelled image and one data file with the prior grain displacements. Since 290 initial rotations are not taken into account, for large deformations where there are large 291 rotations, the possibility of losing grains still remains.

\subsection{Validation of the D-DIC procedure}

293 To validate the implementation of D-DVC in TomoWarp2 a simple uniform rotation 294 check was employed [32, 61]. The rotations of all the grains contained in specimen 295 HNEA01 were individually computed after applying a five degrees $\left(5^{\circ} \mathrm{deg}\right)$ rigid rota- 
296 tion around its vertical $z$-axis. The main objectives of the validation are three: (a) to eval297 uate the attrition rate of the algorithm (i.e., the number of grains that are lost from one 298 image to the next); (b) to evaluate the accuracy and precision with which grain rotation 299 was measured and (c) to explore the possible relationship between the precision of the 300 calculation and the shape of the grains (as grains masks are used as correlation windows, 301 there is some expectation that grains closer to spherical will present a greater deviation 302 from the imposed motion).

303 The check was positive from the attrition viewpoint, with more than $99.8 \%$ of the grains 304 correctly tracked attaining a correlation coefficient between the two image subsets 305 greater than 0.99 for each of them. Figure 4a shows the histogram of the rotations meas306 ured by D-DVC. The rotation measurements follow a normal distribution with a mean 307 value of $4.998^{\circ} \mathrm{deg}$ and $0.042^{\circ} \mathrm{deg}$ standard deviation. Rotations as obtained by this code 308 are as accurate (i.e., have similar mean error), but far more precise (i.e., have much 309 smaller error standard deviation), than those obtained with the ID-track implemented 310 by Andò [32]. Indeed, the coefficient of variation (standard deviation / mean) of meas311 urement error is here below 1\%, while it was above $400 \%$ for ID-track. Another way of 312 conveying this information is by means of a stereogram of the computed grain rotations

313 (Figure 4b). The radial distance from the centre of the stereoplot represents the inclina314 tion $\theta$, whereas the angles on the external perimeter represent the azimuth $\varphi$. As ex315 pected, all the grain rotations are located at the centre of the stereoplot $\left(\theta=0^{\circ}\right)$, indicat316 ing rotations around the vertical axis, with very low deviation from the vertical. Finally,

317 Figure 4c illustrates the relation between measured rotation and sphericity; it is clear that 
318 the deviation from the exact solution $\left(5^{\circ} \mathrm{deg}\right)$ increases symmetrically with the spheric319 ity of the grains. However, the deviation remains very limited (around $\pm 0.1^{\circ} \mathrm{deg}$ ) and, 320 therefore, this inbuilt bias can be safely ignored.

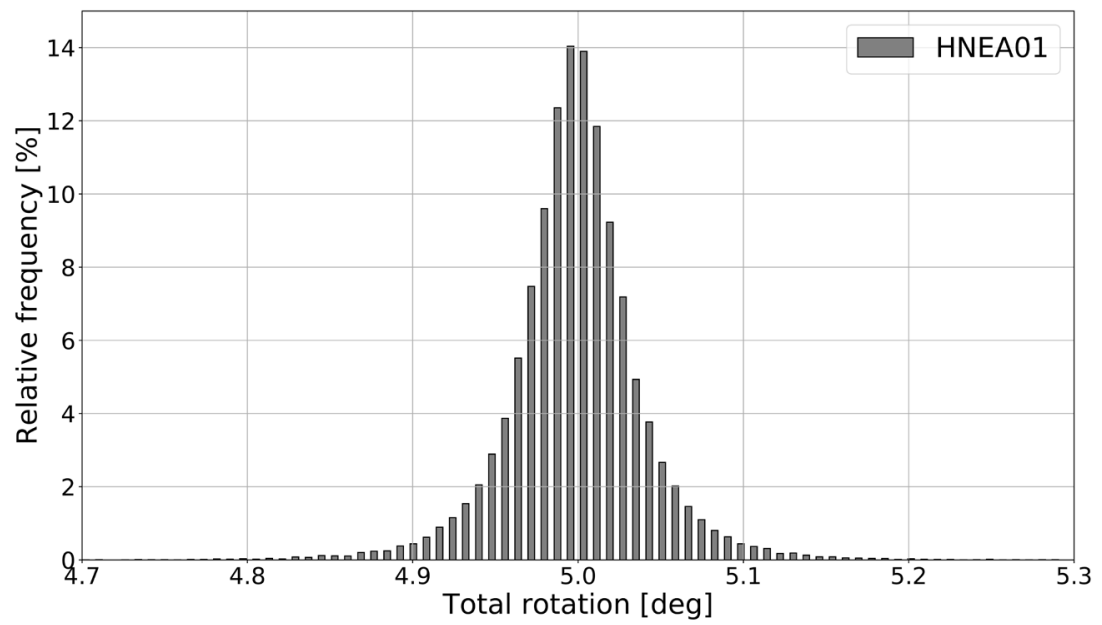

(a)

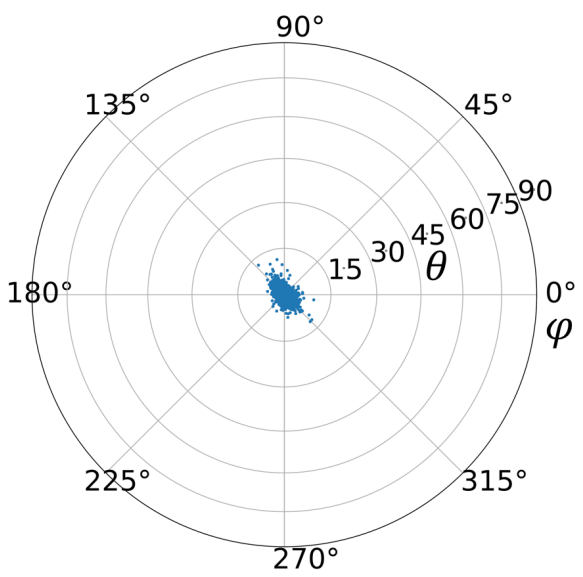

(b) 


\subsection{Shear band identification}

325 The two specimens analysed in this work showed localised deformation through shear 326 banding [54]. In shear bands void ratio increases, coordination numbers are much re327 duced and the microstructural constraints on kinematics are therefore very different. Be328 fore examining the relation between grain shape and grain kinematics it was therefore 329 necessary to first classify the grains, separating those that belonged to the shear band 330 and those that did not. The criterion applied here to classify the grains as belonging to 331 the shear band was based on shear strain.

332 To assign a nominal deviatoric strain to each grain we applied a procedure developed 333 for DEM post-processing by Catalano et al. [62]. In this procedure, available within the 334 code YADE [63], a Voronoi cell hosting each grain is created using a regular Delaunay 335 triangulation having as vertices the mass centres of the labelled grains. Thus, the grain 
336 position at the last loading increments (i.e., 15-16 for HNEA01, 10-11 for COEA04) were

337 calculated by D-DVC and then introduced in YADE. Displacements of neighbouring

338 grains were then used to compute a nominal displacement gradient tensor for the tetra-

339 hedrons whose vertices are the grains centres of mass. A nominal averaged deviatoric

340 strain, $\varepsilon_{\_} \_$g was projected back to each grain and a threshold value of $\varepsilon_{\text {d_g }}$ was used to

341 classify the grains that belonged to the shear band.

\section{$342 \quad 4$ Results}

343

\subsection{Shear band identification}

344 The results of the shear band identification procedure are shown in Figure 5, in which

345 the black grains form the "shear band": it contains 7007 grains for COEA04, and 21000

346 for HNEA01. The threshold value $\varepsilon_{\mathrm{d}_{-} g}$ is set at 0.10 ; the zones identified correspond

347 closely to those apparent in previous studies [54]. A sensitivity study to evaluate of the

348 effect of varying this threshold value was carried out, very little changes were observed

349 for values within the range $0.05-0.20$.

350 The local reference system that will be used to define the virtual plane representing the

351 shear band is shown in Figure 6, in which vector $\vec{n}$ is the normal to the plane and vector

$352 \vec{a}$ indicates the steepest slope direction in the plane. According to Figure 3, showing the

353 spherical coordinates system, both specimens present a shear band with an inclination

354 angle $(\theta)$ of about $45^{\circ}$. 


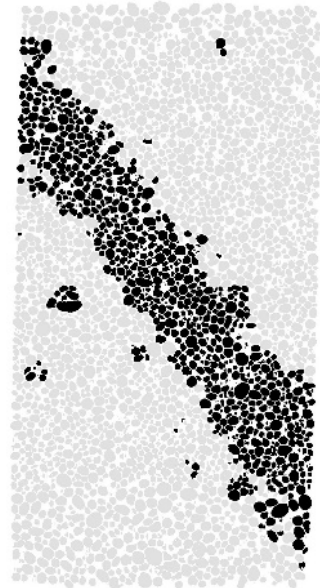

(a)

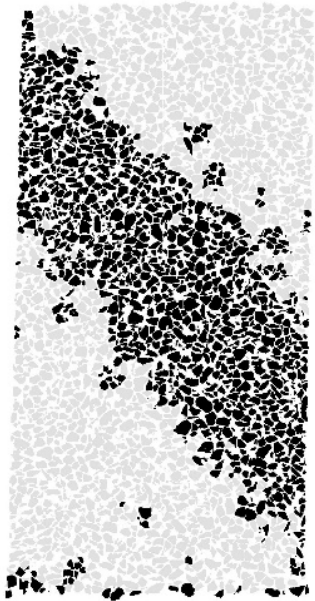

(b)

355 Figure 5: Shear band identification for specimens COEA04 (a) and HNEA01 (b). Particles are coloured

356 black if the "micro-strain" [62] calculated on the Voronoi domain centred on the particle is greater than

3570.10 (i.e., they belong to the shear band).

\section{Figure 6: Local reference system for the shear band}

360 Vector $\vec{b}$ is orthogonal to $\vec{n}$ and $\vec{a}$ and therefore is horizontal $\left(\theta=90^{\circ}\right)$. It can be used to

361 characterise the azimuthal orientation of the shear band with respect to the global Car-

362 tesian coordinates system. The azimuth $(\varphi)$ is different, being of about $135^{\circ}$ for Hostun

363 and $75^{\circ}$ (from the global $x$-axis) for Caicos. The sections represented in Figure 5 corre-

364 spond then to vertical planes orthogonal to vector $\vec{b}$. 
366 A check was performed to verify if particle shape was spatially homogeneously distrib-

367 uted in the specimens. The reason was to exclude any possibility that subsequent locali-

368 sation into shear bands was prompted by non-uniformity in the initial spatial distribu-

369 tion of grain shapes (note that a similar check was performed by Andò [54] with respect

370 to local porosity). To do so, two vertical sections orthogonal to each other (defined re-

371 spectively by vectors $\vec{n}-\vec{b}$ and $\vec{n}-\vec{a}$ ) are examined where the grains have been coloured

372 by their value of degree of true sphericity, as shown in Figure 7. It is evident that grain

373 true sphericity was initially homogeneously distributed within both specimens.

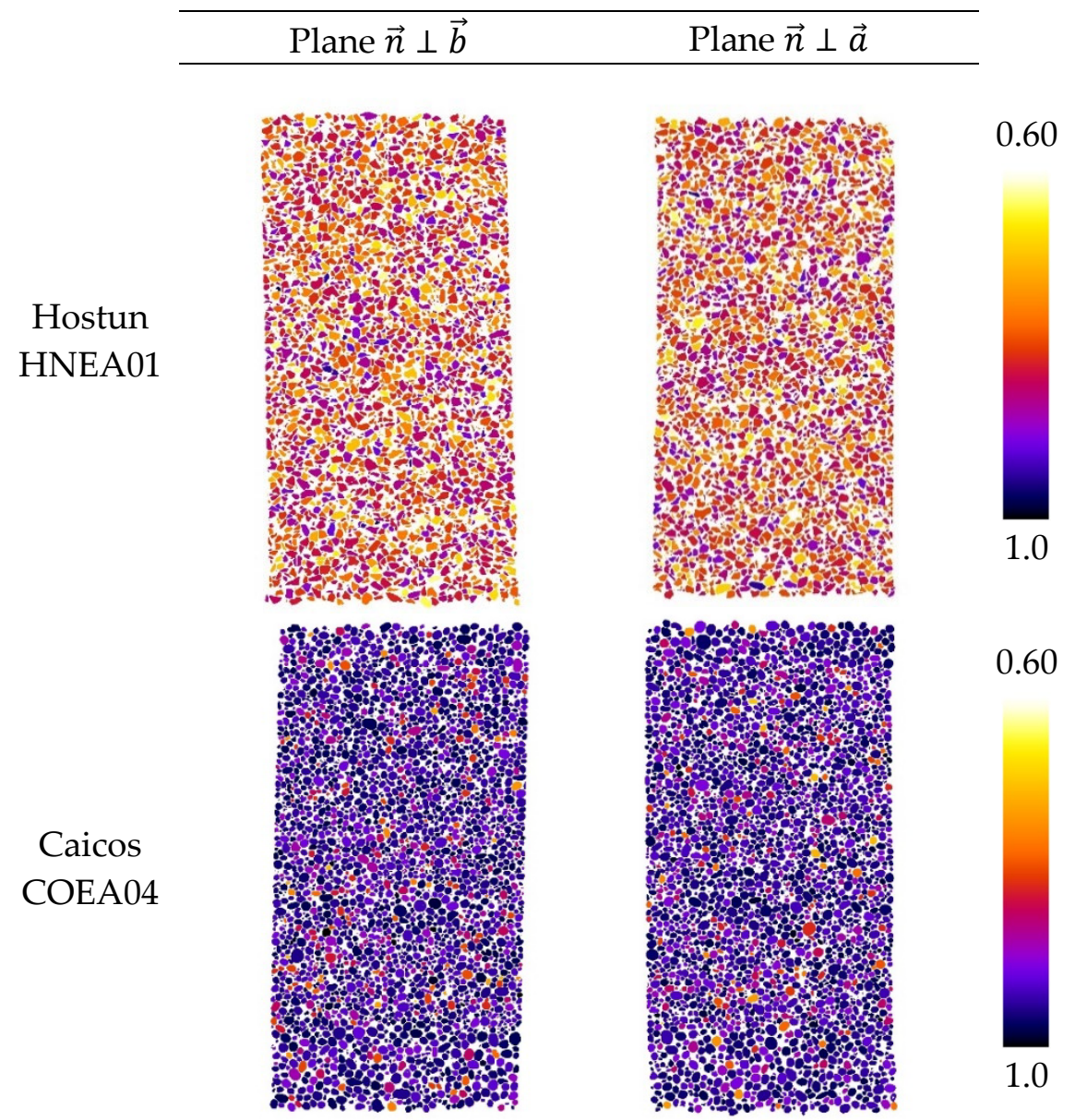

374 Figure 7: Sphericity spatial distribution for Hostun and Caicos sand in two vertical sections: parallel and 
376 Another check was performed on the possibility that shear banding would entrap or

377 select particular grain shapes. To this end, histograms of the degree of true sphericity for

378 the grains located both inside and outside the shear band were plotted; the results are

379 shown in Figure 8. Again, it is evident that there are no significant differences of shape

380 between the grains that were involved in the localisation process and those that re-

381 mained outside the shear band.

Hostun

HNEA01

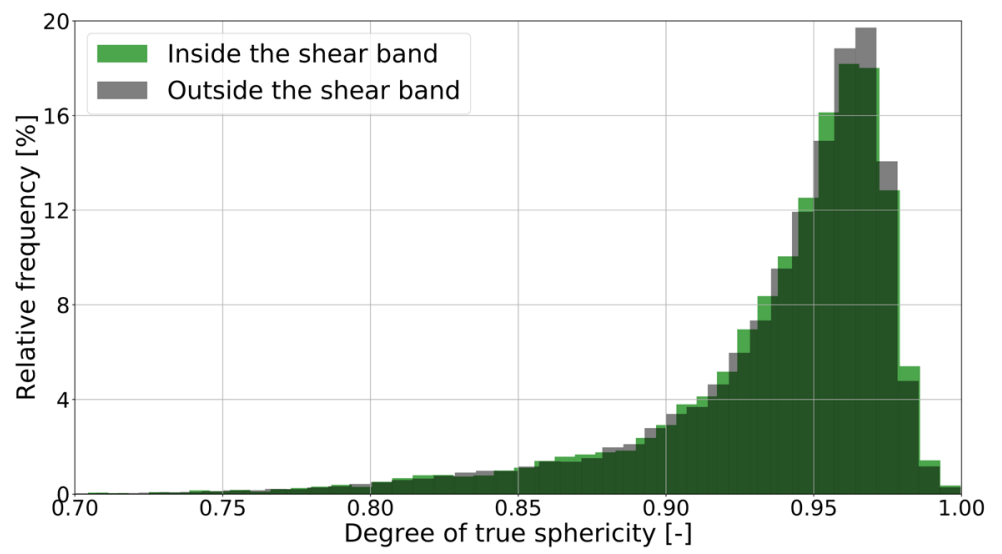

(a)

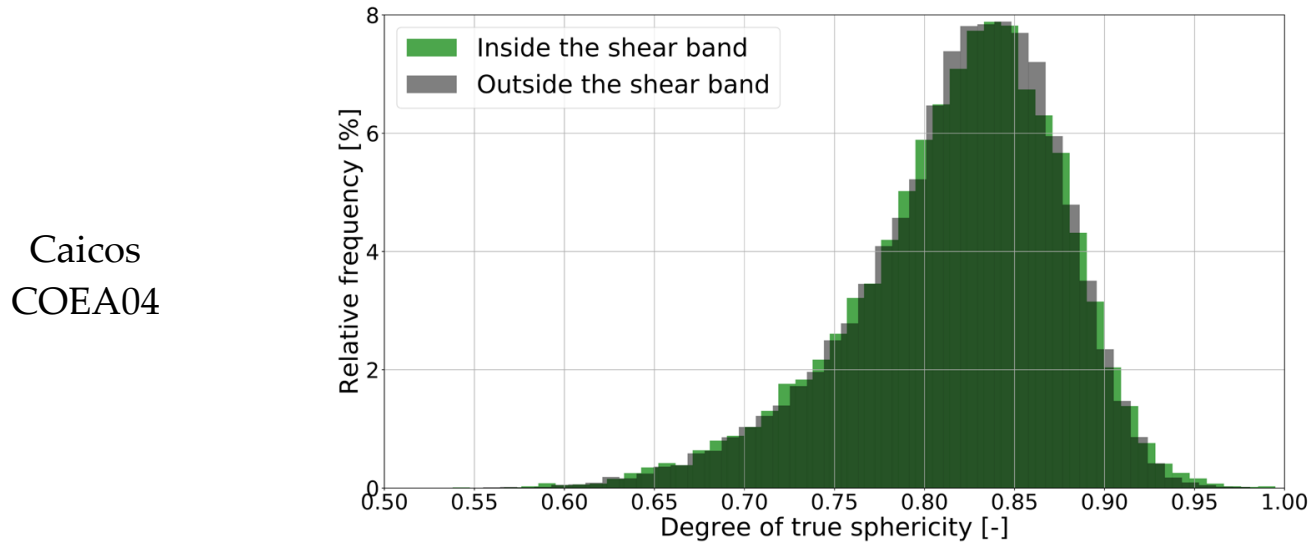

(b)

382 Figure 8: Histograms of true sphericity for Hostun (a) and Caicos (b) sands both inside and outside the shear bands. 


\subsection{Overall grain kinematics}

385 Figure 9 and Figure 10 show the cumulative kinematic histories, in terms of vertical dis-

386 placements and rotations, for Caicos ooids (specimen COEA04) and Hostun sand (spec-

387 imen HNEA01) during several loading increments in the triaxial test (note that similar

388 images, but reporting incremental instead of cumulative values were presented by Andò

389 [32]. Results for both sands are plotted at the same scale and confirm the general obser-

390 vation made from incremental results by Andò [32]: within the shear band, the very

391 rounded Caicos sand grains rotate more than the more angular grains of Hostun sand.

392 On the other hand, it is difficult to tell the difference between the two sands outside the 393 shear band.

\begin{tabular}{cccccc}
\hline $01-02$ & $01-04$ & $01-06$ & $01-08$ & $01-10$ & $01-11$ \\
$\varepsilon_{z}=0.95 \%$ & $\varepsilon_{z}=2.82 \%$ & $\varepsilon_{z}=5.17 \%$ & $\varepsilon_{z}=8.00 \%$ & $\varepsilon_{z}=10.33 \%$ & $\varepsilon_{z}=11.27 \%$ \\
\hline
\end{tabular}

$$
\begin{array}{r}
0 p x(z-d i s p) \\
0^{\circ} \text { deg rotations }
\end{array}
$$
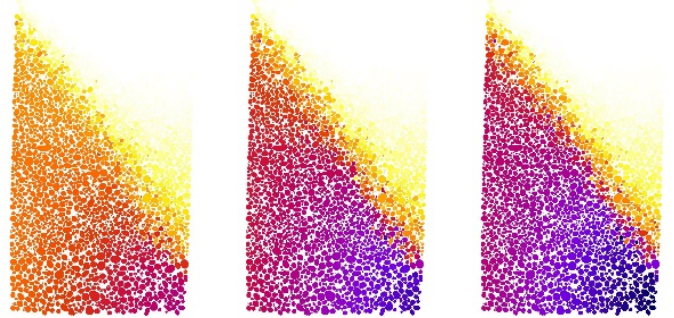

Figure 9: Vertical slices of Caicos sand (specimen COEA04) showing grain vertical displacement (above) 
397 deviatoric loading. Stage "11" = end of the TX test.

\begin{tabular}{cccccc}
\hline $01-02$ & $01-05$ & $01-08$ & $01-11$ & $01-14$ & $01-16$ \\
$\varepsilon_{Z}=0.60 \%$ & $\varepsilon_{Z}=2.1 \%$ & $\varepsilon_{Z}=3.92 \%$ & $\varepsilon_{Z}=7.33 \%$ & $\varepsilon_{Z}=11.67 \%$ & $\varepsilon_{Z}=14.88 \%$ \\
\hline
\end{tabular}

$$
\begin{array}{r}
0 p x(z-d i s p) \\
0^{\circ} \text { deg rotations }
\end{array}
$$
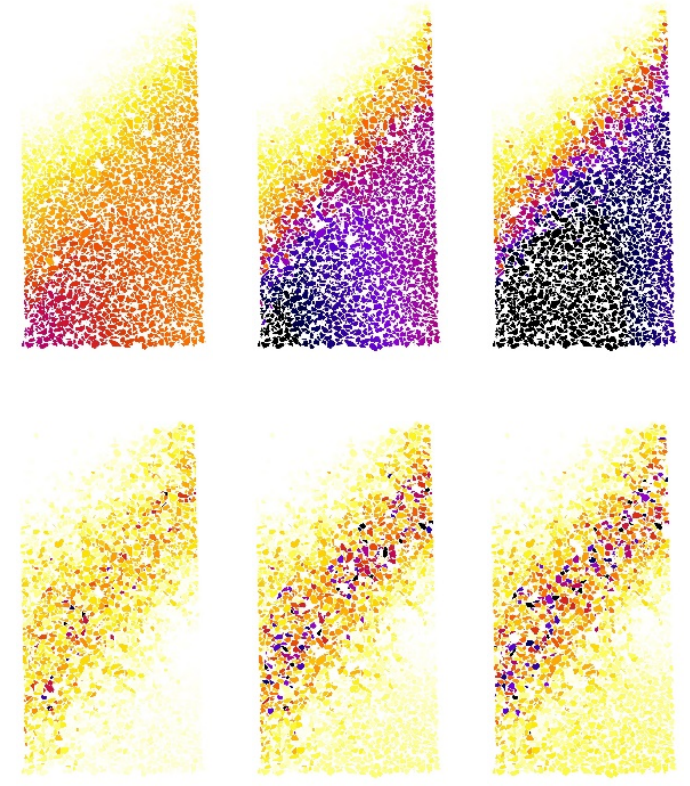

$200 p x(z-d i s p)$

$\sim 60^{\circ}$ deg rotations

398 Figure 10: Vertical slices of Hostun sand (specimen HNEA01) showing grain vertical displacement (above)

and rotation (below) accumulated during the test. Grains are coloured by the value of their measured z-

400 displacement (above) and total rotation (below). Not all the increments are shown. Stage "01" = start of

401 deviatoric loading. Stage " $16 "=$ end of the TX test.

402 This observation is conveyed more precisely in Figure 11, showing the histories of the

403 cumulated mean particle rotation magnitudes, both inside and outside the shear bands.

404 Outside the shear band, the average grain rotations of both sands are very similar and

405 appear quite flat, with a limited increase between $1 \%$ and $5 \%$ axial strain. That increase

406 in the average rotation outside the shear band may reflect the fact that the shear bands

407 become somewhat narrower as deformation progresses [54], whereas the grain classifi-

408 cation criterion is only applied in the final test stage. 


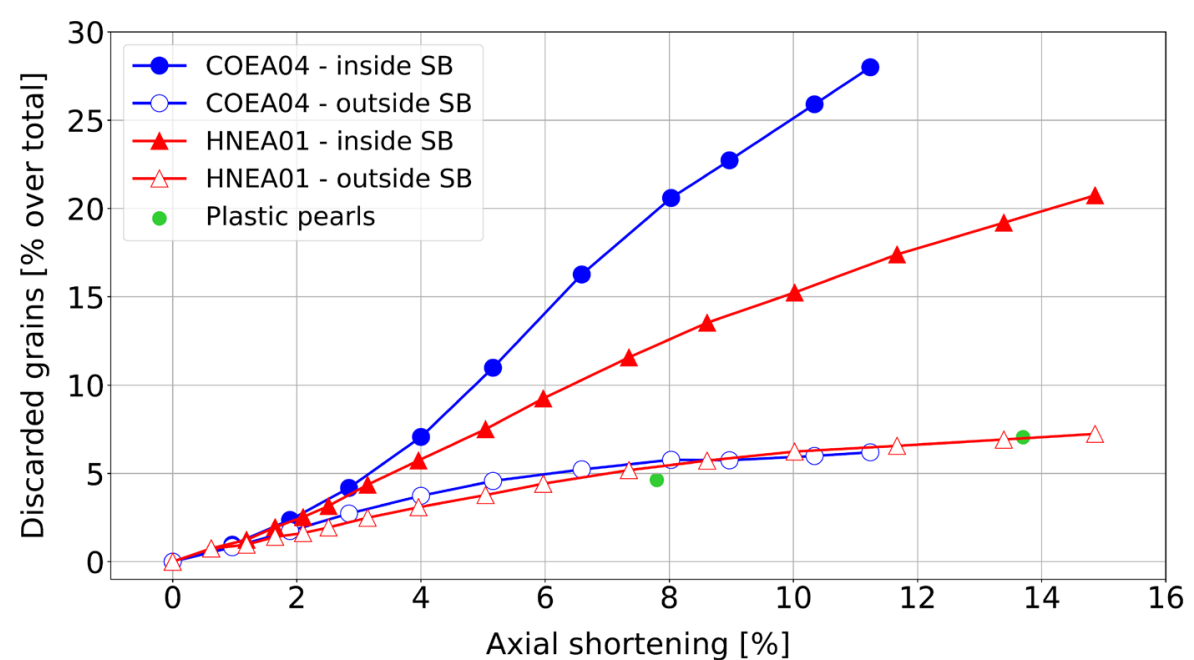

Axial shortening [\%]

411 Figure 11: Histories of cumulated mean particle rotations inside and outside the shear bands (SB in the

412 legend), measured by D-DVC throughout the triaxial tests. The green dots represent interpreted results

413 from Alshibli and Alramahi (2006) for a triaxial experiment involving 400 plastic pearls.

414 Average rotations increase much faster within the shear band. In the Caicos specimen

415 (COEA04) average rotation magnitude raises to about 30 degrees. The trend in the

416 Hostun specimen (HNEA01) is somewhat slower, raising to a level of about 21degrees.

417 The distribution of cumulative rotation magnitudes in the shear bands is rather skewed

418 (Figure 12) with the mode remaining almost constant but the high end tail progressively 419 thickening. 

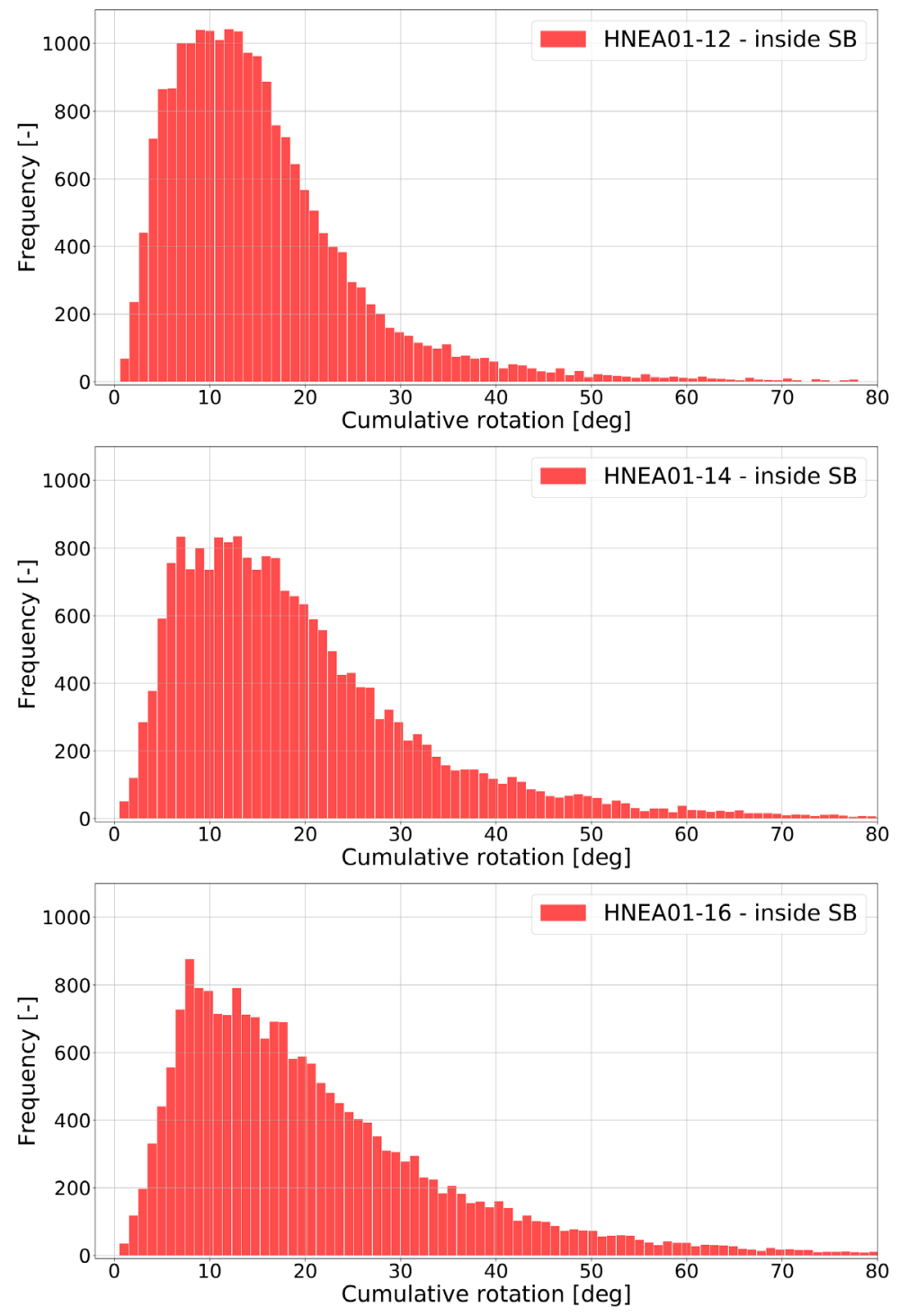

421 particles within the shear band of the Hostun sand HNEA01 specimen.

422 The attrition rate during this sequence of image correlations is shown in Figure 13. It is

423 clear that in this more realistic context, the D-DVC procedure has more difficulties than 424 in the idealized uniform rotation check discussed before. The correlation problems in425 crease as the grains rotate more, which is what happens in the shear band. Despite that, 426 it should be noted that a) the correlation validity criterion was set at a very stringent 427 limit $(\mathrm{CC}=0.98)$ and $\mathrm{b})$ the procedure was able to track to the end almost $80 \%$ of the 428 grains within the shear bands and more than 95\% outside them. 


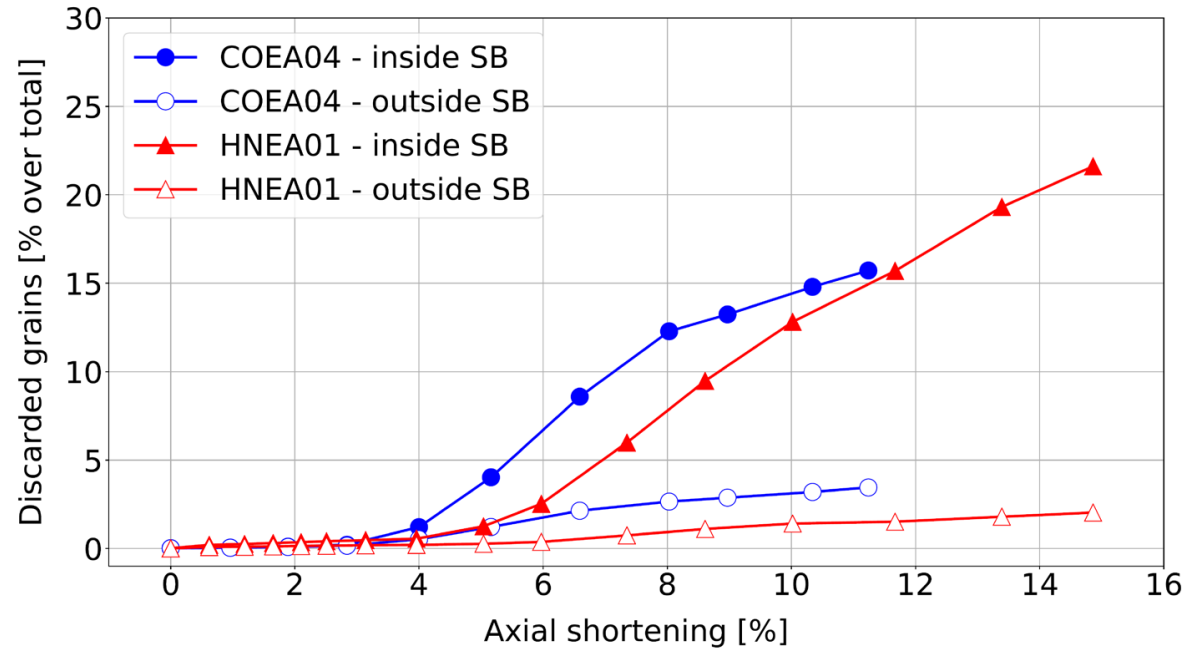

429

430 Figure 13: Particles with correlation maximum below $98 \%$ as a percentage of total number of particles

\subsection{A comparison of secant and cumulative tangent rotations}

432 There is a risk that the secant image correlation approach applied may lead to an under-

estimation of the cumulated total grains rotations, as it computes the "shortest path" of rotation (i.e., the minimum rotation angle) between the initial configuration and that of each step examined. Adding the results from tangent step-by-step correlations such as those performed by Andò [32] would avoid the underestimation problem but, as previously explained, grain re-labelling across images complicates tracking individual grains.

Despite that, a meaningful statistical comparison is still possible based on the average

440 Figure 14 shows the evolution of the average magnitude of grain rotations for Hostun

441 sand for all grains in the specimen as obtained by Andò [32] using step-by-step (i.e. tangent) correlations. This is compared with the values obtained here using the secant approach for two different scenarios. In the first one (corresponding to the results shown 
445 those that are above the correlation threshold). In the second approach the average at 446 each step is computed for all grains, assigning to those that are below the correlation 447 threshold the last rotation value that was obtained for them.

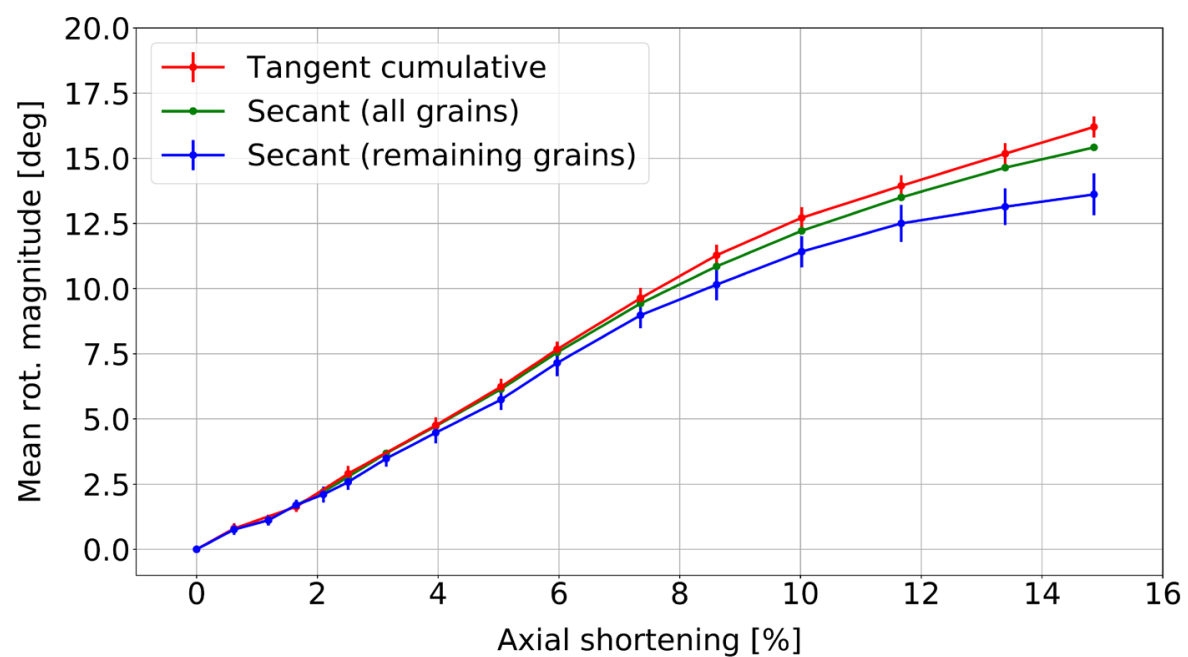

448

449 Figure 14: History of the average magnitudes of rotations for Hostun sand measured with different ap450 proach. The error bars are magnified 10 times.

451 The differences between the "tangent" and "secant" correlation approaches are small.

452 The results for the all-grain secant average are closer to those of the tangent because in 453 the step-by-step correlations the number of grain losses was minimal, whereas in the 454 secant approach the attrition rate is close to $20 \%$ at the end of the test. Moreover, the 455 grains that are lost are typically those with larger rotations, which is reflected in the pro456 gressive divergence of the average restricted to the remaining grains. In any case, it is 457 clear from the comparison that the grain rotations computed with the secant approach 458 are not significantly underestimated. 
460 Stereoplots (see Figure $4 \mathrm{~b}$ ) can be used to investigate the alignment of particle rotation

461 axes during shearing. The orientations of cumulative rotation versors are plotted for all 462 grains (about 110000 in total), both inside and outside the shear bands, at two different 463 test stages in Figure 15 (at approximately 5\% axial strain, corresponding to steps 01-09

464 in Hostun and 01-06 in Caicos) and Figure 16 (at approximately 9\% axial strain, corre465 sponding to 01-12 for Hostun and 01-09 for Caicos). The raw stereoplots are presented 466 alongside binned frequency diagrams.

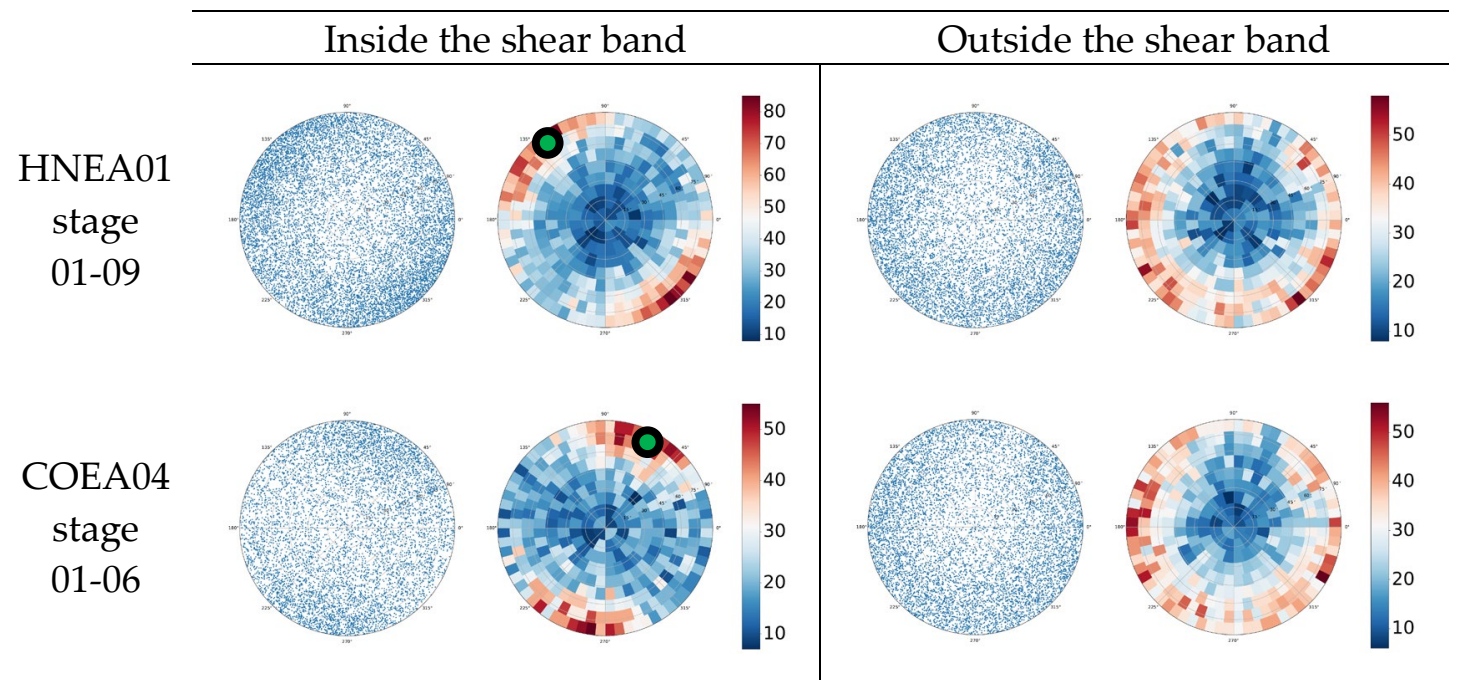

467 Figure 15: Stereoplots showing the rotation versor directions at 5\% shortening. The green dots indicate the

468 orientation of vector $\vec{b}$ (see Figure 6) belonging to the shear bands of Hostun and Caicos sands. The stere-

469 oplot angles markers are not shown for readability, see Figure $4 b$ for reference.

470 


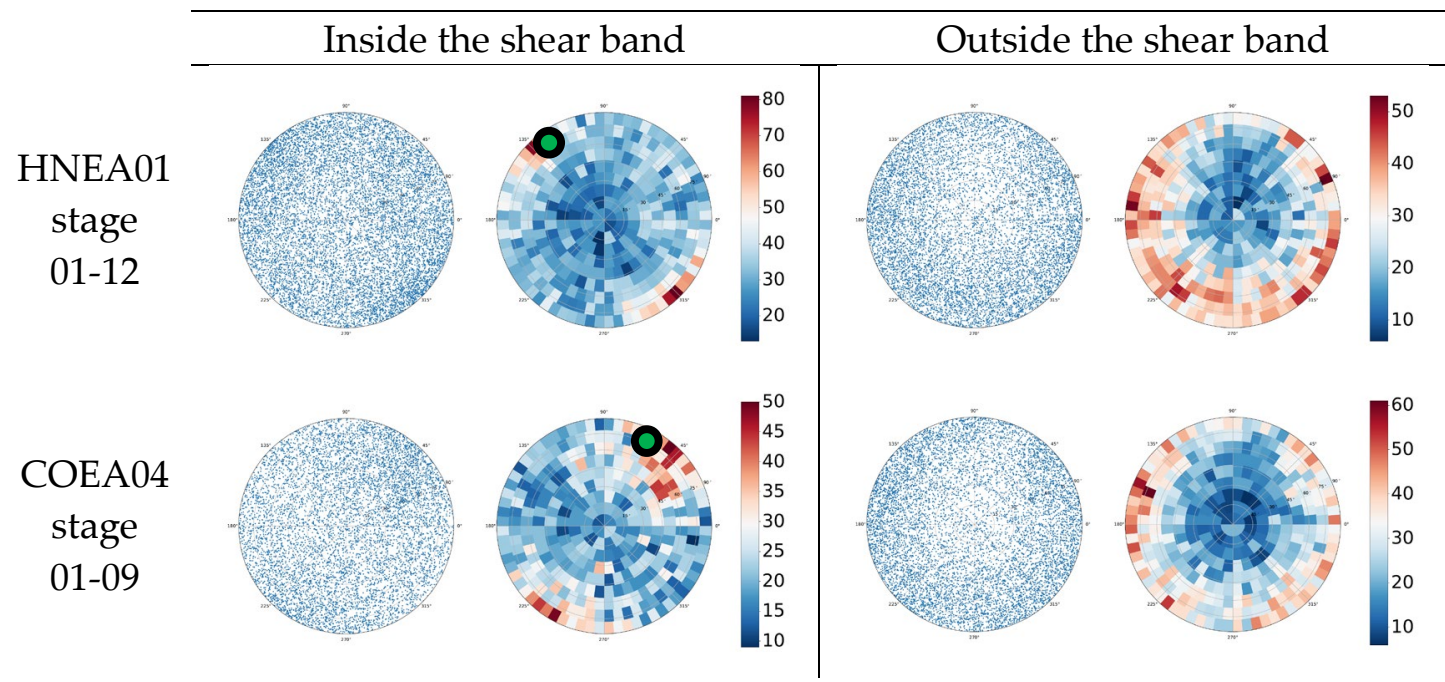

472

473

Figure 16: Stereoplots showing the rotation versor directions at 9\% shortening. The green dots indicate the orientation of vector $\vec{b}$ (see Figure 6) belonging to the shear bands of Hostun and Caicos sands. Stereoplot grid not shown for readability, see Figure $4 b$ for reference.

Both sands exhibit similar trends (Figure 15). Outside the shear bands, the rotation axes accumulate towards the periphery of the stereoplot, with inclination angles close to $90^{\circ}$ that indicate horizontal axes of rotation. The azimuthal angle, on the other hand, is almost homogenously distributed around the stereoplot periphery, indicating no preferential alignment for the grain rotational axis within the horizontal plane.

The situation is different inside the shear band, which is already present at $5 \%$ strain (Figure 9; Figure 10). The rotation axes are still mainly horizontal $\left(\theta=90^{\circ}\right)$, but now the azimuthal angles $(\varphi)$ concentrate around values of about $135^{\circ}$ (Hostun sand) and $75^{\circ}$ (Caicos sand). As indicated in the figures these values are, precisely, the azimuths of vector $\vec{b}$ in Figure 6 i.e., those corresponding to directions orthogonal to that of steepest descent within the shear band. This alignment means that grains are rolling downslope the plane of the shear band. Another azimuthal accumulation point is observed at the diametrically opposed direction in the stereoplot, that is at $315^{\circ}$ for Hostun and $255^{\circ}$ for 
488 Caicos. That position corresponds to grains rotating upslope on the plane of the shear 489 band. These preferential orientations become sharper as localisation progresses (com490 pare with results at 9\% axial strain, shown in Figure 16) and appear generally sharper 491 for Hostun sand than for Caicos ooids.

492 The results obtained contrast with those presented in Andò et al. [32] who attempted a 493 similar analyses for the Hostun HNEA01 specimen. There the alignment of particle ro494 tation axis and shear band normal was not evident. The difference is likely due to the 495 superior precision of particle rotation measurement achieved by the D-DVC technique 496 over the ID-track used in Andò et al. [32]. The presence of particle with opposite spins 497 in shear zones, previously documented in experiments with simplified granular media 498 (such as flat disks [64, 65] or uniform plastic beads [40]), is here confirmed for natural 499 sands.

\section{$500 \quad 4.6$ Relations between grain shape and magnitude of rotation}

501 A first indication of the relationship between particle shape and rotation is already evi-

502 dent in Figure 11. Caicos ooids rotate - on average - far more than Hostun sand grains, 503 but only if belonging to the shear band; for grains that remained outside the shear band 504 there is almost no difference between the more rounded Caicos ooids and the angular 505 Hostun sand. This insensitivity to particle shape outside the critical shearing zone is cor506 roborated by data deduced from Alshibli and Alramahi [40], also plotted in Figure 11.

507 Those authors reported histograms of particle rotations for 400 perforated plastic pearls, 508 almost uniformly spherical, in a triaxial compression test that did not present a clear 
509 shear band. The averaged rotations from that test on plastic beads plot very close to our 510 sand data.

511

512 Although averaged values of rotation are interesting, the data collected allow a more

513 detailed inspection of the effect of grain shape on rotation. Figure 17 presents bivariate

514 frequency density plots exploring the effect of shape descriptors related to form on par-

515 ticle rotations (accumulated up to 5\% axial strain). The histogram contours appear rather

516 flat, indicating little sensitivity of particle rotations to form. The same approach is fol-

517 lowed in Figure 18, but now using shape descriptors that measure sphericity. The histo-

518 gram contours are more sensitive, particularly those at the edge, indicating larger per-

519 centiles. This is particularly evident for convexity and to true sphericity - two shape

520 descriptors that are tightly correlated for these two sands, see [26]).

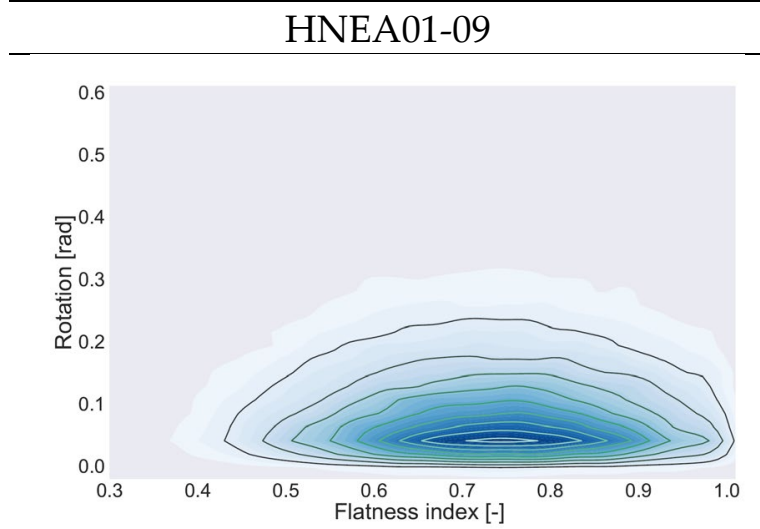

(a)

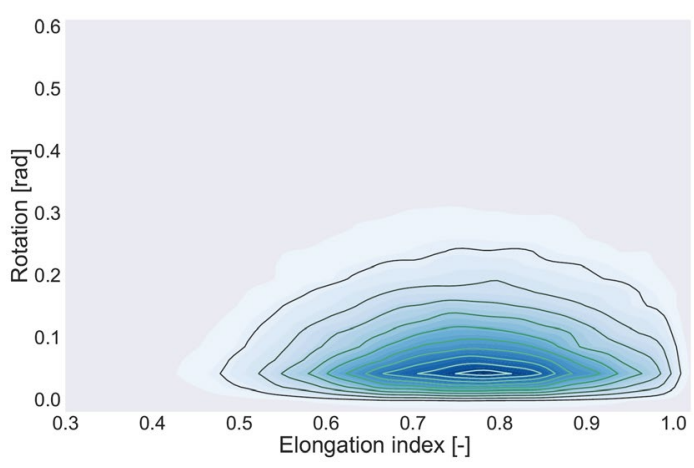

(c)

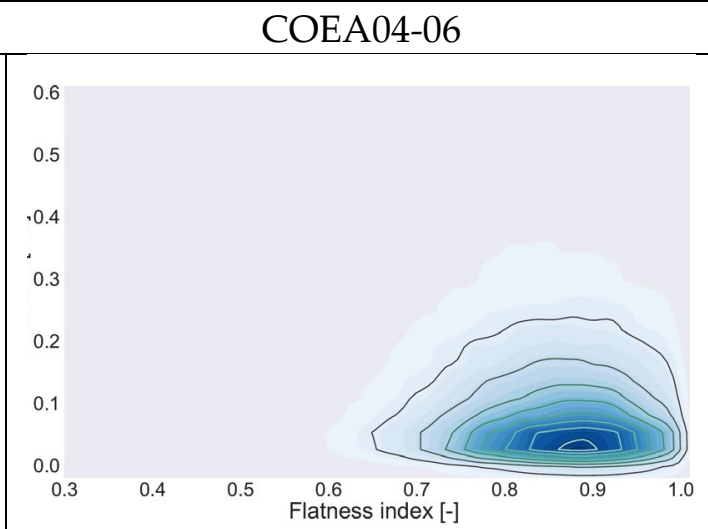

(b)

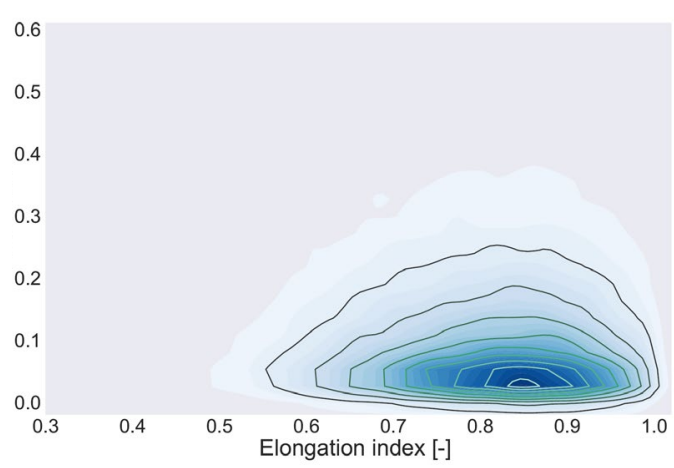

(d) 


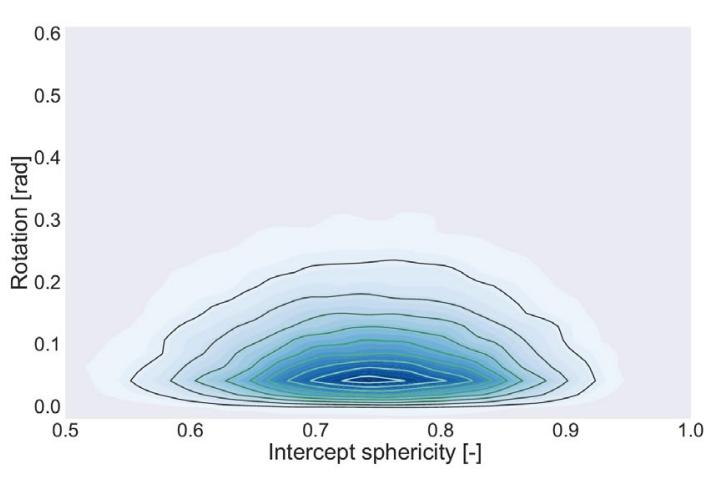

(e)

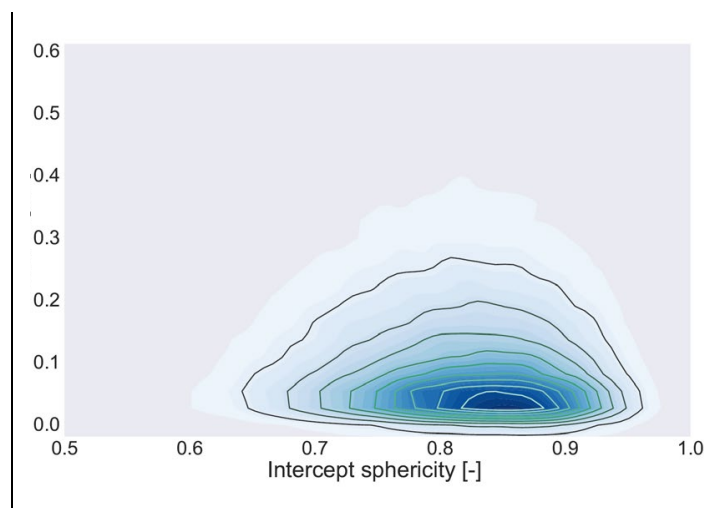

(f)

521 Figure 17: Normalised bivariate frequency density plots of form descriptors versus cumulative grain ro-

522 tation magnitude at 5\% shortening (loading stages HNEA01-09 and COEA04-06, respectively 48.612 and 52365.056 grains). The contours colour bar is shown in Figure 4c.

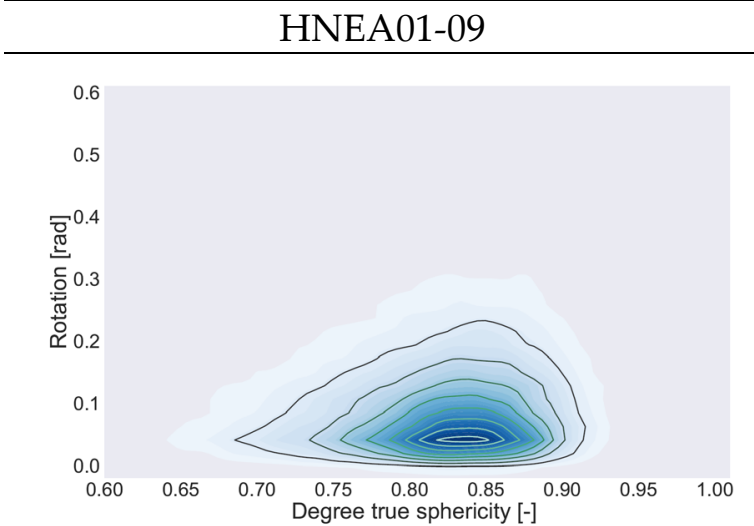

(a)

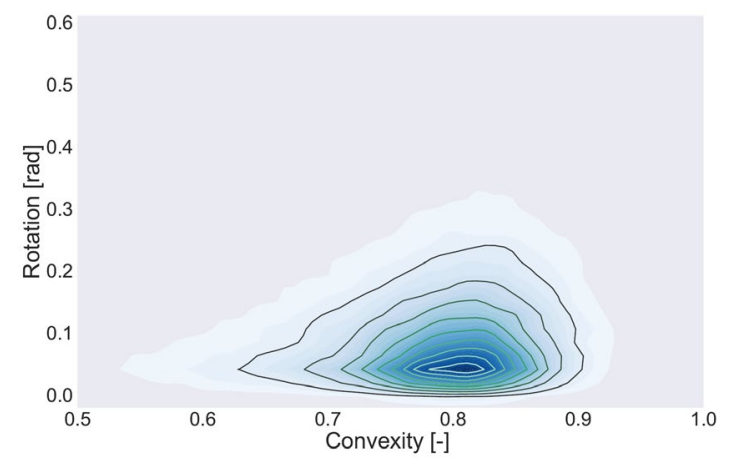

(c)

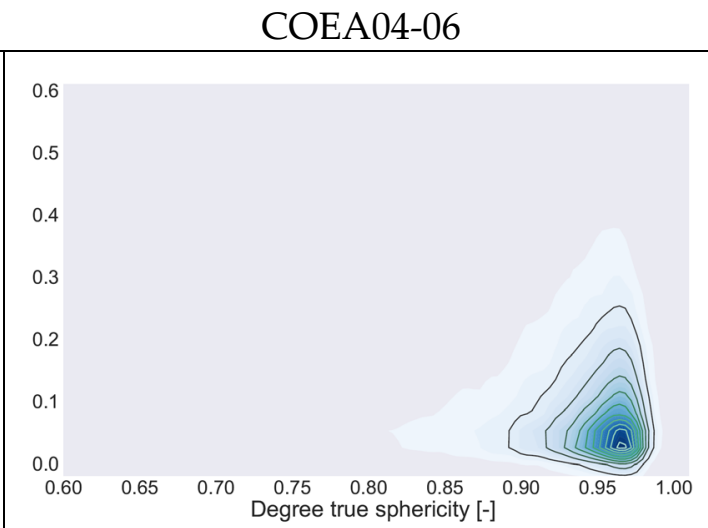

(b)

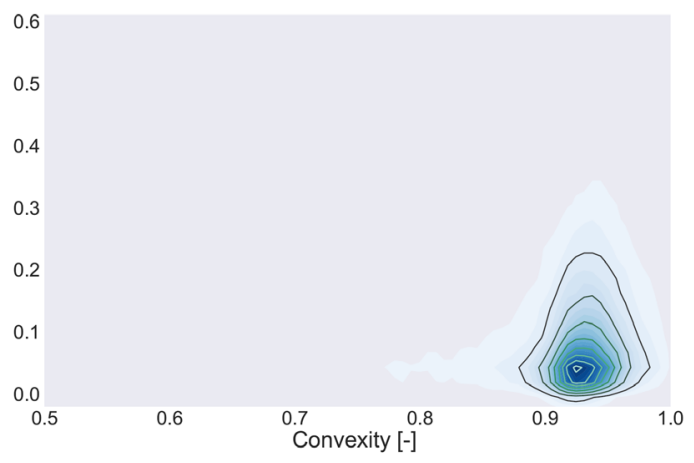

(d) 


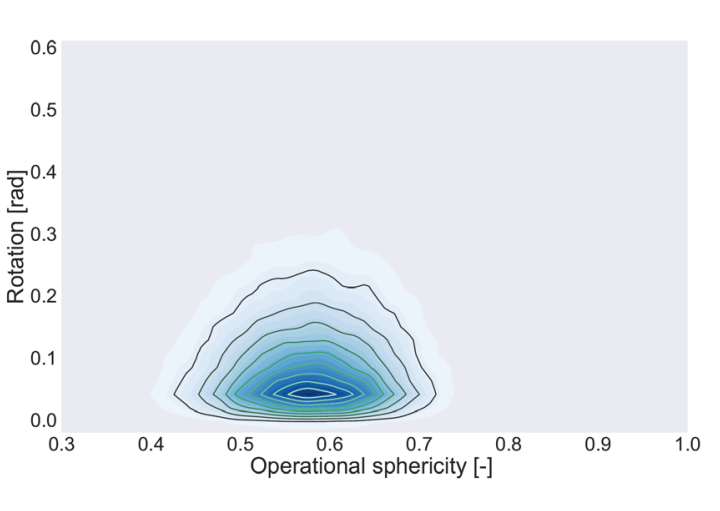

(e)

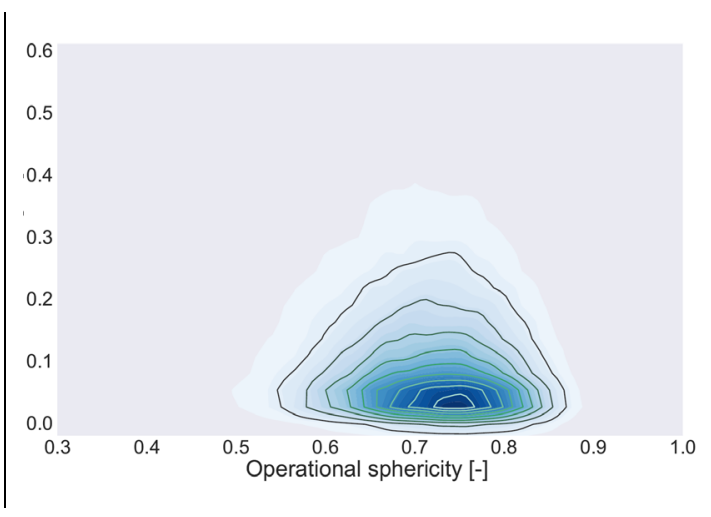

(f)

524 Figure 18: Normalised bivariate frequency density plots of sphericity descriptors versus the cumulative

525 grain rotations measured at 5\% shortening (loading stages HNEA01-09 and COEA04-06, respectively

52648.612 and 65.056 grains). The contours colour bar is shown in Figure 4c.

\begin{tabular}{lll} 
& Inside the Shear Band & Outside the Shear Band \\
\hline 0.7 & 0.7 &
\end{tabular}
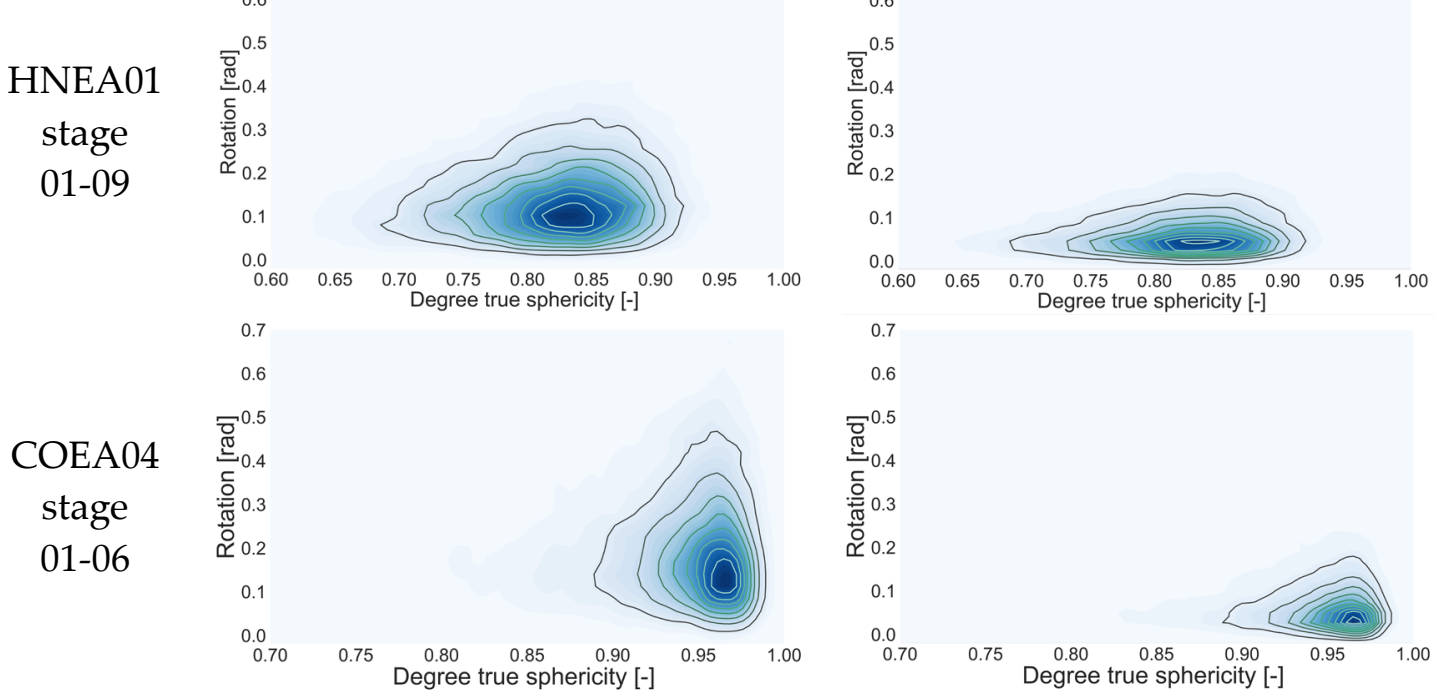

Figure 19: Normalised histograms showing the observed relation between the degrees of true sphericity and

528 the total grains rotation measured at 5\% sample shortening.

529 The histograms become more triangular if restricted to particles in the shear band. Figure

53019 shows that the degree of true sphericity seems to have a significant influence on the

531 upper limit of particle rotation, which increases as particles become more spherical. This

532 idea is explored in more detail in Figure 20 and Figure 21, where mean and extreme values (99.5\% percentiles) of rotation, measured on both Caicos sand and Hostun sand 
534 specimens, are plotted as a function of true sphericity. The values are derived from mar535 ginal distributions, obtained at fixed true sphericity intervals (width 0.025). Because the

536 number of particles in each interval is highly variable, error bands (plus and minus one 537 standard error) are also represented. The error bands for the $99.5 \%$ quantile are esti538 mated using a bootstrapping technique [66], resampling with replacement the original 539 samples (for each interval) one thousand times. Errors band thickness increases with 540 small sample sizes (e.g. at low values of degree of true sphericity) and with marginal vari541 ability (high at large values of degree of true sphericity, as correlating very spherical grains 542 carries more uncertainty).

543 It appears that the mean values of rotation, both inside and outside the shear band are 544 insensitive to particle sphericity, whereas the extreme upper values (the $99.5 \%$ percen545 tile) show a clear positive dependency between rotations and particle sphericity. There 546 is not much difference between the mean values of Caicos and Hostun, at any given true 547 sphericity. On the other hand, the upper limit rotations of Caicos are somewhat above 548 those of Hostun, even at the same sphericity, and particularly for those particles inside 549 the shear band. Andò [54] observed that porosity in the shear band was higher for 550 Hostun than for Caicos, so it is unlikely that connectivity - which is inversely related to 551 porosity - will explain that difference. Still, the differences between the two sands not 552 accounted for true sphericity are less important than the common effect of sphericity on 553 the upper bound. These trends were confirmed when other test stages were analysed, 554 for instance at around 9\% axial strain, Figure 22 and Figure 23. 
Outside the shear band - $5 \%$ shortening

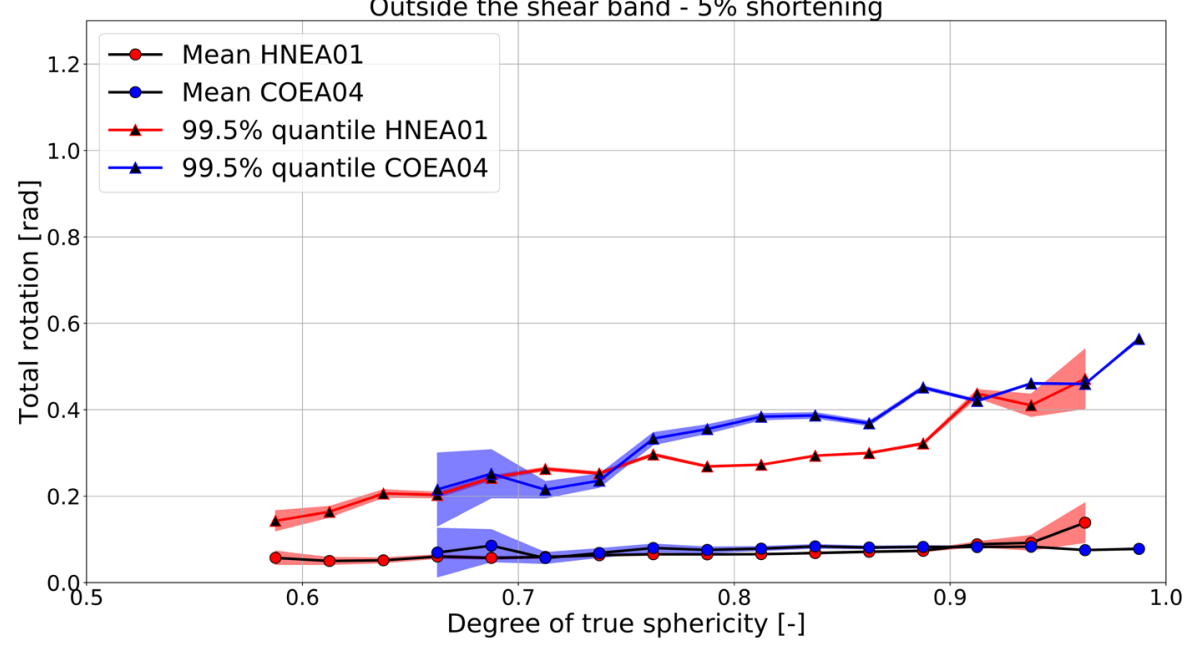

556 Figure 20: Influence of the degree of true sphericity on the total grains rotation (at 5\% shortening) outside 557 the shear band.

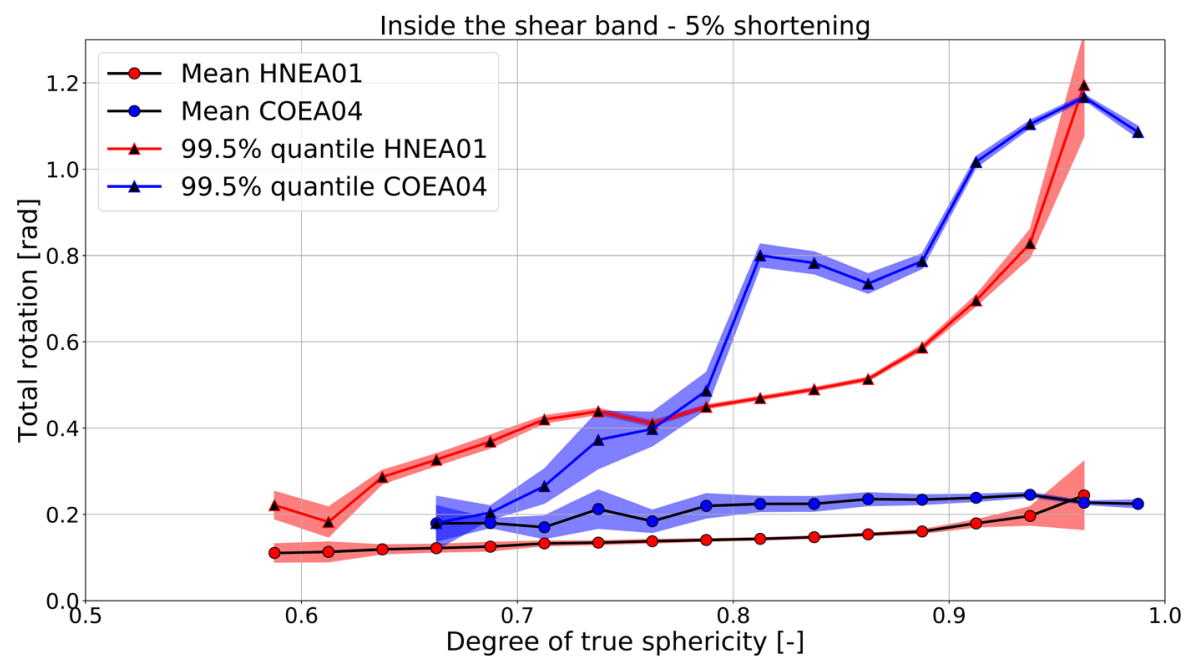
Degree of true sphericity [-]

559 Figure 21: Influence of the degree of true sphericity on the total grains rotation (at 5\% shortening) inside 560 the shear band. 
Outside the shear band - $9 \%$ shortening

561

562 Figure 22: Influence of the degree of true sphericity on the total grains rotation (at 9\% shortening) out-
564

565

566

567

\section{Conclusions}

568 This paper sets out to explore the relationship between particle shape and particle rota-

569 tion at the grain scale, for all the sand grains within triaxial specimens that failed in a

570 localised shear mode. The main findings can be summarised as follows: 
- The systematic use of Discrete-Digital Volume Correlation allowed successful tracking of rotational kinematics in the large majority of grains; those measurements were far more precise than previous attempts using ID-track;

- Kinematics within the shear bands are very different from those outside the shear band. Particle rotation magnitudes increase much faster in the bands. Rotational axes align themselves preferentially, perpendicular to the steepest descent direction of the band;

- Sand grains in the shear plane show both positive and negative spins (upwards and downwards the plane), revealing commonalities in the shear flow mechanisms of sands with those of simpler granular materials;

- Shape descriptors related to particle form, such as elongation or flatness indexes appear to be poorly correlated with observed particle rotation;

- Shape descriptors related to particle sphericity have a significant effect on particle rotation. This effect is far less important on the average value than on the upper limit of rotation.

It may be concluded that the link between particle shape and particle kinematics is only effective at the margin. This was to be expected, as it is a link necessarily mediated by particle connectivity. Despite this limitation, and until particle connectivity can be imaged with equal precision in experiments, the microscale results here presented should facilitate the calibration of advanced DEM contact models to represent shape effects, either directly [67] or indirectly [68]. 


\section{Acknowledgments}

593 The work here described has been supported by the Spanish Ministry of Economy

594 through grants BIA2014-59467-R and BIA2017-84752-R. Laboratoire 3SR is part of the 595 LabEx Tec21 (Investissements d'Avenir - grant agreement nANR-11-LABX-0030).

\section{References}

597 1. Jiang, M., Liu, F., Bolton, M.: Proceedings of the International Symposium on 598 Geomechanics and Geotechnics: from Micro to Macro (IS-Shanghai 2010). CRC 599 Press/Balkema, Shanghai (2011)

600 2. Soga, K., Kumar, K., Biscontin, G., Kuo, M.: Geomechanics from micro to macro : Proceedings of the TC105 ISSMGE International Symposium on Geomechanics from Micro to Macro, Cambridge, UK, 1-3 September 2014. (2014)

3. Baudet, B., Bolton, M.: Editorial Soil mechanics at the grain scale: issue 1 and 2.

612 6. Yang, J., Luo, X.D.: Exploring the relationship between critical state and particle

Géotechnique. 60, 313-314 (2010). doi:10.1680/geot.2010.60.5.313

4. Cho, A.G., Dodds, J., Santamarina, J.C.: Particle Shape Effects on Packing Density, Stiffness and Strength - Natural and Crushed Sands. J. Geotech. Geoenvironmental Eng. 132, 591-602 (2006). doi:10.1061/(ASCE)10900241(2006)132:5(591)

5. Santamarina, J., Cho, G.: Soil behaviour: The role of particle shape. In: Advances in Geotechnical Engineering. Proceedings of the Skempton Conference. pp. 1-14., London (2004) shape for granular materials. J. Mech. Phys. Solids. 84, 196-213 (2015). 
doi:10.1016/j.jmps.2015.08.001

615 7. Xiao, Y., Long, L., Matthew Evans, T., Zhou, H., Liu, H., Stuedlein, A.W.: Effect of 616 Particle Shape on Stress-Dilatancy Responses of Medium-Dense Sands. J. Geotech. 617 Geoenvironmental Eng. 145, (2019). doi:10.1061/(ASCE)GT.1943-5606.0001994

618 8. Vaid, Y., Chern, J., Tumi, H.: Confining pressure, Grain angularity and 619 Liquefaction. J. Geotech. Eng. 111, 1229-1235 (1985)

620 9. Liu, Q.B., Lehane, B.M.: The influence of particle shape on the (centrifuge) cone 621 622

10. Rothenburg, L., Bathurst, R.J.: Micromechanical features of granular assemblies 624 doi:10.1680/geot.1992.42.1.79

11. Ng, T.-T., Lin, X.: A three-dimensional discrete element model using arrays of ellipsoids. Géotechnique. 47, 319-329 (1997). doi:10.1680/geot.1997.47.2.319

12. Cleary, P.W.: The effect of particle shape on simple shear flows. Powder Technol. 179, 144-163 (2008). doi:10.1016/j.powtec.2007.06.018

13. Ferellec, J.-F., Mcdowell, G.R.: A method to model realistic particle shape and inertia in DEM. Granul. Matter. 12, 459-467 (2010). doi:10.1007/s10035-010-0205-8

14. Jiang, M.J., Liu, J.D., Arroyo, M.: Numerical evaluation of three non-coaxial kinematic models using the distinct element method for elliptical granular materials. Int. J. Numer. Anal. Methods Geomech. 40, 2468-2488 (2016). doi:10.1002/nag.2540

15. Matsushima, T., Chang, C.S.: Quantitative evaluation of the effect of irregularly shaped particles in sheared granular assemblies. Granul. Matters. 13, 269-276 
639 16. Iwashita, K., Oda, M.: Rolling resistance at contacts in simulation of shear band 640 641 642 643

644 645 646 647 development by DEM. J. Eng. Mech. 124, 285-292 (1998). doi:10.1061/(ASCE)07339399(1998)124:3(285)

17. Jiang, M.J.J., Yu, H.-S., Harris, D.: A novel discrete model for granular material incorporating rolling resistance. Comput. Geotech. 32, 340-357 (2005). doi:10.1016/j.compgeo.2005.05.001

18. Belheine, N., Plassiard, J.P., Donzé, F. V., Darve, F., Seridi, A.: Numerical simulation of drained triaxial test using 3D discrete element modeling. Comput. Geotech. 36, 320-331 (2009). doi:10.1016/j.compgeo.2008.02.003

19. Huang, X., Hanley, K.J., O’Sullivan, C., Kwok, C.Y.: Implementation of rotational resistance models: A critical appraisal. Particuology. 34, 14-23 (2017). doi:10.1016/j.partic.2016.08.007

20. Coetzee, C.J.: Calibration of the discrete element method and the effect of particle shape. Powder Technol. 297, 50-70 (2016). doi:10.1016/j.powtec.2016.04.003

21. Guillard, F., Marks, B., Einav, I.: Dynamic X-ray radiography reveals particle size and shape orientation fields during granular flow. Sci. Rep. 7, 1-11 (2017). doi:10.1038/s41598-017-08573-y

22. Oda, M., Takemura, T., Takahashi, M.: Microstructure in shear band observed by microfocus X-ray computed tomography. Géotechnique. 54, 539-542 (2004)

23. Matsushima, T., Uesugi, K., Nakano, T., Tsuchiyama, A.: Visualization of Grain Motion inside a Triaxial Specimen by Micro X-ray CT at SPring-8. In: Desrues, J., Besuelle, P., and Viggiani, G. (eds.) Advances in X-ray Tomography for Geomaterials. pp. 35-52. , London (2006) 
662

24. Hall, S.A., Bornert, M., Desrues, J., Pannier, Y., Lenoir, N., Viggiani, G., Bésuelle,

P.: Discrete and continuum analysis of localised deformation in sand using X-ray $\mu \mathrm{CT}$ and volumetric digital image correlation. Géotechnique. 60, 315-322 (2010). doi:10.1680/geot.2010.60.5.315

25. Hasan, A., Alshibli, K.A.: Experimental assessment of 3D particle-to-particle interaction within sheared sand using synchrotron microtomography. Géotechnique. 60, 369-379 (2010). doi:10.1680/geot.2010.60.5.369

26. Rorato, R., Arroyo, M., Andò, E., Gens, A.: Sphericity measures of sand grains. Eng. Geol. 254, 43-53 (2019). doi:10.1016/j.enggeo.2019.04.006

27. Alshibli, K.A., Druckrey, A.M., Al-Raoush, R.I., Weiskittel, T., Lavrik, N. V.: Quantifying Morphology of Sands Using 3D Imaging. J. Mater. Civ. Eng. 27, (2015). doi:10.1061/(ASCE)MT.1943-5533.0001246

28. Zhao, B., Wang, J.: 3D quantitative shape analysis on form, roundness, and compactness with micro-CT. Powder Technol. 291, 262-275 (2016). doi:10.1016/j.powtec.2015.12.029

29. Kong, D., Fonseca, J.: Quantification of the morphology of shelly carbonate sands using 3D images. Géotechnique. 68, 249-261 (2018). doi:10.1680/jgeot.16.P.278

30. Fonseca, J., O'Sullivan, C., Coop, M.R., Lee, P.D.: Non-invasive characterization of particle morphology of natural sands. Soils Found. 52, 712-722 (2012). doi:10.1016/j.sandf.2012.07.011

31. Fonseca, J., O'Sullivan, C., Coop, M.R., Lee, P.D.: Quantifying the evolution of soil fabric during shearing using directional parameters. Géotechnique. 63, 818-829 (2013). doi:10.1680/geot.11.P.150

32. Andò, E., Hall, S.A., Viggiani, G., Desrues, J., Bésuelle, P.: Grain-scale 


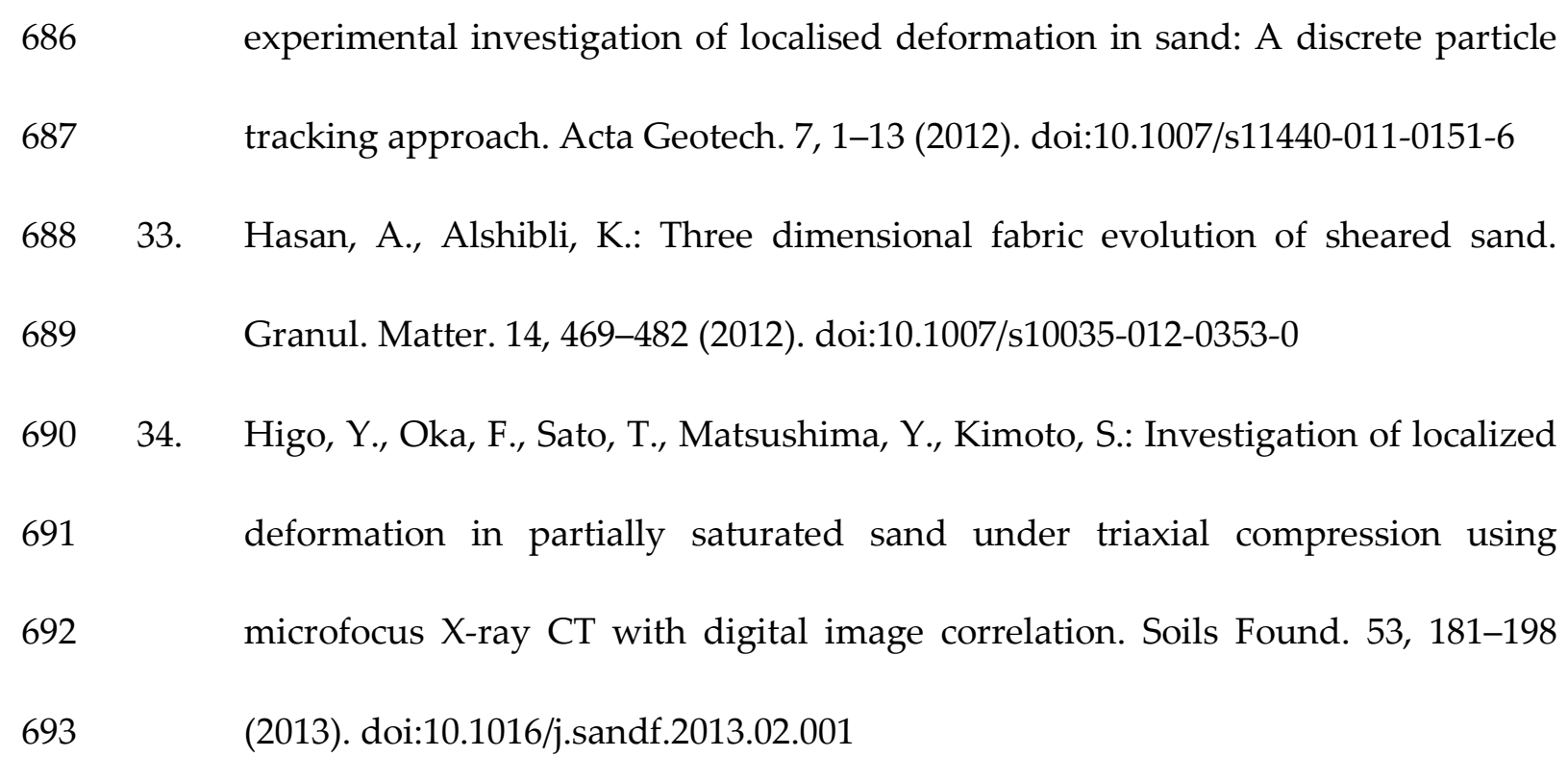
tracking approach. Acta Geotech. 7, 1-13 (2012). doi:10.1007/s11440-011-0151-6

33. Hasan, A., Alshibli, K.: Three dimensional fabric evolution of sheared sand. 689 Granul. Matter. 14, 469-482 (2012). doi:10.1007/s10035-012-0353-0

36. Cheng, Z., Wang, J.: A particle-tracking method for experimental investigation of kinematics of sand particles under triaxial compression. Powder Technol. 328, 436-451 (2018). doi:10.1016/j.powtec.2017.12.071

37. Wiebicke, M., Andò, E., Herle, I., Viggiani, G.: On the metrology of interparticle contacts in sand from x-ray tomography images. Meas. Sci. Technol. 28, 124007 (2018)

38. Wiebicke, M., Andò, E., Salvatore, E., Viggiani, G., Herle, I.: Experimental measurement of granular fabric and its evolution under shearing. In: Radjai, F., Nezamabadi, S., Luding, S., and Delenne, J.Y. (eds.) European Physical Journal Web of Conferences. p. 02020. EDP Sciences (2017)

39. Wiebicke, M., Andò, E., Šmilauer, V., Herle, I., Viggiani, G.: A benchmark strategy for the experimental measurement of contact fabric. Granul. Matter. 21:54, 1-13 
40. Alshibli, K.A., Alramahi, B.A.: Microscopic Evaluation of Strain Distribution in Granular Materials during Shear. J. Geotech. Geoenvironmental Eng. 132, 80-91 (2006). doi:10.1061/(asce)1090-0241(2006)132:1(80)

41. Vlahinić, I., Kawamoto, R., Andò, E., Viggiani, G., Andrade, J.E.: From computed tomography to mechanics of granular materials via level set bridge. Acta Geotech. 12, 85-95 (2017). doi:10.1007/s11440-016-0491-3

42. Cheng, Z., Wang, J.: Experimental investigation of inter-particle contact evolution of sheared granular materials using X-ray micro-tomography. Soils Found. 58, 1492-1510 (2018). doi:10.1016/j.sandf.2018.08.008

43. Sutton, M.A., Schreier, H.W., Orteu, J.-J.: Image correlation for shape, motion and deformation measurements: basic concepts, theory and applications. Springer (2009)

44. Hall, S.A.: Digital Image Correlation in Experimental Geomechanics. In: Gioacchino Viggiani, Stephen A. Hall, and Enrique Romero (eds.) ALERT Doctoral School 2012 Advanced experimental techniques in geomechanics. pp. 69-102. , Aussois (France) (2012)

45. Take, W.A.: Thirty-Sixth Canadian Geotechnical Colloquium: Advances in visualization of geotechnical processes through digital image correlation. Can. Geotech. J. 52, 1199-1220 (2015). doi:10.1139/cgj-2014-0080

46. Pan, B., Qian, K., Xie, H., Asundi, A.: Two-dimensional digital image correlation for in-plane displacement and strain measurement: a review. Meas. Sci. Technol. 20, (2009). doi:10.1088/0957-0233/20/6/062001

47. Stanier, S.A., Blaber, J., Take, W.A., White, D.J.: Improved image-based 
deformation measurement for geotechnical applications. Can. Geotech. J. 53, 727739 (2016). doi:10.1139/cgj-2015-0253

736 48. Pinyol, N.M., Alvarado, M.: Novel analysis for large strains based on particle

52. Zingg,

$$
\text { T.: } \quad \text { Beitrag }
$$

zur

Schotteranalyse, http://ecollection.library.ethz.ch/view/eth:21472, (1935)

53. Krumbein, W.C.: Measurement and Geological Significance of Shape and Roundness of Sedimentary Particles. J. Sediment. Res. 11, 64-72 (1941)

54. Andò, E.: Experimental investigation of microstructural changes in deforming granular media using x-ray tomography, (2013)

55. Salvatore, E., Modoni, G., Andò, E., Albano, M., Viggiani, G.: Determination of the critical state of granular materials with triaxial tests. Soils Found. 57, 733-744 (2017). doi:10.1016/j.sandf.2017.08.005

757 57. Lorensen, W.E., Cline, H.E.: Marching cubes: A high resolution 3D surface 
construction algorithm. ACM siggraph Comput. Graph. 21, 163-169 (1987). doi:10.1145/37402.37422

58. Tudisco, E., Andò, E., Cailletaud, R., Hall, S.A.: TomoWarp2: A local digital volume correlation code. SoftwareX. 6, 267-270 (2017). doi:10.1016/J.SOFTX.2017.10.002

59. Campello, E.M.B.: A description of rotations for DEM models of particle systems. Comp. Part. Mech. 2, 109-125 (2015). doi:10.1007/s40571-015-0041-z

60. Andò, E., Cailletaud, R., Roubin, E., Stamati, O., the spam contributors: SPAM: The Software for the Practical Analysis of Materials, (2017)

61. Pannier, Y., Lenoir, N., Bornert, M.: Discrete volumetric digital image correlation for the investigation of granular type media at microscale: accuracy assessment. EPJ Web Conf. 6, (2010). doi:10.1051/epjconf/20100635003

62. Catalano, E., Chareyre, B., Barthélémy, E.: Pore-scale modeling of fluid-particles interaction and emerging poromechanical effects. Int. J. Numer. Anal. Methods Geomech. 38, 51-71 (2014). doi:10.1002/nag.2198

63. Šmilauer, V. et al.: Yade Documentation 2nd ed. The Yade Project. (2015)

64. Veje, C.T., Howell, D.W., Behringer, R.P.: Kinematics of a two-dimensional granular Couette experiment at the transition to shearing. Phys. Rev. E - Stat. Physics, Plasmas, Fluids, Relat. Interdiscip. Top. 59, 739-745 (1999). doi:10.1103/PhysRevE.59.739

65. Pasternak, E., Dyskin, A. V., Esin, M., Hassan, G.M., MacNish, C.: Rotations and pattern formation in granular materials under loading. Philos. Mag. 95, 3122-3145 (2015). doi:10.1080/14786435.2015.1059517

66. Efron, B., Tibshirani, R.: An introduction to the bootstrap. Chapman \& Hall (1994) 
782 67. Kawamoto, R., Andò, E., Viggiani, G., Andrade, J.E.: All you need is shape: 783 Predicting shear banding in sand with LS-DEM. J. Mech. Phys. Solids. 111, 375$784 \quad 392(2018)$. doi:10.1016/j.jmps.2017.10.003

785 68. Rorato, R., Arroyo, M., Gens, A., Andò, E., Viggiani, G.: Particle Shape 786 Distribution Effects on the Triaxial Response of Sands: A DEM Study. In: Giovine, 787 P. and et al. (eds.) micro to MACRO Mathematical Modelling in Soil Mechanics, 788 Trends in Mathematics. pp. 277-286. , Reggio Calabria (Italy) (2018) 


\section{Linking shape and rotation of grains during triaxial compression of}

2 sand

3 Riccardo Rorato, Dr.

4 Universitat Politécnica de Catalunya (UPC), Barcelona (Spain) - Department of Civil and

5 Environmental Engineering.

$6 \quad$ riccardo.rorato@upc.edu

7 ORCID ID: 0000-0002-4189-3058

8 UPC - Barcelonatech

9 Moduli D2 Campus Nord UPC - Office 212

10 C Jordi Girona 1-3

11 Barcelona 08034

12

\section{Marcos Arroyo Alvarez de Toledo, Prof.}

14 Universitat Politécnica de Catalunya (UPC), Barcelona (Spain) - Department of Civil and

15 Environmental Engineering

16 marcos.arroyo@upc.edu

17 ORCID ID: 0000-0001-9384-9107

18

Edward Carlo Giorgio Andò, Prof.

20 Univ. Grenoble Alpes, CNRS, Grenoble INP, 3SR, F-38000 Grenoble (France)

21 edward.ando@3sr-grenoble.fr

22 ORCID ID: 0000-0001-5509-5287

23

\section{Antonio Gens, Prof.}

Universitat Politécnica de Catalunya (UPC), Barcelona (Spain) - Department of Civil and Environmental Engineering

antonio.gens@upc.edu

ORCID ID: 0000-0001-7588-7054

Gioacchino Viggiani, Prof.

Univ. Grenoble Alpes, CNRS, Grenoble INP, 3SR, F-38000 Grenoble (France)

cino.viggiani@3sr-grenoble.fr

33 ORCID ID: 0000-0002-2609-6077 


\section{Declaration}

36 Funding:

37 - Spanish Ministry of Economy (grants BIA2014-59467-R and BIA2017-84752-R).

38 - Laboratoire 3SR is part of the LabEx Tec21 (Investissements d'Avenir - grant agree-

39 ment nANR-11-LABX-0030).

40

41 Conflicts of interest/Competing interests: Not applicable.

42

43 Availability of data and material (data transparency): Available on request.

44

45 Code availability (software application or custom code): Open-source Python programming

46 language used.

\section{Compliance with ethical standards}

48 Not applicable. No conflicts of interests. All sources of funding have been cited. 


\section{Abstract}

51 Particle shape has a strong effect on the mechanical response of coarse soils. This has

52 been usually observed examining specimen-scale or engineering-scale responses, which

53 are the sum of many microscale interactions. In this work we observe the effects of par-

54 ticle shape directly at the microscale level. X-ray tomography $(\mu-\mathrm{CT})$ of two sand speci-

55 mens is exploited to measure three-dimensional particle shape descriptors but also to

56 track individual particle motions during triaxial compression. A discrete Digital Volume

57 Correlation (DVC) algorithm is employed to track the motion of individual grains

58 (around 50000 for each sand specimen) during the test and measure, with good preci-

59 sion, their cumulated displacements and rotations. The specimens examined failed in a

60 clearly localised shear mode. Advantage is taken of this to obtain data relevant for very

61 different kinematical regimes: one uniform and more constrained and the other close to

62 critical state. A direct comparison between the shape and kinematic databases shows to

63 what degree particle shape descriptors are related to observed kinematics. It appears

64 that true sphericity is a good predictor of upper bound rotational restraint.

66 Keywords: Laboratory equipment; Microscopy; Particle-scale behaviour; Sands; Shear

67 strength; Statistical analysis.

\section{$68 \quad 1$ Introduction}

69 Granular soils are made of discrete particles that interact with each other, therefore

70 changes at the small-scale (i.e., grain-scale) affect the material response at the large-scale

71 (i.e., engineering-scale) [1-3]. For granular soils, for instance, it is well-documented that 
72 particle shape strongly affects soil properties such as extreme void ratios [4, 5], critical

state friction [6] or dilatancy and peak friction [7], as well as engineering scale responses, like liquefaction resistance [8] or cone tip resistance [9].

It follows that particle shape must affect grain-scale interactions to produce those effects.

This hypothesis has been repeatedly supported, from various perspectives, by the results of numerical simulation. In numerous discrete element models direct control of element shape has been shown to result in major changes in ensemble mechanical responses [10$15]$.

It is noteworthy, however, that similar macroscopic effects are observed when particle shape effects are represented indirectly, through appropriately modified element contact interaction laws, for instance introducing some resistance against rolling at the contact [16-19]. Both direct and indirect shape modelling strategies inevitably involve some degree of simplification, to be adjusted in applications under typically conflicting constraints of computational speed, accuracy and ease of calibration [20].

In this context, direct experimental observation of the microscale effects of particle shape appears relevant, as it may provide evidence beyond that implicit in the ensemble behaviour of the specimen. This has been a relatively unexplored avenue, because it requires relevant and accurately measured shape descriptors, as well as particle-scale resolution of internal mechanisms. There are few experimental techniques useful for that purpose [21] and the main one is relatively recent: microfocus or x-rays $\mu$-tomography [22-25]. 
96 Despite significant difficulties, progress in 3D tomographic imaging and post-processing

97 technologies [26-30], has made accurate grain shape determination feasible for most

98 sands. Identification of particle-scale mechanisms is more difficult, as it requires imaging

99 not just isolated particles, but particles in collective interaction, within specimens. Parti-

100 cles need to be separated from one another, within the imaged ensemble. Ideally, the

101 existing contacts amongst particles need to be identified, as interactions between parti-

102 cles occur through contact forces in coarse soils. Single snapshots of microstructures

103 (typically acquired "post-mortem", after dismounting the test $[22,25,31]$ ) cannot reveal

104 kinematics. For that purpose a sequence of images needs to be acquired during a test,

105 and triaxial tests have been the target for most of this kind of work [32-36]. Clearly, one

106 added difficulty here is the need to track particles confidently across different images.

107 Progress in these tasks has been also very significant, but there are still some important

108 obstacles, particularly in the area of contact detection and measurement. Indeed, the

109 level of image resolution required to image particle contacts - and contact properties

110 such as orientation - appears far more demanding than that required to image, identify

111 and measure particles [37-39]. This has implicitly limited the scope (number of tracked

112 particles and/or number of imaged test steps) of kinematic contact fabric imaging studies

$113[33,40-42]$.

114

115 Current technology may be exploited to obtain more statistically sound results if the fo-

116 cus is restricted to particle kinematics. This is the avenue explored in this work, in which

117 we examine in detail the relations between individual grain shape and individual kine-

118 matical history of sand grains as observed during triaxial compression of two dense sand

119 specimens that jointly provide a database of 110000 grains. For the purposes of this 
study, the specimens selected for examination had the advantage of failing in sharply

121 localised shear modes. As clearly identified in previous research [22, 24, 25] the structure and kinematics of particles within a shear band are very different from those outside, as particles in a shear band approach critical state conditions. As long as a criterion for

124 belonging or not into the shear band could be clearly established, this experimental feature ensured that the influence of particle shape could be examined in two very different and separate kinematic settings (i.e., within the band and outside it), thus making the study relevant for a larger set of conditions. In what follows, we first give some background on particle tracking and shape description terminology. We then describe the test and image analysis procedures employed and the results obtained before presenting some conclusions.

\section{Background}

\subsection{Digital image correlation for quantifying particle kinematics}

Digital Image Correlation (DIC) is the ideal tool for comparing and analysing images of deforming materials, such the ones obtained from x-ray scans. DIC is a widely used technique in experimental mechanics to deduce motion and shape features of an object by comparing its appearance in different images [43]. A first classification of DIC may be based on the dimensional support of the images employed in the comparison [44]: surface-DIC is based on bi-dimensional images, whereas volumetric DIC (or, simply, digital volume correlation, DVC), is based on three-dimensional images. Surface-DIC is widely 
employed in field and laboratory experimental geotechnics [45]. DVC has seen fewer

141 applications because of the increased difficulties associated with 3D image acquisition.

142 In DIC a subset $F$ of intensity values from a reference image is systematically compared

143 with subsets $G_{i}$ of the transformed image until some optimality condition is achieved

144 [46]. This optimality condition is frequently based on a cross correlation measure, for

145 instance searching for a maximum normalised cross correlation:

146

$$
N C C=\frac{F * G_{i}}{\|F\|\left\|G_{i}\right\|}
$$

147 Different algorithms are obtained depending on how the subset $F$ is chosen, what kind

148 of motion is assumed to relate $F$ and $G_{i}$ and how the search window (SW, the zone in

149 which $G_{i}$ is searched for) is defined.

150 Two broad variants of DVC have been employed in geotechnical applications: continuum

151 (C-DVC) and discrete (D-DVC). In C-DVC, the subset $F$ (usually referred to as correlation

152 window, $C W$ ) is a cubical cell centred around some pre-established evaluation grid

153 points. Although more complex transformations are sometimes used [47], the motion

154 relating $F$ and $G$ is usually assumed as a simple rigid translation, and cross correlation

155 is employed to find a displacement vector, which is assigned to the grid node. From the

156 displacement field thus obtained, strain measures are derived using different procedures

157 [48]. The underlying assumption is that subset $F$ is a representative volume element RVE

158 in a continuum; therefore, the scale of the $C W$ should contain enough grains to make that

159 assumption realistic.

160 C-DVC is not well adapted to identify particle kinematics. When the resolution of the 161 images is such that individual grains may be identified, other alternatives are possible. 
162 Hall et al. [24] proposed a novel discrete grain-based approach (D-DVC) to track individ163 ual particles. The method has as a starting point a segmented labelled image, in which 164 groups of voxels are identified as grains. In D-DVC the subset $F$ is selected considering 165 which voxels have been previously assigned to a certain grain and is named a grain 166 mask. The assumed motion between $F$ and $G$ is a rigid body motion, including transla167 tion and rotation. With D-DVC the kinematics of each identified particle is thus directly 168 obtained. Hall et al. [24] went on to illustrate the potential of D-DVC obtaining maps of 169 incremental displacements and rotations in a triaxial specimen of Hostun sand, showing 170 also that the kinematic history of single grains was very different if they were involved 171 in a shear band or not.

172 Andò et al. [32] proposed an alternative method to follow grain kinematics across 173 images, called ID-track. In this method grain match between successive images is based 174 on listed properties of grains, such as volume, surface area, etc. obtained through single175 image analysis. The method requires two segmented images as input. The grain match176 ing operation is faster than in D-DVC, as volume cross-correlation is not needed. With 177 some modifications, ID-track has been later used by Alshibli et al. [35] and Cheng \& 178 Wang [36], amongst others. However, ID-track has some difficulties to assign precise 179 rotation values, particularly when dealing with very spherical particles [32], and was 180 therefore extended to include a D-DVC based technique for rotation measurement in 181 Andò et al. [49]. For this reason, the work presented here was based on the more robust, if slower, D-DVC technique. 


\subsection{Particle shape description}

184 There are different approaches to describe the shape of soil grains and, as a result, many

185 different shape descriptors are currently in use. Table 1 summarises the 3D shape de-

186 scriptors that are employed in this work whereas Table 2 lists the fundamental measures

187 from which the shape descriptors are derived. Several shape descriptors try to measure 188 particle similitude with a sphere (i.e., sphericity), i.e., the historical proposal of Wadell

189 [50], called true sphericity, but also the convexity and operational sphericity descriptors. We

190 also use some shape descriptors that are more relevant to particle form [51] such as flat-

191 ness index, elongation index and - despite its name - intercept sphericity. Rorato et al. [26]

192 present a detailed study of the relationships amongst these and other 3D and 2D shape 193 descriptors.

\begin{tabular}{cccc}
\hline Name & Symbol & Definition & Reference \\
\hline True Sphericity & $\Psi$ & $\frac{s_{n}}{S}$ & {$[50]$} \\
\hline Flatness index & FI & $c / b$ & {$[52]$} \\
\hline Elongation index & EI & $b / a$ & {$[52]$} \\
\hline $\begin{array}{c}\text { Intercept sphericity } \\
\text { Operational } \\
\text { Sphericity }\end{array}$ & $\Psi_{\text {int }}$ & $\sqrt[3]{\frac{b c}{a^{2}}}=\sqrt[3]{F I(E I)^{2}}$ & {$[53]$} \\
\hline Convexity & $\Psi_{\mathrm{op}}$ & $\sqrt[3]{\frac{V}{V_{c m}}}=\frac{D_{n}}{D_{c m}} \approx \frac{D_{n}}{a}$ & {$[53]$} \\
\hline
\end{tabular}

194

Table 1: Selected 3D shape descriptors [26]

195

\begin{tabular}{ccc}
\hline Shape property & Symbol & $\begin{array}{c}\text { Equivalent } \\
\text { diameter }\end{array}$ \\
\hline Volume & $V$ & $D_{n}$ \\
\hline Surface area & $S$ & \\
\hline
\end{tabular}




\begin{tabular}{ccc}
\hline $\begin{array}{c}\text { Shape property } \\
\text { Surface area of the equivalent } \\
\text { sphere (same volume) }\end{array}$ & $s_{n}$ & $\begin{array}{c}\text { Equivalent } \\
\text { diameter }\end{array}$ \\
\hline $\begin{array}{c}\text { Maximum, intermediate, minimum } \\
\text { lengths }\end{array}$ & $a, b, c$ & \\
\hline $\begin{array}{c}\text { Convex hull volume } \\
\text { sphere }\end{array}$ & $V_{C H}$ & $D_{C H}$ \\
\hline $\begin{array}{c}\text { Volume of the maximum inscribed } \\
\text { Volume of the minimum circum- } \\
\text { scribing sphere }\end{array}$ & $V_{i M}$ & $D_{i M}$ \\
\hline
\end{tabular}

Table 2: Fundamental measures from which 3D shape descriptors are derived [26]

\section{Methodology}

\subsection{Data acquisition}

This study analyses data obtained at Laboratoire 3SR (Grenoble, France) from two sand triaxial specimens, approximately $10 \mathrm{~mm}$ diameter and $20 \mathrm{~mm}$ height [54]. Both specimens were prepared by dry pluviation and then subject to triaxial compression under $100 \mathrm{kPa}$ of confining pressure. The triaxial tests were performed "in-camera" within the x-ray scanner at Laboratoire 3SR. Results from two sand specimens that cover a wide range of particle sphericity values were selected.

The first specimen (HNEA01) was formed with Hostun HN31 sand at relative density of $83.2 \%$ (initial void ratio, $\mathrm{e}=0.658$; dry density, $\gamma_{d}=1.60 \mathrm{~g} / \mathrm{cm}^{3}$ ). Hostun is a quartz quarry sand whose grains appear very irregular, see Figure 1a. The grain size distribution, Figure $1 \mathrm{c}$, is very narrow $\left(C_{U}=1.41\right)$, with a D50 equal to $338 \mu \mathrm{m}$. The second specimen analysed (COEA04) was formed with Caicos ooids $\left(\mathrm{e}=0.468 ; \gamma_{d}=1.76 \mathrm{~g} / \mathrm{cm}^{2}\right)$. 
210 Due to lack of material, minimum and maximum void ratios were not measured for this

211 sand, but comparison with relevant database results [6] suggest that the specimen void

212 ratio was close to its likely minimum. This sand is a natural sand made of calcium car-

213 bonate $(\mathrm{CaCO} 3)$ minerals. Ooids are formed by slow chemical accretion and have a very

214 round shape (Figure 1b). The grain size distribution (Figure 1c) is close to that of

215 HNEA01, being also poorly graded $\left(C_{U}=1.39\right)$ with a D50 of $420 \mu m$.

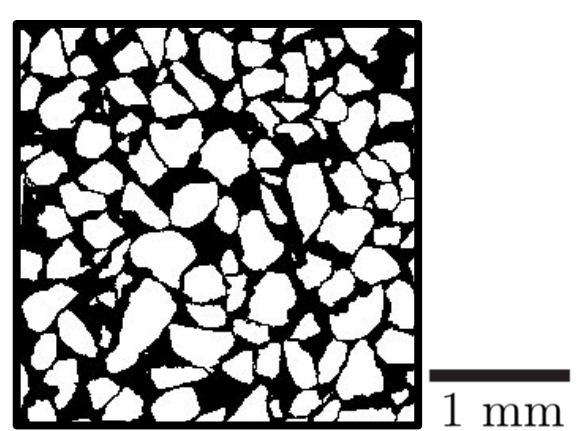

(a)

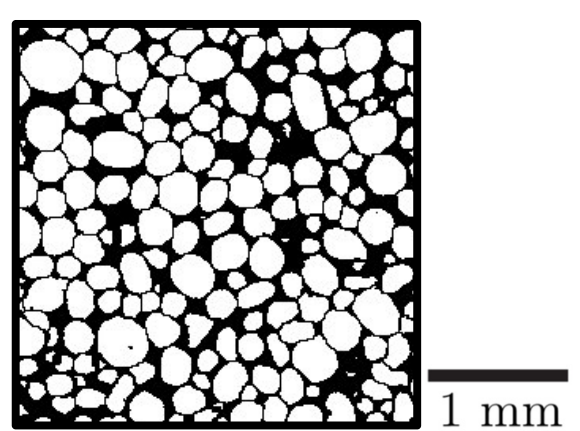

(b)

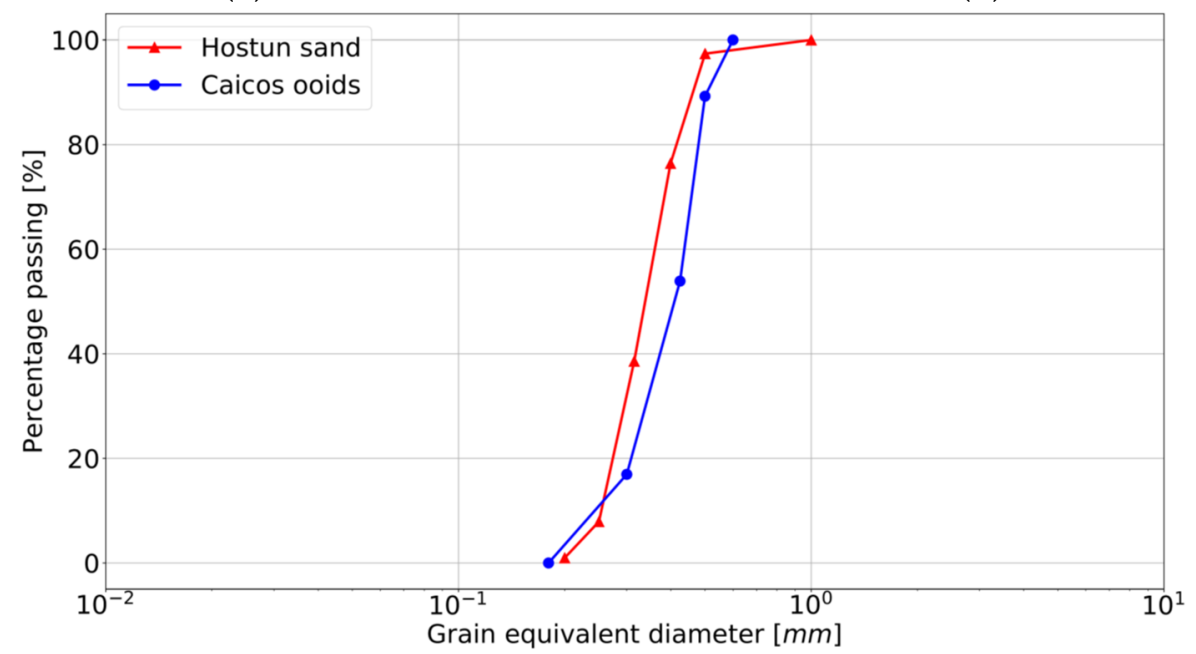

(c)

216 Figure 1a-b-c: (a) Horizontal section of the scanned Hostun (a) and Caicos (b) specimens. (c) Grain Size

217 Distribution of both sands from sieving [54]

218 The specimens were scanned by $\mathrm{x}$-rays at several loading stages during the test (16 for 219 test HNEA01 and 11 for COEA04). The stress-volumetric-strain curves, with indication 220 of scanning stages are shown in Figure 2. The macroscopic responses of both specimens are typical of dense sands, with a stress peak followed by shearing at overall constant 
222 volume. Both specimens failed in a localized shear mode: Andò [32] verified that within

223 the shear zone constant volume was also attained (at different porosity than the overall

224 value, see also [55]). No breakage was visible in any of the tomographic images. Rorato

225 et al (2019) compared the initial and final images to show that the statistics of all shape

226 parameters remained practically invariant during the tests.

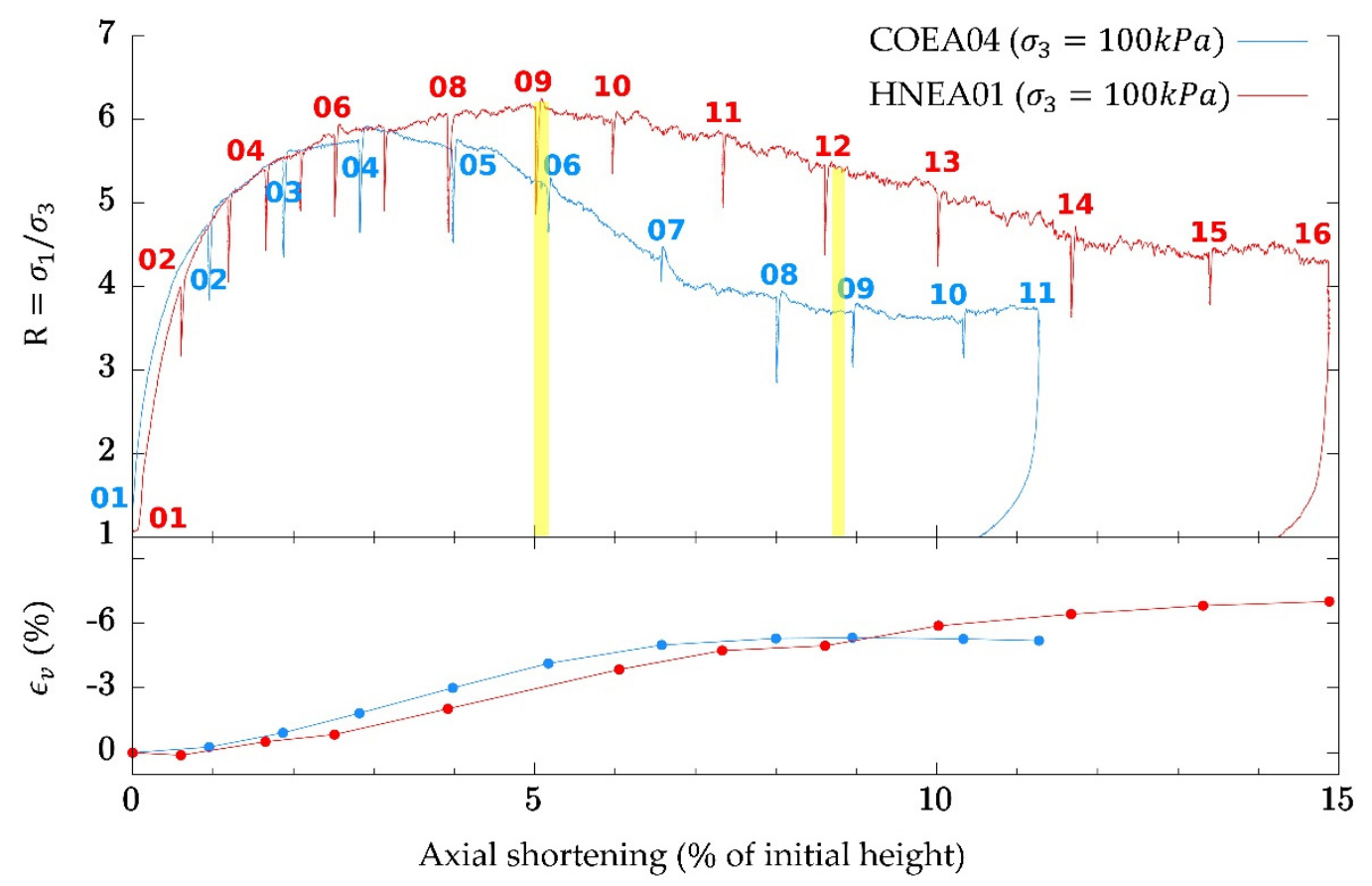

228 Figure 2: Triaxial responses of the specimens HNEA01 and COEA04 with loading stages markers. The

229 yellow stripes indicate loading stages that are later investigated in more detail.

230 The pixel size selected to image the sand specimens was $15.56 \mu \mathrm{m} / p x$, to maintain a field

231 of view of approximately $30.5 \mathrm{~mm} \times 23.0 \mathrm{~mm}$. For the specimens analysed, this results

232 in about 22/26 pixels across a grain. Further details of these tests, including the scanning

233 equipment and tomographic image acquisition procedures have been presented else-

234 where $[54,56]$. 
236 The reconstruction of each x-ray scan results simply in a 3D distribution of grey-scale

237 values which represents the frequency-lumped x-ray attenuation coefficient measured

238 in that location. Therefore, before studying individual grains, it is necessary to binarise,

239 separate and label the tomographic images. The procedures applied here for these tasks

240 are described by Andò [32]. At this point, it is possible to extract single grains from the

241 3D labelled images. The 3D tomographic images representing Hostun (specimen

242 HNEA01) and Caicos (specimen COEA04) sands contain respectively 48612 and 65056

243 particles.

245 Geometrical properties (e.g. volume, surface area, inertia tensor...) of the image subset

246 assigned to each grain are obtained through subsequent post-processing. These proper-

247 ties may be used, in turn, to obtain different shape descriptors in 3D or 2D. The proce-

248 dures applied for this purpose are described in detail by Rorato et al. [26]; who also pre-

249 sented an exhaustive database of 3D shape descriptors for all the grains in this speci-

250 mens, evaluating significant statistics. It is worth mentioning that surface area measure-

251 ments for grains were obtained using a Marching Cubes algorithm [57], to ensure preci-

252 sion in the evaluation of Wadell true sphericity values. Rorato [26] also verified that there

253 were no significant shape changes during the triaxial tests. 


\subsection{Tracking grain kinematics with D-DVC}

255 The D-DVC software that has been used in this work to obtain the grains kinematics (3D

256 displacements and rotations) is the TomoWarp2 code [58]. In this code, grain displace-

257 ments are expressed in pixels (the pixel-size is fixed) and 3D rotations as rotation vectors

258 using a Rodrigues parametrisation [59]. In a rotation vector, the components represent

259 the direction of the axis of rotation and the norm the magnitude of the angle of rotation

260 around that axis. This representation system for rigid body rotations has practical ad-

261 vantages over more complex alternatives, such as those based on Euler angles or quater-

262 nions [59].

263 To visualize the 3D unit rotation vector orientation, stereographic projection is some-

264 times used below. The angular coordinates used in this projection are illustrated in Fig-

265 ure 3. The angle $\theta$ (inclination) goes from $0^{\circ}$ (vertical) to $90^{\circ}$ (horizontal), while the angle

$266 \varphi$ (azimuth) goes from $0^{\circ}$ to $360^{\circ}$, being the north $\left(\varphi=0^{\circ}\right)$ the direction of the Cartesian $x-$

267 axis of the specimen. Stereograms were created using the plotting tool "orientationPlot268 ter" from the external open-source Python package SPAM [60].

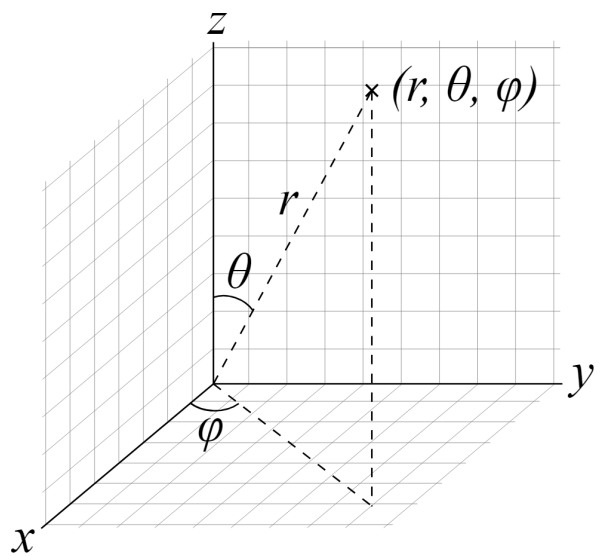

$270 \quad$ Figure 3: Spherical coordinates system adopted for the stereoplots

271 Previous applications of D-DVC had focused mostly on incremental grain kinematics

272 [24, 32]. In such approach only the incremental kinematics between two subsequent 
273 loading steps (e.g. 1-2, 2-3, 3-4, etc...) were obtained. The starting point are the two 3D 274 greyscale images bracketing the increment (i.e., initial and deformed configurations); of 275 these two the image corresponding to the initial configuration has to be already labelled, so that grain bounding-boxes that are used as correlation windows can be extracted.

277 This incremental or "tangent" correlation approach cannot be applied sequentially to obtain cumulative kinematics of the grains. The reason is that grain labels assigned to the same grains by processing different scans of the same specimen will be different. To ensure consistency, a single set of grain labels, obtained from the first scan, is required.

The method used here to get the history of grain displacements and rotations is based on "secant" correlation (usually referred to as "leapfrog" in C-DVC applications). In this approach, the initial labelled image is always selected for paired searches on those resulting from all the subsequent scans (i.e., 1-2, 1-3, 1-4, etc...). A direct secant approach has clear limitations, being both very expensive (as the grain search window would have to increase during the process) and prone to errors.

The algorithm applied here aims to overcome those difficulties using a mixed approach, in which a secant correlation scheme $(1-2,1-3, \ldots, 1-10)$ is still employed, but the search is aided by the results of the previous steps, namely the cumulative grains displacement up to the last correlation step. The initial search window is translated by a vector pointing the position of the grain in the previous correlation and can remain of a small size, saving calculation time. The inputs required in this procedure are four: two greyscale images, one labelled image and one data file with the prior grain displacements. Since

294 therotations that precede the analysed step are not taken into account for the correlation, it is still possible to lose grains when large rotations are present.. 
297 To validate the implementation of D-DVC in TomoWarp2 a simple uniform rotation

298 check was employed [32, 61]. The rotations of all the grains contained in specimen

299 HNEA01 were individually computed after applying a five degrees $\left(5^{\circ} \mathrm{deg}\right)$ rigid rota-

300 tion around its vertical $z$-axis. The main objectives of the validation are three: (a) to eval-

301 uate the attrition rate of the algorithm (i.e., the number of grains that are lost from one

302 image to the next); (b) to evaluate the accuracy and precision with which grain rotation

303 was measured and (c) to explore the possible relationship between the precision of the

304 calculation and the shape of the grains (as grains masks are used as correlation windows,

305 it is expected that grains closer to a spherical shape will be tracked with less precision).

306 The check was positive from the attrition viewpoint, with more than $99.8 \%$ of the grains

307 correctly tracked attaining a correlation coefficient between the two image subsets

308 greater than 0.99 for each of them. Figure 4a shows the histogram of the rotations meas-

309 ured by D-DVC. The rotation measurements follow a normal distribution with a mean

310 value of $4.998^{\circ} \mathrm{deg}$ and $0.042^{\circ} \mathrm{deg}$ standard deviation. Rotations as obtained by this code

311 are as accurate (i.e., have similar mean error), but far more precise (i.e., have much

312 smaller error standard deviation), than those obtained with the ID-track implemented

313 by Andò [32]. Indeed, the coefficient of variation (standard deviation / mean) of meas-

314 urement error is here below 1\%, while it was above $400 \%$ for ID-track. Another way of

315 conveying this information is by means of a stereogram of the computed grain rotations

316 (Figure $4 \mathrm{~b}$ ). The radial distance from the centre of the stereoplot represents the inclina-

317 tion $\theta$, whereas the angles on the external perimeter represent the azimuth $\varphi$. As ex- 
318 pected, all the grain rotations are located at the centre of the stereoplot $\left(\theta=0^{\circ}\right)$, indicat319 ing rotations around the vertical axis, with very low deviation from the vertical. Finally,

320 Figure 4c illustrates the relation between measured rotation and sphericity; it is clear that

321 the deviation from the exact solution $\left(5^{\circ} \mathrm{deg}\right)$ increases symmetrically with the spheric-

322 ity of the grains. However, the deviation remains very limited (around $\pm 0.1^{\circ} \mathrm{deg}$ ) and,

323 therefore, this inbuilt bias can be safely ignored.

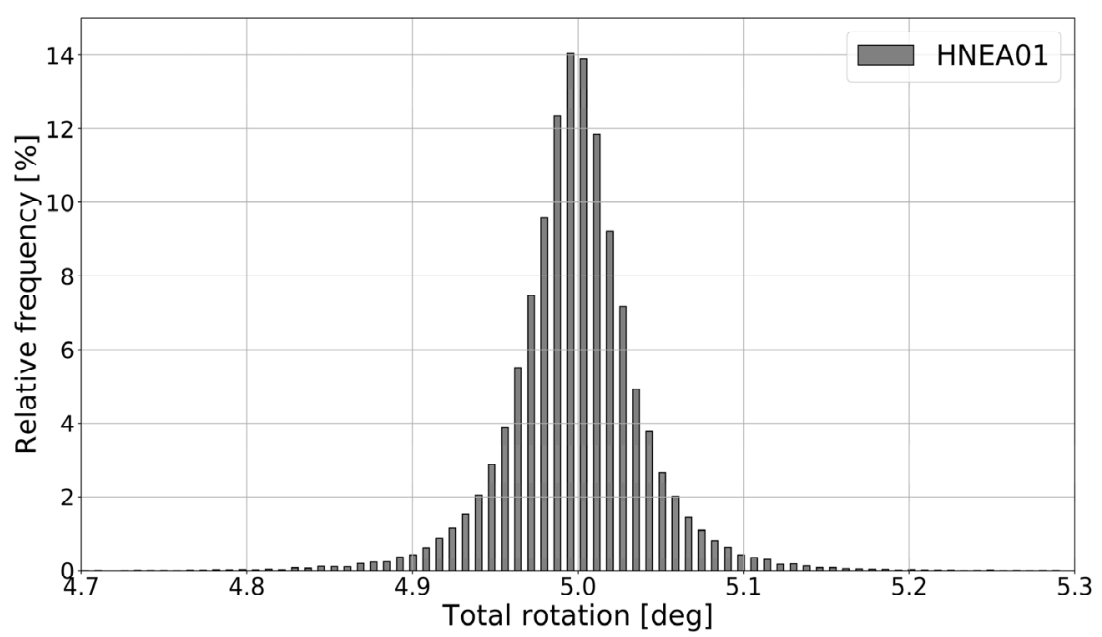

(a)

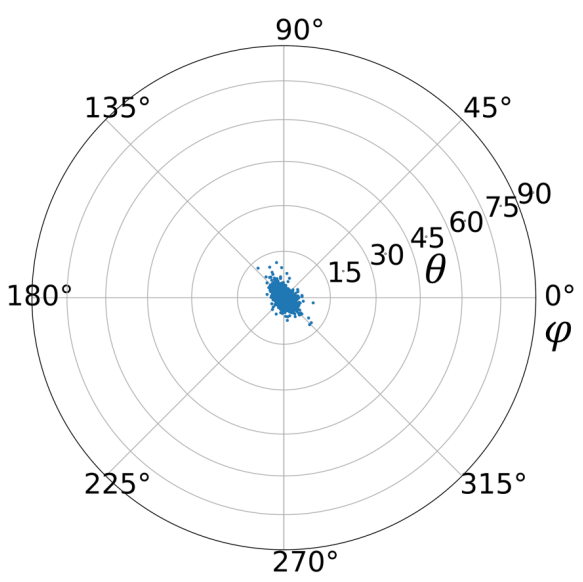

(b) 


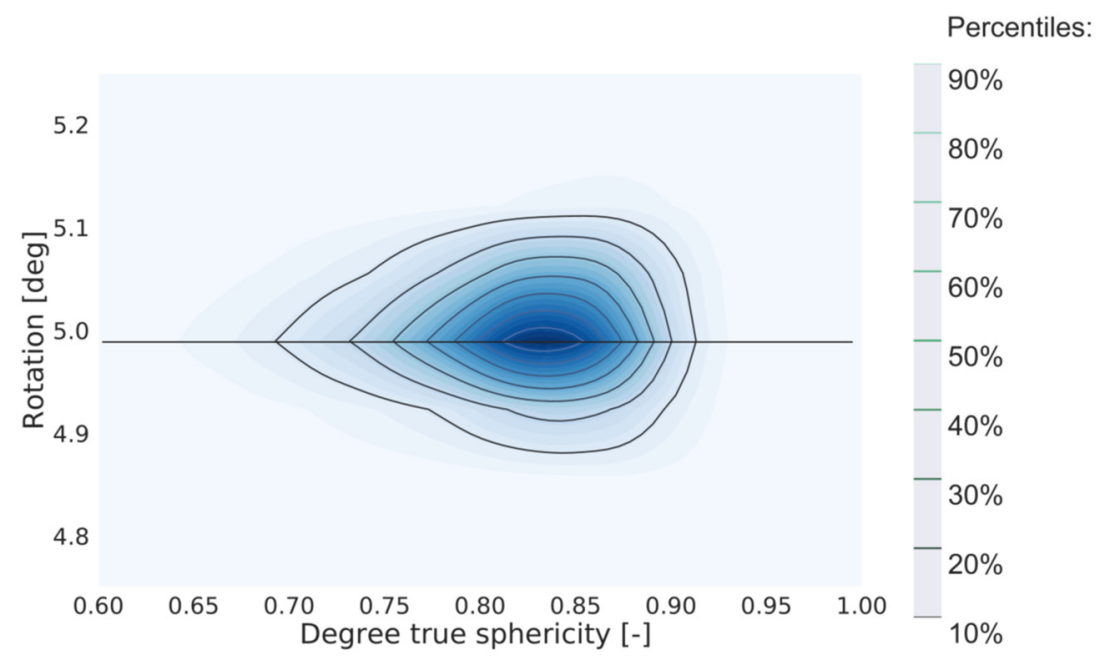

(c)

324 Figure 4a-b-c: (a) Histogram of measured rotation after rigid rotation of the specimen (b) Stereoplot show-

325 ing the rotation versor of each grain (c) 2D histogram showing the correlation between grains sphericity

326 and grains rotation.

\subsection{Shear band identification}

328 The two specimens analysed in this work showed localised deformation through shear

329 banding [54]. In shear bands void ratio increases, coordination numbers are much re-

330 duced and the microstructural constraints on kinematics are therefore very different. Be-

331 fore examining the relation between grain shape and grain kinematics it was therefore

332 necessary to first classify the grains, separating those that belonged to the shear band

333 and those that did not. The criterion applied here to classify the grains as belonging to

334 the shear band was based on shear strain.

335 To assign a nominal deviatoric strain to each grain we applied a procedure developed

336 for DEM post-processing by Catalano et al. [62]. In this procedure, available within the

337 code YADE [63], a Voronoi cell hosting each grain is created using a regular Delaunay triangulation having as vertices the mass centres of the labelled grains. Thus, the grain 
339 position at the last loading increments (i.e., 15-16 for HNEA01, 10-11 for COEA04) were 340 calculated by D-DVC and then introduced in YADE. Displacements of neighbouring 341 grains were then used to compute a nominal displacement gradient tensor for the tetra-

342 hedrons whose vertices are the grains centres of mass. A nominal averaged deviatoric 343 strain, $\varepsilon_{\_}$g was projected back to each grain and a threshold value of $\varepsilon_{\text {d_g }}$ was used to 344 classify the grains that belonged to the shear band.

\section{$345 \quad 4$ Results}

\section{$346 \quad 4.1$ Shear band identification}

347 The results of the shear band identification procedure are shown in Figure 5, in which 348 the black grains form the "shear band": it contains 7007 grains for COEA04, and 21000 349 for HNEA01. The threshold value $\varepsilon_{\mathrm{d}_{-} g}$ is set at 0.10 ; the zones identified correspond 350 closely to those apparent in previous studies [54]. A sensitivity study to evaluate of the 351 effect of varying this threshold value was carried out, very little changes were observed 352 for values within the range $0.05-0.20$.

353 The local reference system that will be used to define the virtual plane representing the 354 shear band is shown in Figure 6, in which vector $\vec{n}$ is the normal to the plane and vector $355 \vec{a}$ indicates the steepest slope direction in the plane. According to Figure 3, showing the 356 spherical coordinates system, both specimens present a shear band with an inclination 357 angle $(\theta)$ of about $45^{\circ}$. 


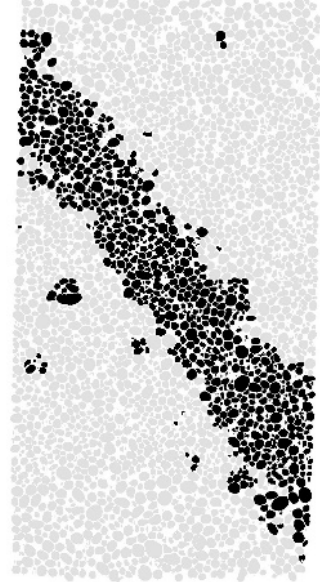

(a)

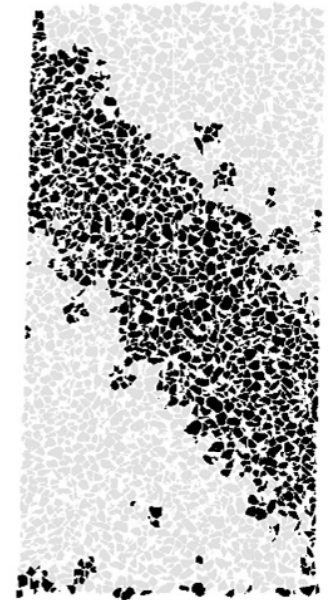

(b)

358 Figure 5: Shear band identification for specimens COEA04 (a) and HNEA01 (b). Particles are coloured

359 black if the "micro-strain" [62] calculated on the Voronoi domain centred on the particle is greater than

$360 \quad 0.10$ (i.e., they belong to the shear band).

\section{Figure 6: Local reference system for the shear band}

363 Vector $\vec{b}$ is orthogonal to $\vec{n}$ and $\vec{a}$ and therefore is horizontal $\left(\theta=90^{\circ}\right)$. It can be used to

364 characterise the azimuthal orientation of the shear band with respect to the global Car-

365 tesian coordinates system. The azimuth $(\varphi)$ is different, being of about $135^{\circ}$ for Hostun

366 and $75^{\circ}$ (from the global $x$-axis) for Caicos. The sections represented in Figure 5 corre-

367 spond then to vertical planes orthogonal to vector $\vec{b}$. 
369 A check was performed to verify if particle shape was spatially homogeneously distrib-

370 uted in the specimens. The reason was to exclude any possibility that subsequent locali-

371 sation into shear bands was prompted by non-uniformity in the initial spatial distribu-

372 tion of grain shapes (note that a similar check was performed by Andò [54] with respect

373 to local porosity). To do so, two vertical sections orthogonal to each other (defined re-

374 spectively by vectors $\vec{n}-\vec{b}$ and $\vec{n}-\vec{a}$ ) are examined where the grains have been coloured

375 by their value of degree of true sphericity, as shown in Figure 7. It is evident that grain

376 true sphericity was initially homogeneously distributed within both specimens.

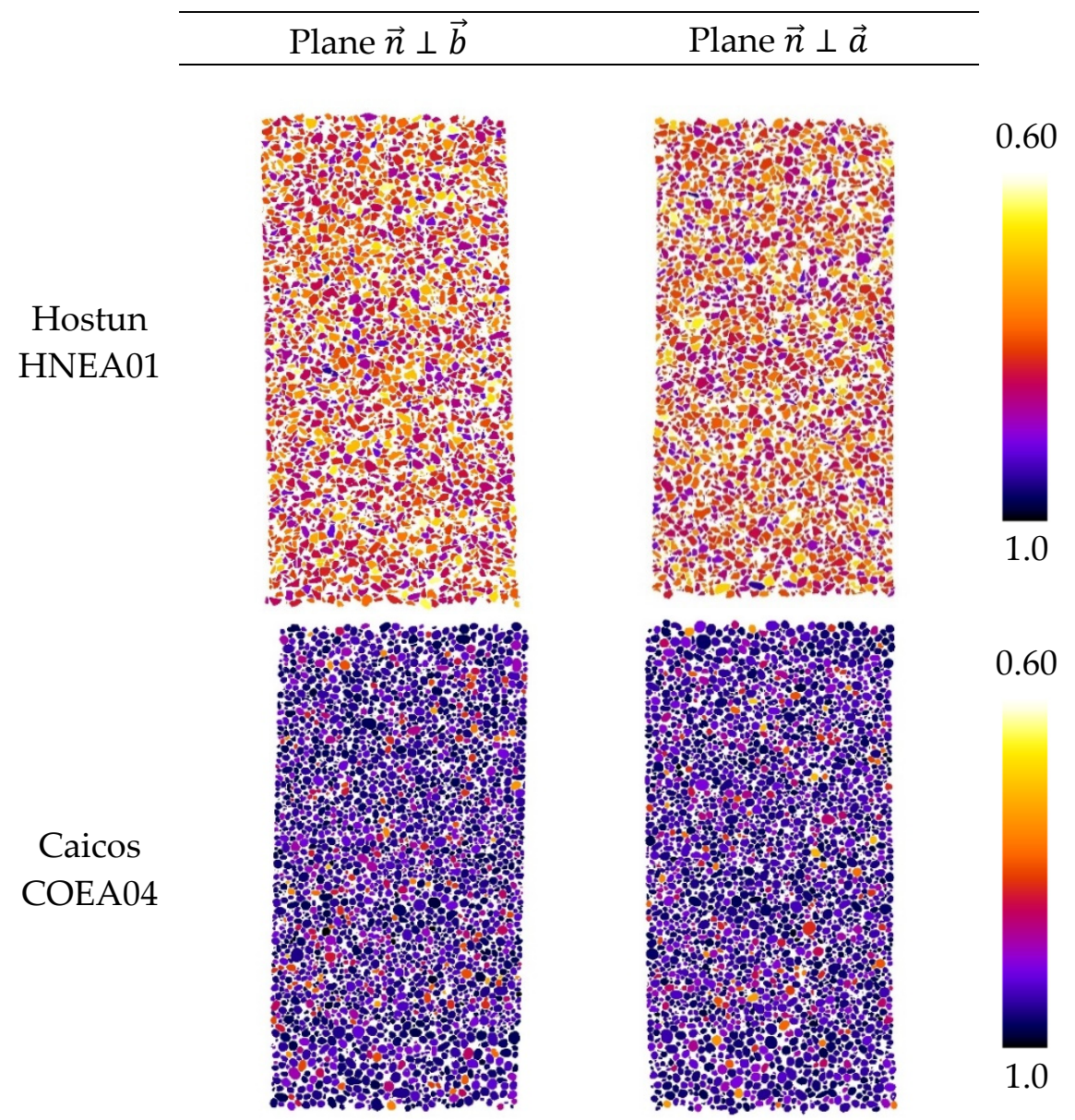

377 Figure 7: Sphericity spatial distribution for Hostun and Caicos sand in two vertical sections: parallel and 
379 Another check was performed on the possibility that shear banding would entrap or 380 select particular grain shapes. To this end, histograms of the degree of true sphericity for

381 the grains located both inside and outside the shear band were plotted; the results are

382 shown in Figure 8. Again, it is evident that there are no significant differences of shape

383 between the grains that were involved in the localisation process and those that re-

384 mained outside the shear band.

Hostun

HNEA01

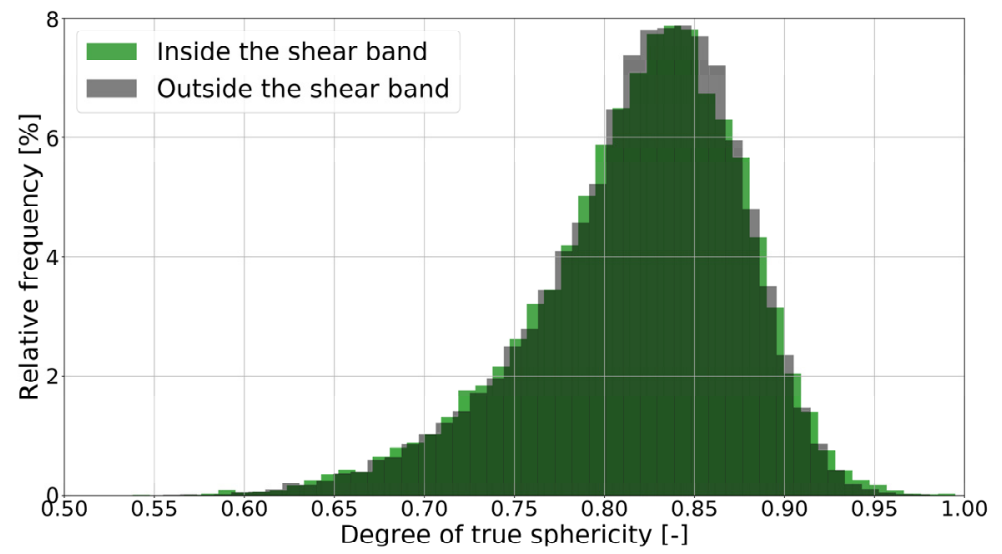

(a)

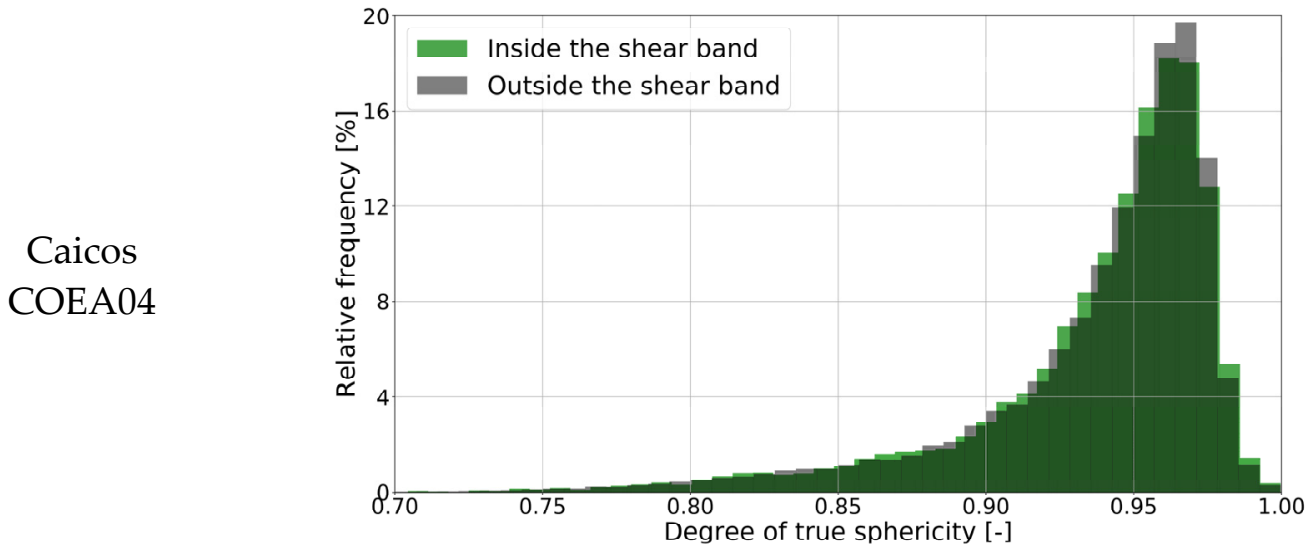

(b)

385 Figure 8: Histograms of true sphericity for Hostun (a) and Caicos (b) sands both inside and outside the 386 shear bands. 


\subsection{Overall grain kinematics}

388 Figure 9 and Figure 10 show the cumulative kinematic histories, in terms of vertical dis-

389 placements and rotations, for Caicos ooids (specimen COEA04) and Hostun sand (spec-

390 imen HNEA01) during several loading increments in the triaxial test (note that similar

391 images, but reporting incremental instead of cumulative values were presented by Andò

392 [32]. Results for both sands are plotted at the same scale and confirm the general obser-

393 vation made from incremental results by Andò [32]: within the shear band, the very

394 rounded Caicos sand grains rotate more than the more angular grains of Hostun sand.

395 On the other hand, it is difficult to tell the difference between the two sands outside the 396 shear band.

\begin{tabular}{cccccc}
\hline 01-02 & $01-04$ & $01-06$ & $01-08$ & $01-10$ & $01-11$ \\
$\varepsilon_{Z}=0.95 \%$ & $\varepsilon_{Z}=2.82 \%$ & $\varepsilon_{Z}=5.17 \%$ & $\varepsilon_{Z}=8.00 \%$ & $\varepsilon_{z}=10.33 \%$ & $\varepsilon_{Z}=11.27 \%$ \\
\hline
\end{tabular}

$$
\begin{array}{r}
0 p x(z-d i s p) \\
0^{\circ} \text { deg rotations }
\end{array}
$$
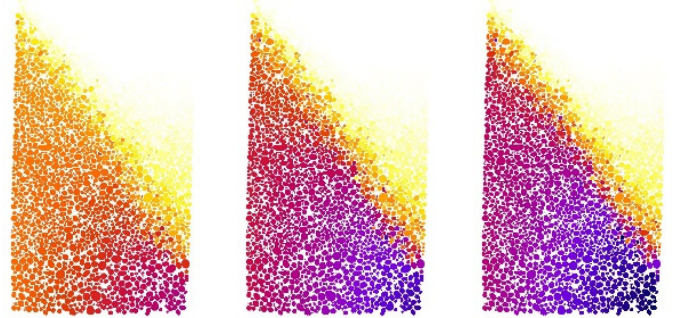

Figure 9: Vertical slices of Caicos sand (specimen COEA04) showing grain vertical displacement (above) 


\begin{tabular}{cccccc}
\hline $01-02$ & $01-05$ & $01-08$ & $01-11$ & $01-14$ & $01-16$ \\
$\varepsilon_{z}=0.60 \%$ & $\varepsilon_{z}=2.1 \%$ & $\varepsilon_{z}=3.92 \%$ & $\varepsilon_{z}=7.33 \%$ & $\varepsilon_{z}=11.67 \%$ & $\varepsilon_{z}=14.88 \%$ \\
\hline
\end{tabular}

$$
\begin{array}{r}
0 p x(z-\operatorname{disp}) \\
0^{\circ} \text { deg rotations }
\end{array}
$$
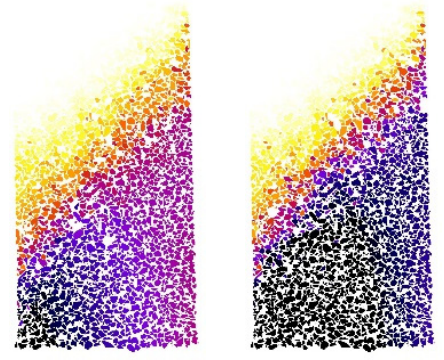

401

Figure 10: Vertical slices of Hostun sand (specimen HNEA01) showing grain vertical displacement (above)

and rotation (below) accumulated during the test. Grains are coloured by the value of their measured zdisplacement (above) and total rotation (below). Not all the increments are shown. Stage "01" = start of deviatoric loading. Stage "16" = end of the TX test.

405 This observation is conveyed more precisely in Figure 11, showing the histories of the 406 cumulated mean particle rotation magnitudes, both inside and outside the shear bands.

407 Outside the shear band, the average grain rotations of both sands are very similar and 408 appear quite flat, with a limited increase between $1 \%$ and $5 \%$ axial strain. That increase 409 in the average rotation outside the shear band may reflect the fact that the shear bands 410 become somewhat narrower as deformation progresses [54], whereas the grain classifi411 cation criterion is only applied in the final test stage. 


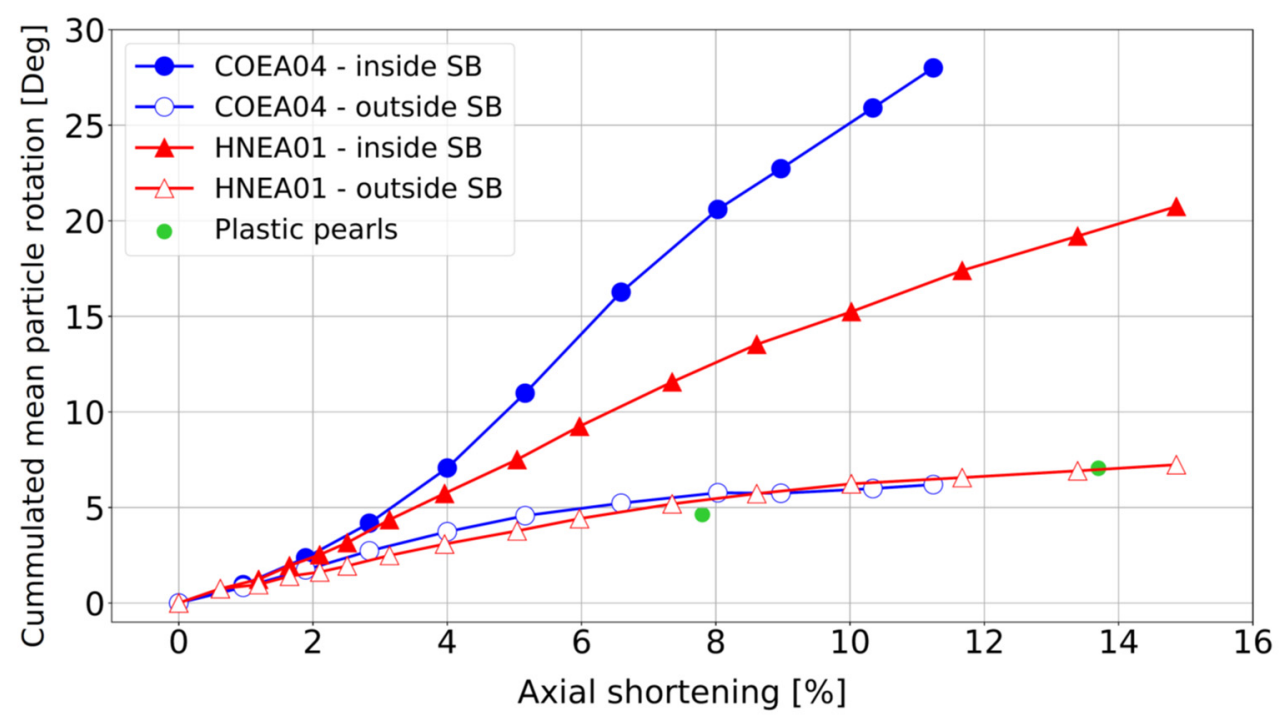

413

414 Figure 11: Histories of cummulated mean particle rotations inside and outside the shear bands (SB in the

415 legend), measured by D-DVC throughout the triaxial tests. The green dots represent interpreted results

416 from Alshibli and Alramahi (2006) for a triaxial experiment involving 400 plastic pearls.

417 Average rotations increase much faster within the shear band. In the Caicos specimen

418 (COEA04) average rotation magnitude raises to about 30 degrees. The trend in the

419 Hostun specimen (HNEA01) is somewhat slower, raising to a level of about 21 degrees.

420 The distribution of cumulative rotation magnitudes in the shear bands is rather skewed

421 (Figure 12) with the mode remaining almost constant but the high end tail progressively

422 thickening 

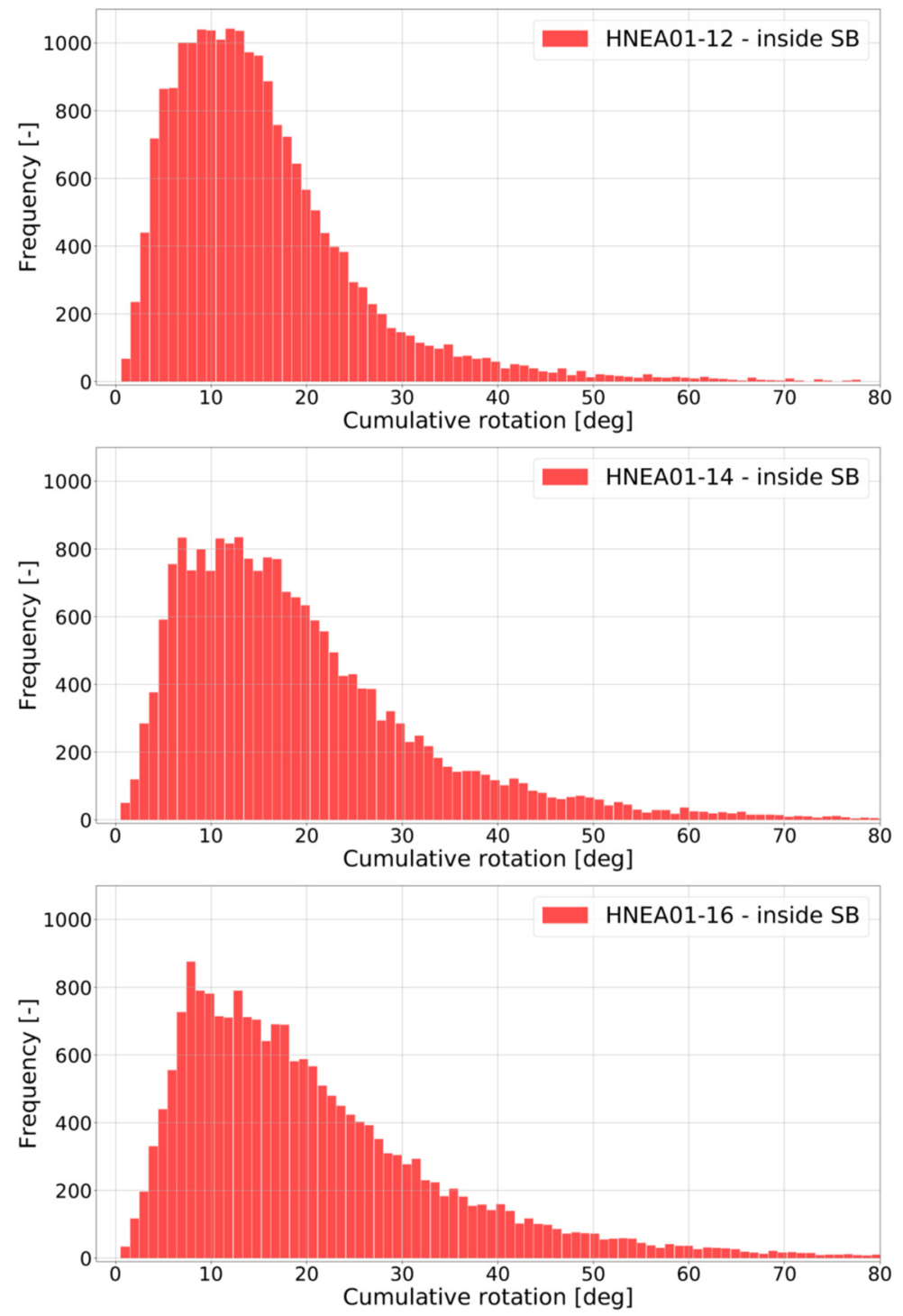

424 particles within the shear band of the Hostun sand HNEA01 specimen.

425 The attrition rate during this sequence of image correlations is shown in Figure 13. It is

426 clear that in this more realistic context, the D-DVC procedure has more difficulties than

427 in the idealized uniform rotation check discussed before. The correlation problems in-

428 crease as the grains rotate more, which is what happens in the shear band. Despite that,

429 it should be noted that a) the correlation validity criterion was set at a very stringent

430 limit $(\mathrm{CC}=0.98)$ and $\mathrm{b})$ the procedure was able to track to the end almost $80 \%$ of the 431 grains within the shear bands and more than 95\% outside them. 


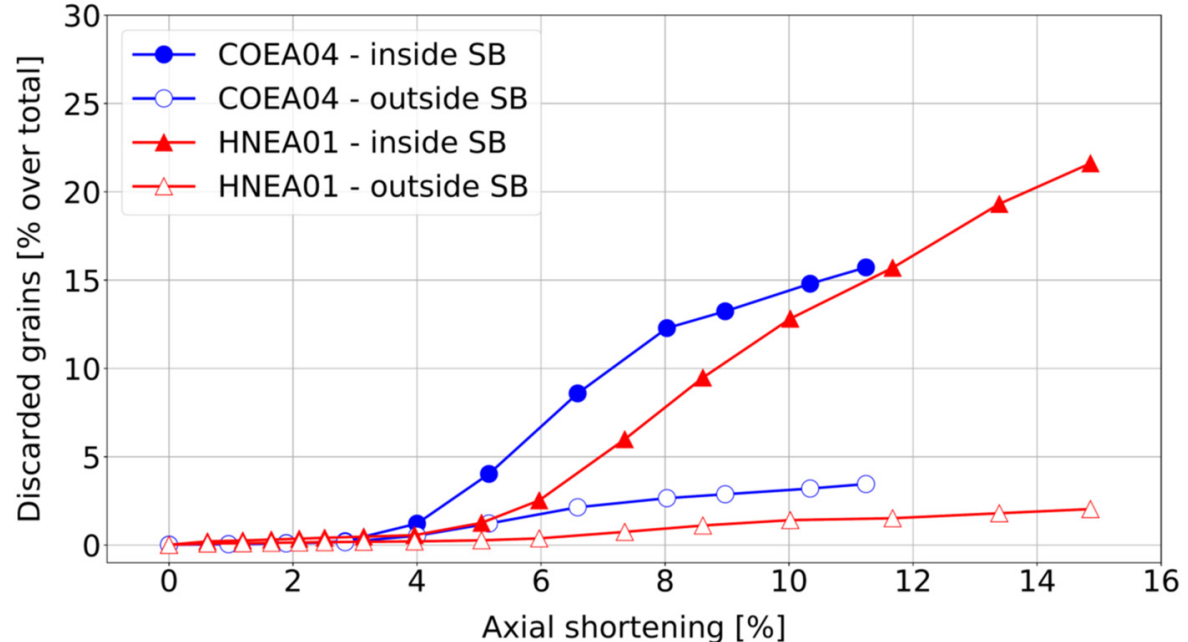

432

433 Figure 13: Particles with correlation maximum below $98 \%$ as a percentage of total number of particles

\subsection{A comparison of secant and cumulative tangent rotations}

435 There is a risk that the secant image correlation approach applied may lead to an under-

436 estimation of the cumulated total grains rotations, as it computes the "shortest path" of

437 rotation (i.e., the minimum rotation angle) between the initial configuration and that of

438 each step examined. Adding the results from tangent step-by-step correlations such as

439 those performed by Andò [32] would avoid the underestimation problem but, as previ-

440 ously explained, grain re-labelling across images complicates tracking individual grains.

441 Despite that, a meaningful statistical comparison is still possible based on the average

442 values of rotations for all grains.

443 Figure 14 shows the evolution of the average magnitude of grain rotations for Hostun

444 sand for all grains in the specimen as obtained by Andò [32] using step-by-step (i.e. tan-

445 gent) correlations. This is compared with the values obtained here using the secant ap-

446 proach for two different scenarios. In the first one (corresponding to the results shown

447 above) the average rotation at each step is computed only for the remaining grains (i.e. 
448 those that are above the correlation threshold). In the second approach the average at 449 each step is computed for all grains, assigning to those that are below the correlation 450 threshold the last rotation value that was obtained for them.

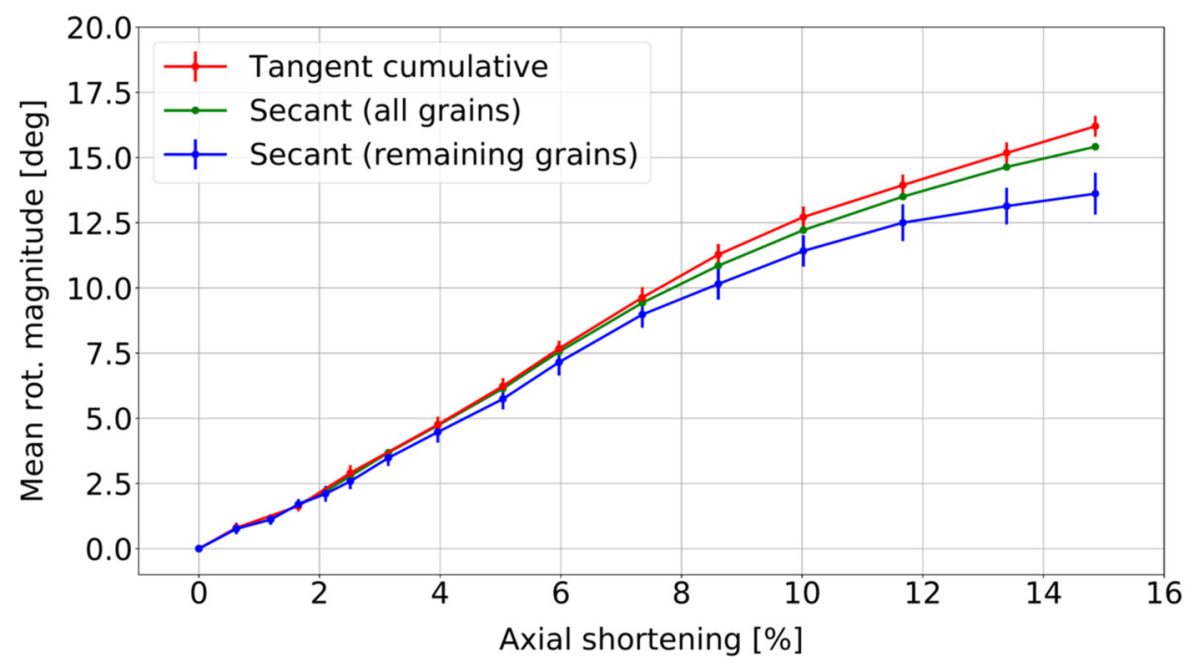

Figure 14: History of the average magnitudes of rotations for Hostun sand measured with different approach. The error bars are magnified 10 times.

454 The differences between the "tangent" and "secant" correlation approaches are small.

455 The results for the all-grain secant average are closer to those of the tangent because in 456 the step-by-step correlations the number of grain losses was minimal, whereas in the 457 secant approach the attrition rate is close to $20 \%$ at the end of the test. Moreover, the 458 grains that are lost are typically those with larger rotations, which is reflected in the pro459 gressive divergence of the average restricted to the remaining grains. In any case, it is 460 clear from the comparison that the grain rotations computed with the secant approach 461 are not significantly underestimated. 


\subsection{Axes of rotation}

463 Stereoplots (see Figure $4 \mathrm{~b}$ ) can be used to investigate the alignment of particle rotation

464 axes during shearing. The orientations of cumulative rotation versors are plotted for all

465 grains (about 110000 in total), both inside and outside the shear bands, at two different

466 test stages in Figure 15 (at approximately 5\% axial strain, corresponding to steps 01-09

467 in Hostun and 01-06 in Caicos) and Figure 16 (at approximately 9\% axial strain, corre-

468 sponding to 01-12 for Hostun and 01-09 for Caicos). The raw stereoplots are presented 469 alongside binned frequency diagrams.

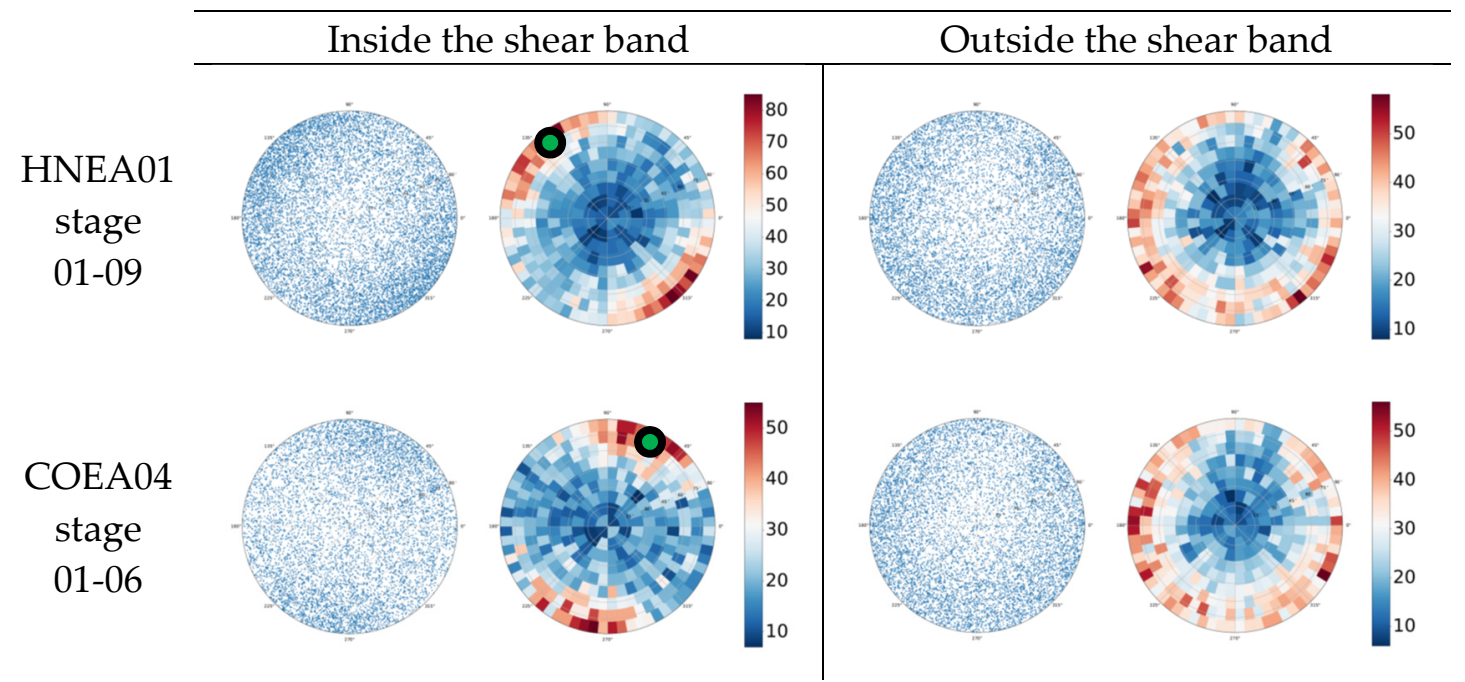

$470 \quad$ Figure 15: Stereoplots showing the rotation versor directions at 5\% shortening. The green dots indicate the orientation of vector $\vec{b}$ (see Figure 6) belonging to the shear bands of Hostun and Caicos sands. The stereoplot angles markers are not shown for readability, see Figure $4 b$ for reference. 


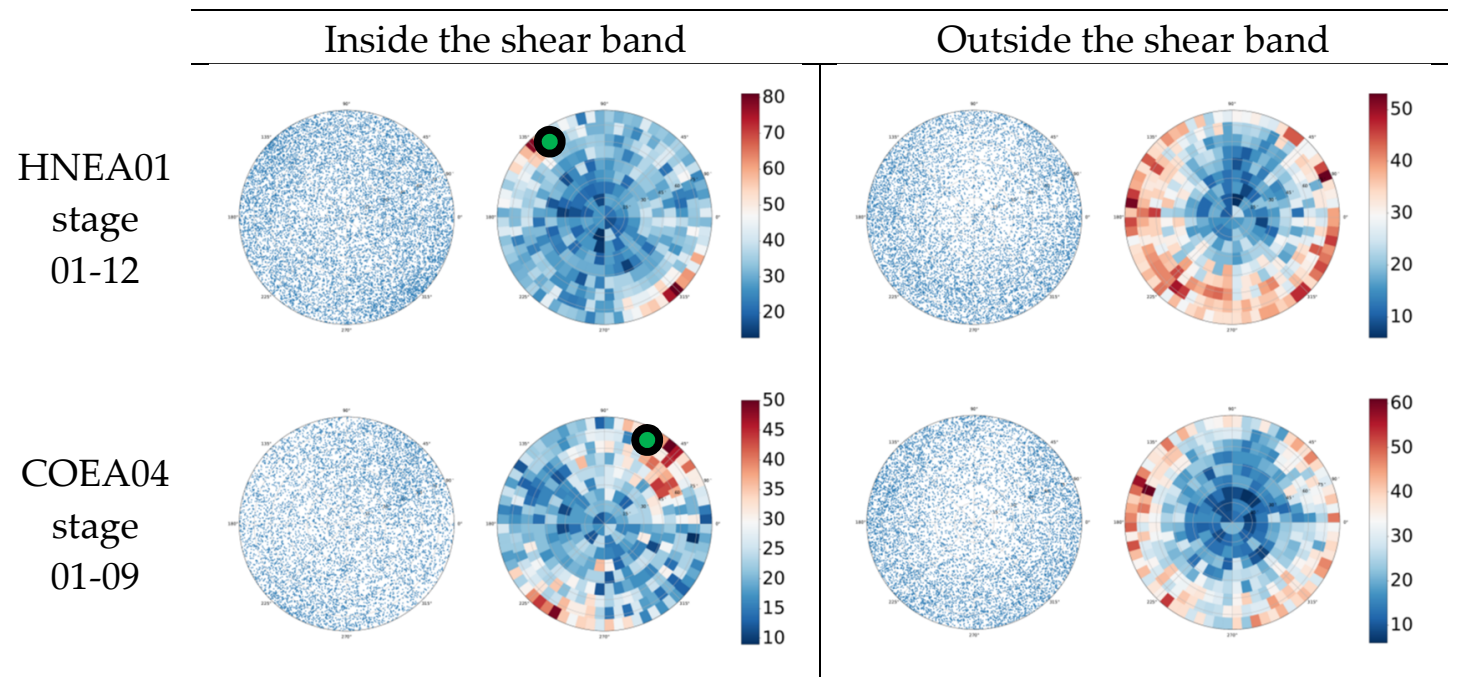

475

Figure 16: Stereoplots showing the rotation versor directions at 9\% shortening. The green dots indicate the orientation of vector $\vec{b}$ (see Figure 6) belonging to the shear bands of Hostun and Caicos sands. Stereoplot grid not shown for readability, see Figure $4 b$ for reference.

Both sands exhibit similar trends (Figure 15). Outside the shear bands, the rotation axes accumulate towards the periphery of the stereoplot, with inclination angles close to $90^{\circ}$ that indicate horizontal axes of rotation. The azimuthal angle, on the other hand, is almost homogenously distributed around the stereoplot periphery, indicating no preferential alignment for the grain rotational axis within the horizontal plane.

The situation is different inside the shear band, which is already present at $5 \%$ strain (Figure 9; Figure 10). The rotation axes are still mainly horizontal $\left(\theta=90^{\circ}\right)$, but now the azimuthal angles $(\varphi)$ concentrate around values of about $135^{\circ}$ (Hostun sand) and $75^{\circ}$ (Caicos sand). As indicated in the figures these values are, precisely, the azimuths of vector $\vec{b}$ in Figure 6 i.e., those corresponding to directions orthogonal to that of steepest descent within the shear band. This alignment means that grains are rolling downslope the plane of the shear band. Another azimuthal accumulation point is observed at the diametrically opposed direction in the stereoplot, that is at $315^{\circ}$ for Hostun and $255^{\circ}$ for 
491 Caicos. That position corresponds to grains rotating upslope on the plane of the shear

492 band. These preferential orientations become sharper as localisation progresses (com-

493 pare with results at 9\% axial strain, shown in Figure 16) and appear generally sharper

494 for Hostun sand than for Caicos ooids.

495 The results obtained contrast with those presented in Andò et al. [32] who attempted a

496 similar analyses for the Hostun HNEA01 specimen. There the alignment of particle ro-

497 tation axis and shear band normal was not evident. The difference is likely due to the

498 superior precision of particle rotation measurement achieved by the D-DVC technique

499 over the ID-track used in Andò et al. [32]. The presence of particle with opposite spins

500 in shear zones, previously documented in experiments with simplified granular media

501 (such as flat disks [64, 65] or uniform plastic beads [40]), is here confirmed for natural 502 sands.

\section{$503 \quad 4.6$ Relations between grain shape and magnitude of rotation}

504 A first indication of the relationship between particle shape and rotation is already evi-

505 dent in Figure 11. Caicos ooids rotate - on average - far more than Hostun sand grains,

506 but only if belonging to the shear band; for grains that remained outside the shear band

507 there is almost no difference between the more rounded Caicos ooids and the angular

508 Hostun sand. This insensitivity to particle shape outside the critical shearing zone is cor-

509 roborated by data deduced from Alshibli and Alramahi [40], also plotted in Figure 11.

510 Those authors reported histograms of particle rotations for 400 perforated plastic pearls,

511 almost uniformly spherical, in a triaxial compression test that did not present a clear 
512 shear band. The averaged rotations from that test on plastic beads plot very close to our 513 sand data.

514

515 Although averaged values of rotation are interesting, the data collected allow a more 516 detailed inspection of the effect of grain shape on rotation. Figure 17 presents bivariate

517 frequency density plots exploring the effect of shape descriptors related to form on par-

518 ticle rotations (accumulated up to $5 \%$ axial strain). The histogram contours appear rather

519 flat, indicating little sensitivity of particle rotations to form. The same approach is fol-

520 lowed in Figure 18, but now using shape descriptors that measure sphericity. The histo-

521 gram contours are more sensitive, particularly those at the edge, indicating larger per-

522 centiles. This is particularly evident for convexity and to true sphericity - two shape

523 descriptors that are tightly correlated for these two sands, see [26]).

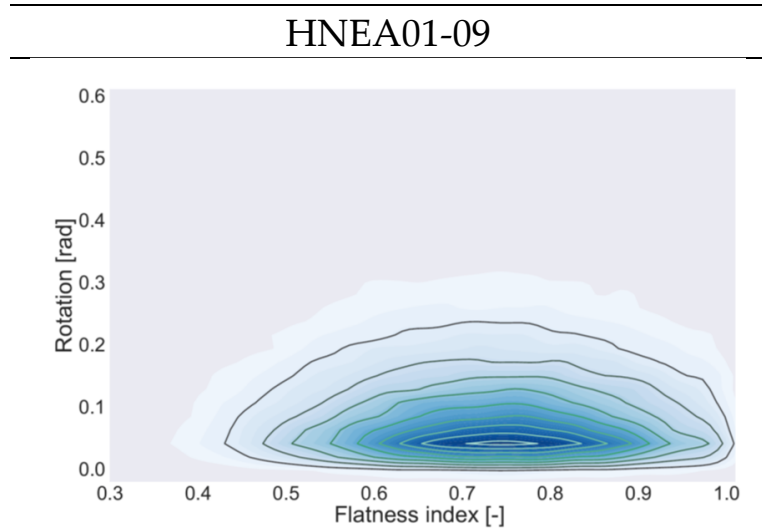

(a)

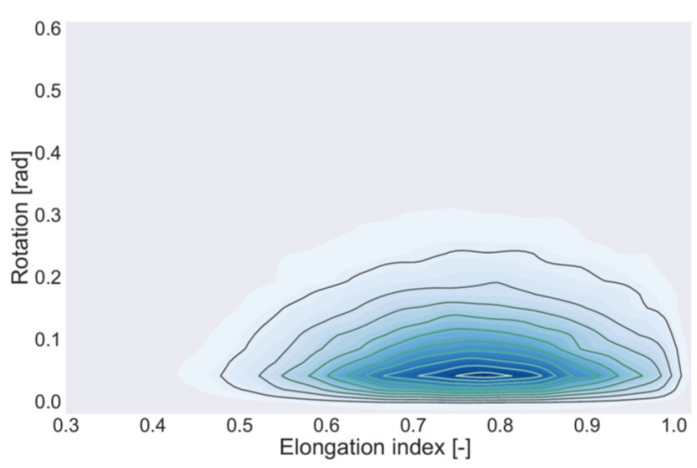

(c)

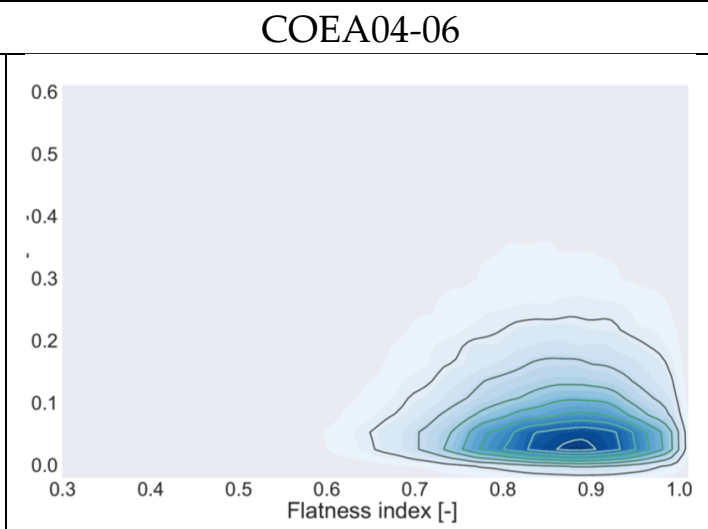

(b)

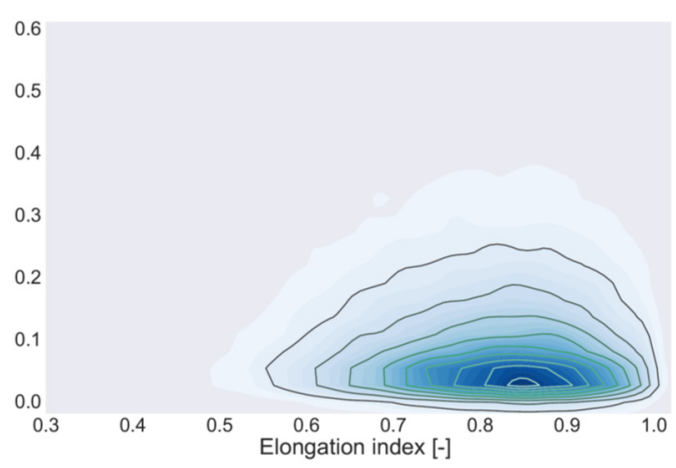

(d) 


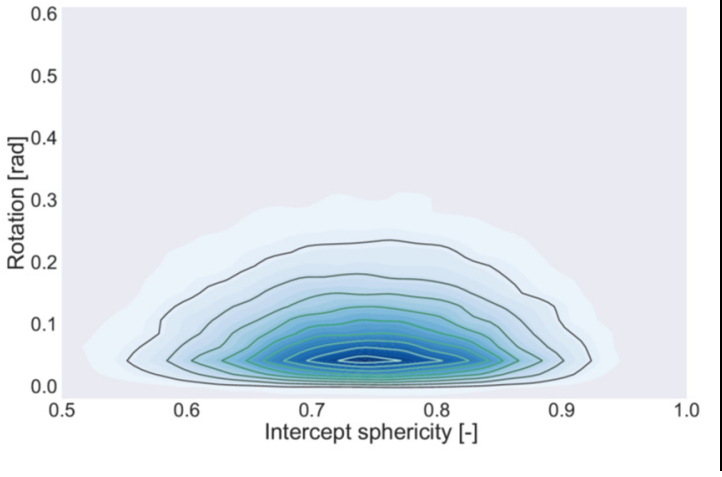

(e)

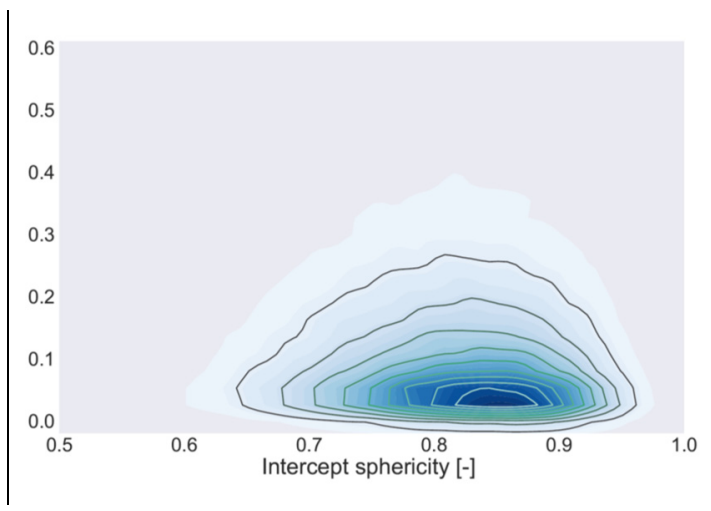

(f)

524 Figure 17: Normalised bivariate frequency density plots of form descriptors versus cumulative grain ro-

525 tation magnitude at 5\% shortening (loading stages HNEA01-09 and COEA04-06, respectively 48.612 and

52665.056 grains). The contours colour bar is shown in Figure 4c.

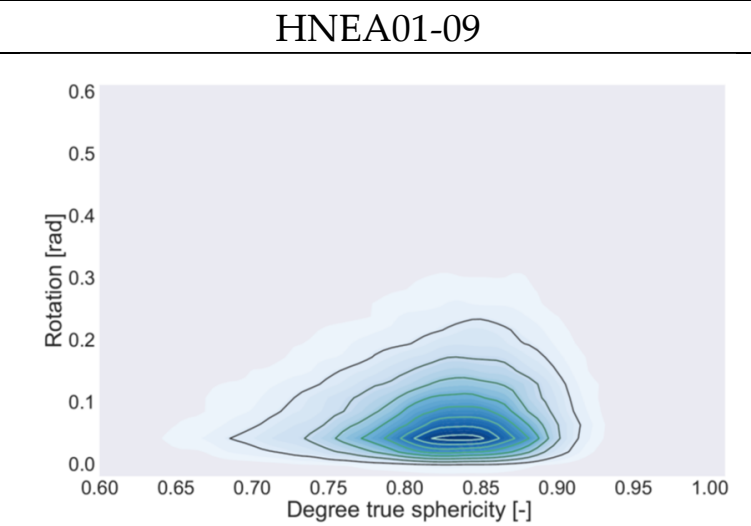

(a)

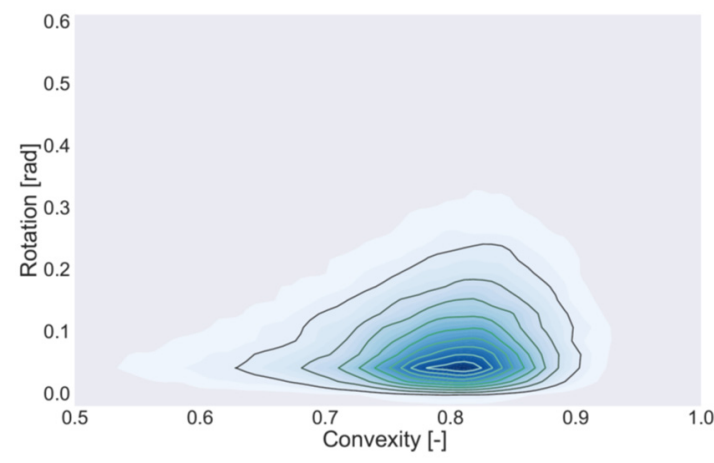

(c)

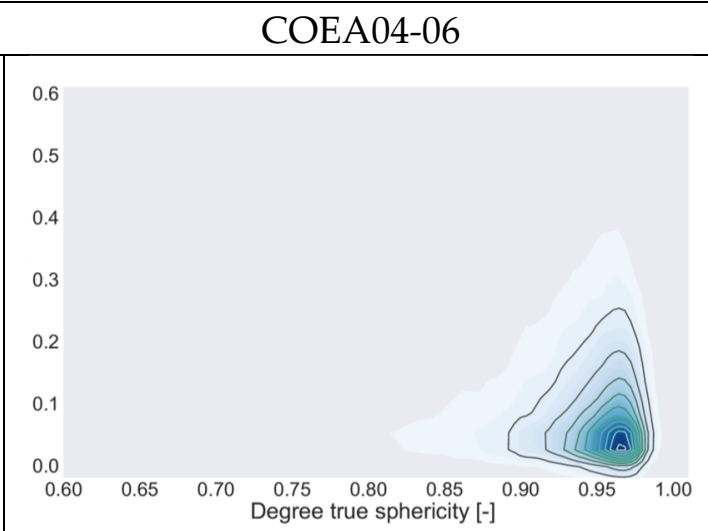

(b)

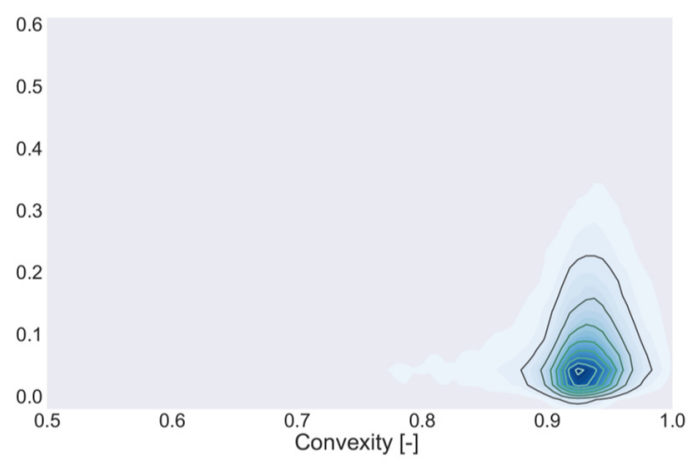

(d) 


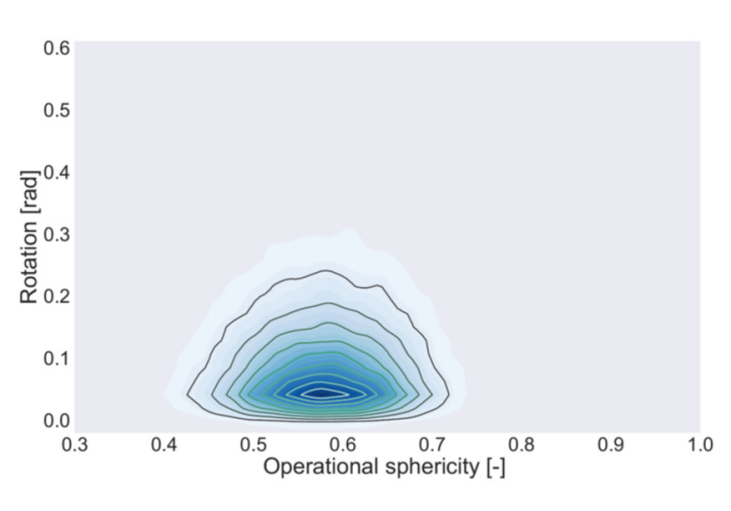

(e)

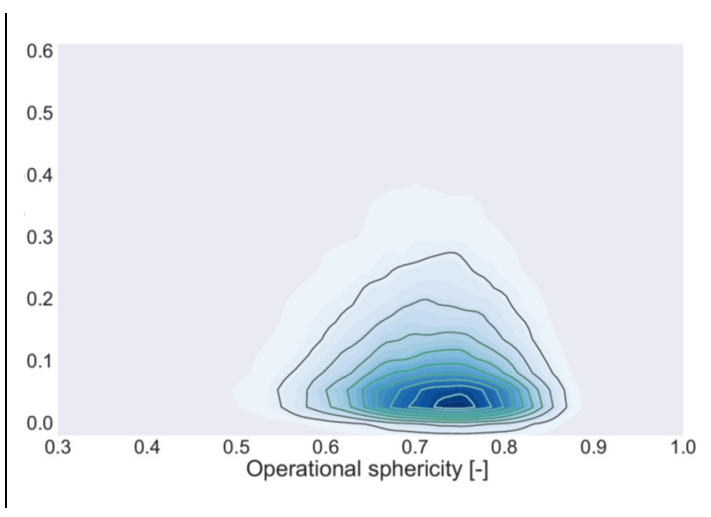

(f)

527 Figure 18: Normalised bivariate frequency density plots of sphericity descriptors versus the cumulative

528 grain rotations measured at 5\% shortening (loading stages HNEA01-09 and COEA04-06, respectively

52948.612 and 65.056 grains). The contours colour bar is shown in Figure 4c.

\begin{tabular}{lll} 
& Inside the Shear Band & Outside the Shear Band \\
\hline 0.7 & & 0.7
\end{tabular}
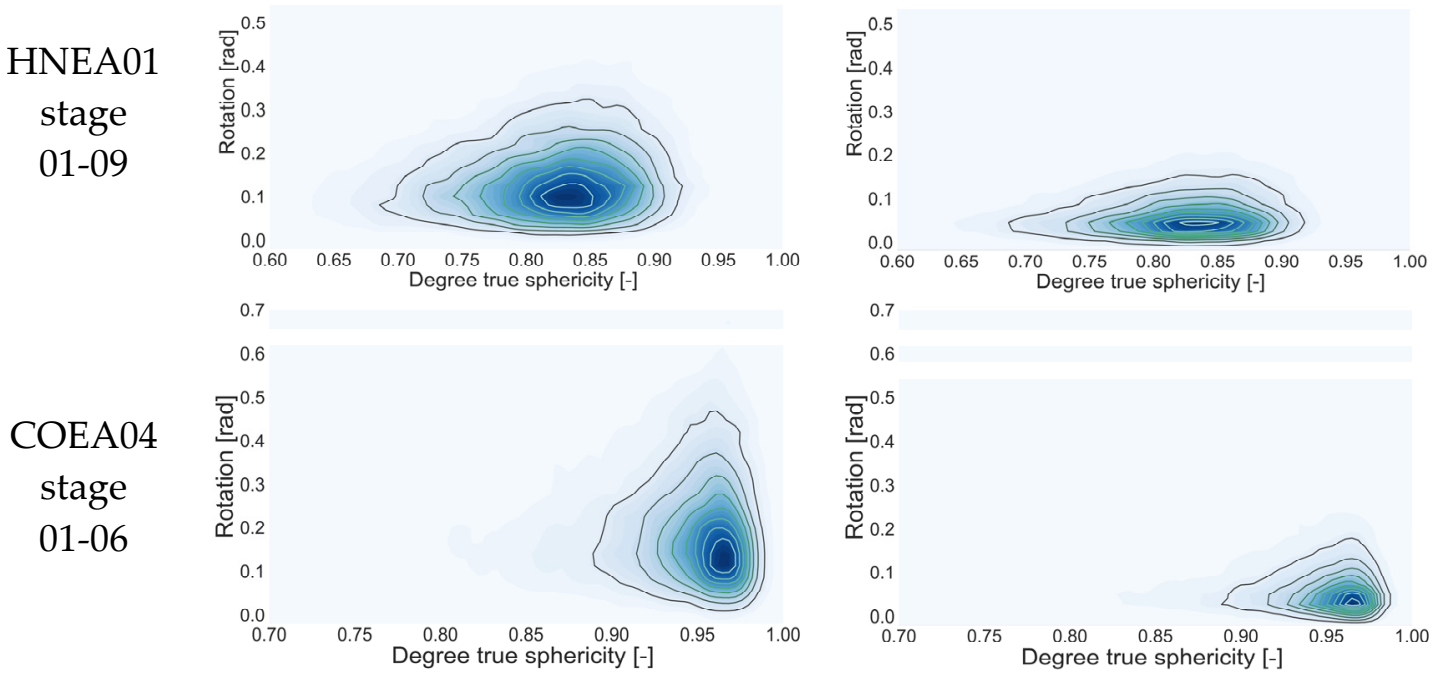

530 Figure 19: Normalised histograms showing the observed relation between the degrees of true sphericity and

531 the total grains rotation measured at 5\% sample shortening.

532 The histograms become more triangular if restricted to particles in the shear band. Figure

53319 shows that the degree of true sphericity seems to have a significant influence on the

534 upper limit of particle rotation, which increases as particles become more spherical. This

535 idea is explored in more detail in Figure 20 and Figure 21, where mean and extreme

536 values (99.5\% percentiles) of rotation, measured on both Caicos sand and Hostun sand 
537 specimens, are plotted as a function of true sphericity. The values are derived from mar538 ginal distributions, obtained at fixed true sphericity intervals (width 0.025). Because the

539 number of particles in each interval is highly variable, error bands (plus and minus one 540 standard error) are also represented. The error bands for the $99.5 \%$ quantile are esti541 mated using a bootstrapping technique [66], resampling with replacement the original 542 samples (for each interval) one thousand times. Errors band thickness increases with 543 small sample sizes (e.g. at low values of degree of true sphericity) and with marginal vari544 ability (high at large values of degree of true sphericity, as correlating very spherical grains 545 carries more uncertainty).

546 It appears that the mean values of rotation, both inside and outside the shear band are 547 insensitive to particle sphericity, whereas the extreme upper values (the $99.5 \%$ percen548 tile) show a clear positive dependency between rotations and particle sphericity. There 549 is not much difference between the mean values of Caicos and Hostun, at any given true 550 sphericity. On the other hand, the upper limit rotations of Caicos are somewhat above 551 those of Hostun, even at the same sphericity, and particularly for those particles inside 552 the shear band. Andò [54] observed that porosity in the shear band was higher for 553 Hostun than for Caicos, so it is unlikely that connectivity - which is inversely related to 554 porosity - will explain that difference. Still, the differences between the two sands not 555 accounted for true sphericity are less important than the common effect of sphericity on 556 the upper bound. These trends were confirmed when other test stages were analysed, 557 for instance at around 9\% axial strain, Figure 22 and Figure 23. 
559 Figure 20: Influence of the degree of true sphericity on the total grains rotation (at 5\% shortening) outside

560 the shear band.
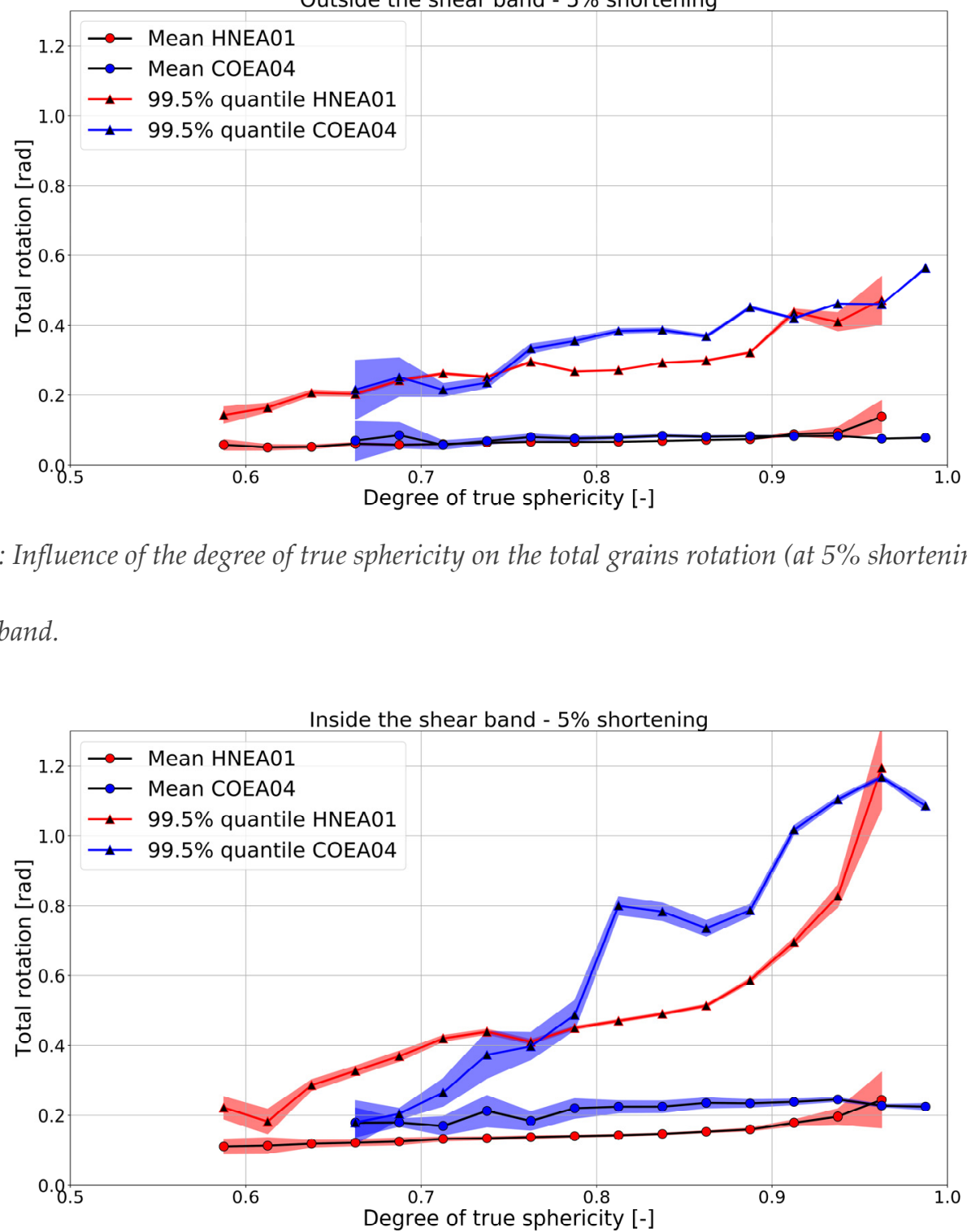

562 Figure 21: Influence of the degree of true sphericity on the total grains rotation (at 5\% shortening) inside 563 the shear band. 
564

565 Figure 22: Influence of the degree of true sphericity on the total grains rotation (at 9\% shortening) out-

566 side the shear band.

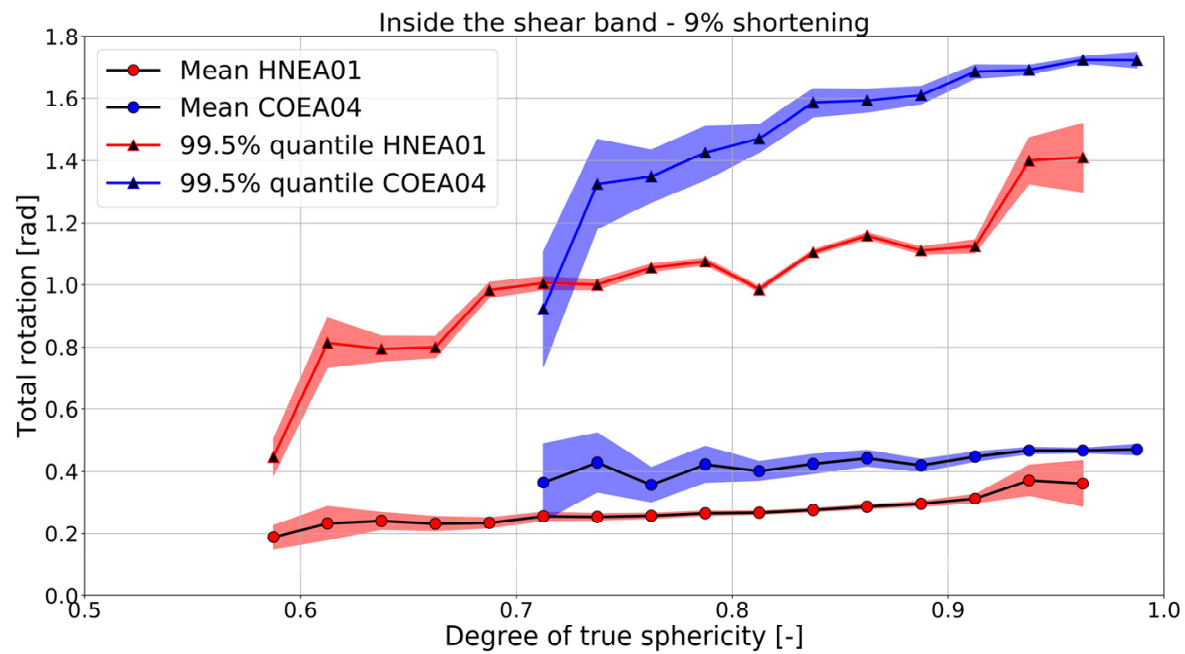

567

568

569

Figure 23: Influence of the degree of true sphericity on the total grains rotation (at 9\% shortening) inside

\section{Discussion}

571 From the previous result it may be concluded that the link between particle shape and

572 particle kinematics is only effective at the margin. This was to be expected, as it is a link

573 necessarily mediated by particle connectivity. Particle shape cannot control particle ro-

574 tation on its own, as rotational equilibrium is a result of contact force magnitudes and 
575 positions and, as such, a result of particle shape and particle connectivity. In a shear 576 band, particle connectivity is low and therefore the role of particle shape in controlling

577 rotation is increased. The same reasoning suggests that particle shape effects should be 578 more intense in loose than in dense sand. This may explain the different effect of particle 579 shape dependency of extreme void ratios, which is even stronger for the minimum than 580 for the maximum void ratio [4].

581 The interplay of connectivity and particle shape can also be related to the stress-strain 582 response of the sand specimens illustrated in Figure 2. It is apparent that both specimens 583 reach a similar value of peak strength, despite the Caicos specimen being initially denser 584 than Hostun $(\mathrm{e}=0.468$ vs $\mathrm{e}=0.658)$. The inter-granular contact friction angle of Caicos is 585 likely similar to that of Hostun $[67 ; 68]$. This leaves the more spherical shape of Caicos 586 as the likely cause of a peak appearing at lower densities than in the more angular 587 Hostun. Other mesoscopic effects of shape are apparent in the lower residual strength 588 of Caicos, which may be related to the larger rotations observed for this material in the 589 shear band.

590 The previous observations cannot be proved by image analysis only, at least until parti591 cle connectivity can be imaged in experiments with equal precision as shape. The alter592 native, obviously, is to use DEM. The particle scale results presented here may be use to 593 calibrate and/or verify DEM models in which shape effects are represented. If a direct 594 representation of shape is used [69] it may be expected that the differential trends in 595 particle kinematics noted here would also emerge from the simulations. A different ap596 proach is proposed in $[70,71]$ where the observed particle kinematics are used to cali597 brate a general link between moment-rotation contact law parameters and particle sphe598 ricity. 
600 This paper set out to explore the relationship between particle shape and particle rota601 tion at the grain scale, for all the sand grains within triaxial specimens that failed in a 602 localised shear mode. The main findings can be summarised as follows:

603 - The systematic use of Discrete-Digital Volume Correlation allowed successful tracking of rotational kinematics in the large majority of grains; those measurements were far more precise than previous attempts using ID-track;

- Kinematics within the shear bands are very different from those outside the shear band. Particle rotation magnitudes increase much faster in the bands. Rotational axes align themselves preferentially, perpendicular to the steepest descent direction of the band;

- Sand grains in the shear plane show both positive and negative spins (upwards and downwards the plane), revealing commonalities in the shear flow mechanisms of sands with those of simpler granular materials;

- Shape descriptors related to particle form, such as elongation or flatness indexes appear to be poorly correlated with observed particle rotation;

- Shape descriptors related to particle sphericity have a significant effect on particle rotation. This effect is far less important on the average value than on the upper limit of rotation.

These findings are applicable to particles of relatively rotund shapes, such as the sand grains examined here, and may not necessarily apply to flatter or more elongated particles. 
622 The work here described has been supported by the Spanish Ministry of Economy 623 through grants BIA2014-59467-R and BIA2017-84752-R. Laboratoire 3SR is part of the 624 LabEx Tec21 (Investissements d'Avenir - grant agreement nANR-11-LABX-0030).

\section{References}

626 1. Jiang, M., Liu, F., Bolton, M.: Proceedings of the International Symposium on 627 Geomechanics and Geotechnics: from Micro to Macro (IS-Shanghai 2010). CRC Press/Balkema, Shanghai (2011)

2. Soga, K., Kumar, K., Biscontin, G., Kuo, M.: Geomechanics from micro to macro : Proceedings of the TC105 ISSMGE International Symposium on Geomechanics from Micro to Macro, Cambridge, UK, 1-3 September 2014. (2014)

3. Baudet, B., Bolton, M.: Editorial Soil mechanics at the grain scale: issue 1 and 2.

641 6. Yang, J., Luo, X.D.: Exploring the relationship between critical state and particle

Géotechnique. 60, 313-314 (2010). doi:10.1680/geot.2010.60.5.313

4. Cho, A.G., Dodds, J., Santamarina, J.C.: Particle Shape Effects on Packing Density, Stiffness and Strength - Natural and Crushed Sands. J. Geotech. Geoenvironmental Eng. 132, 591-602 (2006). doi:10.1061/(ASCE)10900241(2006)132:5(591)

5. Santamarina, J., Cho, G.: Soil behaviour: The role of particle shape. In: Advances in Geotechnical Engineering. Proceedings of the Skempton Conference. pp. 1-14., London (2004) shape for granular materials. J. Mech. Phys. Solids. 84, 196-213 (2015). 
644 7. Xiao, Y., Long, L., Matthew Evans, T., Zhou, H., Liu, H., Stuedlein, A.W.: Effect of 645 Particle Shape on Stress-Dilatancy Responses of Medium-Dense Sands. J. Geotech. Geoenvironmental Eng. 145, (2019). doi:10.1061/(ASCE)GT.1943-5606.0001994

647 8. Vaid, Y., Chern, J., Tumi, H.: Confining pressure, Grain angularity and Liquefaction. J. Geotech. Eng. 111, 1229-1235 (1985)

649 9. Liu, Q.B., Lehane, B.M.: The influence of particle shape on the (centrifuge) cone with planar elliptica doi:10.1680/geot.1992.42.1.79

11. Ng, T.-T., Lin, X.: A three-dimensional discrete element model using arrays of ellipsoids. Géotechnique. 47, 319-329 (1997). doi:10.1680/geot.1997.47.2.319

12. Cleary, P.W.: The effect of particle shape on simple shear flows. Powder Technol. 179, 144-163 (2008). doi:10.1016/j.powtec.2007.06.018

13. Ferellec, J.-F., Mcdowell, G.R.: A method to model realistic particle shape and inertia in DEM. Granul. Matter. 12, 459-467 (2010). doi:10.1007/s10035-010-0205-8

14. Jiang, M.J., Liu, J.D., Arroyo, M.: Numerical evaluation of three non-coaxial kinematic models using the distinct element method for elliptical granular materials. Int. J. Numer. Anal. Methods Geomech. 40, 2468-2488 (2016). 
668 16. Iwashita, K., Oda, M.: Rolling resistance at contacts in simulation of shear band 669 development by DEM. J. Eng. Mech. 124, 285-292 (1998). doi:10.1061/(ASCE)07339399(1998)124:3(285)

17. Jiang, M.J.J., Yu, H.-S., Harris, D.: A novel discrete model for granular material incorporating rolling resistance. Comput. Geotech. 32, 340-357 (2005). doi:10.1016/j.compgeo.2005.05.001

18. Belheine, N., Plassiard, J.P., Donzé, F. V., Darve, F., Seridi, A.: Numerical simulation of drained triaxial test using 3D discrete element modeling. Comput. Geotech. 36, 320-331 (2009). doi:10.1016/j.compgeo.2008.02.003

19. Huang, X., Hanley, K.J., O'Sullivan, C., Kwok, C.Y.: Implementation of rotational resistance models: A critical appraisal. Particuology. 34, 14-23 (2017). doi:10.1016/j.partic.2016.08.007

20. Coetzee, C.J.: Calibration of the discrete element method and the effect of particle shape. Powder Technol. 297, 50-70 (2016). doi:10.1016/j.powtec.2016.04.003

21. Guillard, F., Marks, B., Einav, I.: Dynamic X-ray radiography reveals particle size and shape orientation fields during granular flow. Sci. Rep. 7, 1-11 (2017). doi:10.1038/s41598-017-08573-y

22. Oda, M., Takemura, T., Takahashi, M.: Microstructure in shear band observed by microfocus X-ray computed tomography. Géotechnique. 54, 539-542 (2004)

23. Matsushima, T., Uesugi, K., Nakano, T., Tsuchiyama, A.: Visualization of Grain Motion inside a Triaxial Specimen by Micro X-ray CT at SPring-8. In: Desrues, J., Besuelle, P., and Viggiani, G. (eds.) Advances in X-ray Tomography for Geomaterials. pp. 35-52. , London (2006) 
691

692

693

694

695

696

697

698

699

700

701

702

703

704

705

706

707

708

709

710

711

712

713

714

24. Hall, S.A., Bornert, M., Desrues, J., Pannier, Y., Lenoir, N., Viggiani, G., Bésuelle, P.: Discrete and continuum analysis of localised deformation in sand using X-ray $\mu \mathrm{CT}$ and volumetric digital image correlation. Géotechnique. 60, 315-322 (2010). doi:10.1680/geot.2010.60.5.315

25. Hasan, A., Alshibli, K.A.: Experimental assessment of 3D particle-to-particle interaction within sheared sand using synchrotron microtomography. Géotechnique. 60, 369-379 (2010). doi:10.1680/geot.2010.60.5.369

26. Rorato, R., Arroyo, M., Andò, E., Gens, A.: Sphericity measures of sand grains. Eng. Geol. 254, 43-53 (2019). doi:10.1016/j.enggeo.2019.04.006

27. Alshibli, K.A., Druckrey, A.M., Al-Raoush, R.I., Weiskittel, T., Lavrik, N. V.: Quantifying Morphology of Sands Using 3D Imaging. J. Mater. Civ. Eng. 27, (2015). doi:10.1061/(ASCE)MT.1943-5533.0001246

28. Zhao, B., Wang, J.: 3D quantitative shape analysis on form, roundness, and compactness with micro-CT. Powder Technol. 291, 262-275 (2016). doi:10.1016/j.powtec.2015.12.029

29. Kong, D., Fonseca, J.: Quantification of the morphology of shelly carbonate sands using 3D images. Géotechnique. 68, 249-261 (2018). doi:10.1680/jgeot.16.P.278

30. Fonseca, J., O'Sullivan, C., Coop, M.R., Lee, P.D.: Non-invasive characterization of particle morphology of natural sands. Soils Found. 52, 712-722 (2012). doi:10.1016/j.sandf.2012.07.011

31. Fonseca, J., O'Sullivan, C., Coop, M.R., Lee, P.D.: Quantifying the evolution of soil fabric during shearing using directional parameters. Géotechnique. 63, 818-829 (2013). doi:10.1680/geot.11.P.150 
experimental investigation of localised deformation in sand: A discrete particle tracking approach. Acta Geotech. 7, 1-13 (2012). doi:10.1007/s11440-011-0151-6

33. Hasan, A., Alshibli, K.: Three dimensional fabric evolution of sheared sand.

Granul. Matter. 14, 469-482 (2012). doi:10.1007/s10035-012-0353-0

36. Cheng, Z., Wang, J.: A particle-tracking method for experimental investigation of kinematics of sand particles under triaxial compression. Powder Technol. 328, 436-451 (2018). doi:10.1016/j.powtec.2017.12.071

37. Wiebicke, M., Andò, E., Herle, I., Viggiani, G.: On the metrology of interparticle contacts in sand from x-ray tomography images. Meas. Sci. Technol. 28, 124007 (2018)

38. Wiebicke, M., Andò, E., Salvatore, E., Viggiani, G., Herle, I.: Experimental measurement of granular fabric and its evolution under shearing. In: Radjai, F., Nezamabadi, S., Luding, S., and Delenne, J.Y. (eds.) European Physical Journal Web of Conferences. p. 02020. EDP Sciences (2017)

39. Wiebicke, M., Andò, E., Šmilauer, V., Herle, I., Viggiani, G.: A benchmark strategy for the experimental measurement of contact fabric. Granul. Matter. 21:54, 1-13 

(2019). doi:10.1007/s10035-019-0902-x

40. Alshibli, K.A., Alramahi, B.A.: Microscopic Evaluation of Strain Distribution in Granular Materials during Shear. J. Geotech. Geoenvironmental Eng. 132, 80-91 (2006). doi:10.1061/(asce)1090-0241(2006)132:1(80)

41. Vlahinić, I., Kawamoto, R., Andò, E., Viggiani, G., Andrade, J.E.: From computed tomography to mechanics of granular materials via level set bridge. Acta Geotech. 12, 85-95 (2017). doi:10.1007/s11440-016-0491-3

42. Cheng, Z., Wang, J.: Experimental investigation of inter-particle contact evolution of sheared granular materials using X-ray micro-tomography. Soils Found. 58, 1492-1510 (2018). doi:10.1016/j.sandf.2018.08.008

43. Sutton, M.A., Schreier, H.W., Orteu, J.-J.: Image correlation for shape, motion and deformation measurements : basic concepts, theory and applications. Springer (2009)

44. Hall, S.A.: Digital Image Correlation in Experimental Geomechanics. In: Gioacchino Viggiani, Stephen A. Hall, and Enrique Romero (eds.) ALERT Doctoral School 2012 Advanced experimental techniques in geomechanics. pp. 69-102. , Aussois (France) (2012)

45. Take, W.A.: Thirty-Sixth Canadian Geotechnical Colloquium: Advances in visualization of geotechnical processes through digital image correlation. Can. Geotech. J. 52, 1199-1220 (2015). doi:10.1139/cgj-2014-0080

46. Pan, B., Qian, K., Xie, H., Asundi, A.: Two-dimensional digital image correlation for in-plane displacement and strain measurement: a review. Meas. Sci. Technol. 20, (2009). doi:10.1088/0957-0233/20/6/062001 
deformation measurement for geotechnical applications. Can. Geotech. J. 53, 727739 (2016). doi:10.1139/cgj-2015-0253

48. Pinyol, N.M., Alvarado, M.: Novel analysis for large strains based on particle image velocimetry. Can. Geotech. J. 54, 933-944 (2017)

49. Andò, E., Hall, S.A., Viggiani, G., Desrues, J., Bésuelle, P.: Experimental

52. Zingg, T.: Beitrag zur Schotteranalyse, http://ecollection.library.ethz.ch/view/eth:21472, (1935)

53. Krumbein, W.C.: Measurement and Geological Significance of Shape and Roundness of Sedimentary Particles. J. Sediment. Res. 11, 64-72 (1941)

54. Andò, E.: Experimental investigation of microstructural changes in deforming granular media using x-ray tomography, (2013)

55. Salvatore, E., Modoni, G., Andò, E., Albano, M., Viggiani, G.: Determination of the critical state of granular materials with triaxial tests. Soils Found. 57, 733-744 (2017). doi:10.1016/j.sandf.2017.08.005

56. Viggiani, G., Andò, E., Takano, D., Santamarina, J.C.: Laboratory X-ray Tomography: A Valuable Experimental Tool for Revealing Processes in Soils. Geotech. Test. J. 38, 61-71 (2015). doi:10.1520/GTJ20140060

786 57. Lorensen, W.E., Cline, H.E.: Marching cubes: A high resolution 3D surface 
construction algorithm. ACM siggraph Comput. Graph. 21, 163-169 (1987). doi:10.1145/37402.37422

58. Tudisco, E., Andò, E., Cailletaud, R., Hall, S.A.: TomoWarp2: A local digital volume correlation code. SoftwareX. 6, 267-270 (2017). doi:10.1016/J.SOFTX.2017.10.002

59. Campello, E.M.B.: A description of rotations for DEM models of particle systems.

Comp. Part. Mech. 2, 109-125 (2015). doi:10.1007/s40571-015-0041-z

60. Andò, E., Cailletaud, R., Roubin, E., Stamati, O., the spam contributors: SPAM: The Software for the Practical Analysis of Materials, (2017)

61. Pannier, Y., Lenoir, N., Bornert, M.: Discrete volumetric digital image correlation for the investigation of granular type media at microscale: accuracy assessment.

803 64. Veje, C.T., Howell, D.W., Behringer, R.P.: Kinematics of a two-dimensional

62. Catalano, E., Chareyre, B., Barthélémy, E.: Pore-scale modeling of fluid-particles interaction and emerging poromechanical effects. Int. J. Numer. Anal. Methods Geomech. 38, 51-71 (2014). doi:10.1002/nag.2198

63. Šmilauer, V. et al.: Yade Documentation 2nd ed. The Yade Project. (2015) granular Couette experiment at the transition to shearing. Phys. Rev. E - Stat. Physics, Plasmas, Fluids, Relat. Interdiscip. Top. 59, 739-745 (1999). doi:10.1103/PhysRevE.59.739

65. Pasternak, E., Dyskin, A. V., Esin, M., Hassan, G.M., MacNish, C.: Rotations and pattern formation in granular materials under loading. Philos. Mag. 95, 3122-3145 (2015). doi:10.1080/14786435.2015.1059517

66. Efron, B., Tibshirani, R.: An introduction to the bootstrap. Chapman \& Hall (1994) 
811 67. Cole, D. M. (2015). Laboratory observations of frictional sliding of individual 812 contacts in geologic materials. Granular Matter, 17(1), 95-110.

813 68. Nardelli, V., \& Coop, M. R. (2019). The experimental contact behaviour of natural 814 sands: normal and tangential loading. Géotechnique, 69(8), 672-686.

815 69. Kawamoto, R., Andò, E., Viggiani, G., Andrade, J.E.: All you need is shape: 816 Predicting shear banding in sand with LS-DEM. J. Mech. Phys. Solids. 111, 375817 392 (2018). doi:10.1016/j.jmps.2017.10.003

818 70. Rorato, R., Arroyo, M., Gens, A., Andò, E., Viggiani, G.: Particle Shape 819 Distribution Effects on the Triaxial Response of Sands: A DEM Study. In: Giovine, 820 P. and et al. (eds.) micro to MACRO Mathematical Modelling in Soil Mechanics, 821 Trends in Mathematics. pp. 277-286. , Reggio Calabria (Italy) (2018)

822 71. Rorato, R., Arroyo, M., Gens, A., Andó, E. \& Viggiani, G. (2020) Image-based 823 calibration of rolling resistance in discrete element models of sand, under review 824 Computers \& Geotechnics 